University of Nebraska - Lincoln

DigitalCommons@University of Nebraska - Lincoln

2008

\title{
Evapotranspiration Rates of Riparian Forests, Platte River, Nebraska, 2002-06
}

Matthew K. Landon

U.S. Geological Survey

David L. Rus

U.S. Geological Survey

Benjamin J. Dietsch

U.S. Geological Survey, bdietsch@usgs.gov

Michaela R. Johnson

U.S. Geological Survey

Kathleen D. Eggemeyer

U.S. Geological Survey

Follow this and additional works at: https://digitalcommons.unl.edu/usgspubs

Part of the Earth Sciences Commons

Landon, Matthew K.; Rus, David L.; Dietsch, Benjamin J.; Johnson, Michaela R.; and Eggemeyer, Kathleen D., "Evapotranspiration Rates of Riparian Forests, Platte River, Nebraska, 2002-06" (2008). Publications of the US Geological Survey. 89.

https://digitalcommons.unl.edu/usgspubs/89

This Article is brought to you for free and open access by the US Geological Survey at DigitalCommons@University of Nebraska - Lincoln. It has been accepted for inclusion in Publications of the US Geological Survey by an authorized administrator of DigitalCommons@University of Nebraska - Lincoln. 
In Cooperation with the Nebraska Platte River Cooperative Hydrology Study Group and Central Platte Natural Resources District

\section{Evapotranspiration Rates of Riparian Forests, Platte River, Nebraska, 2002-06}

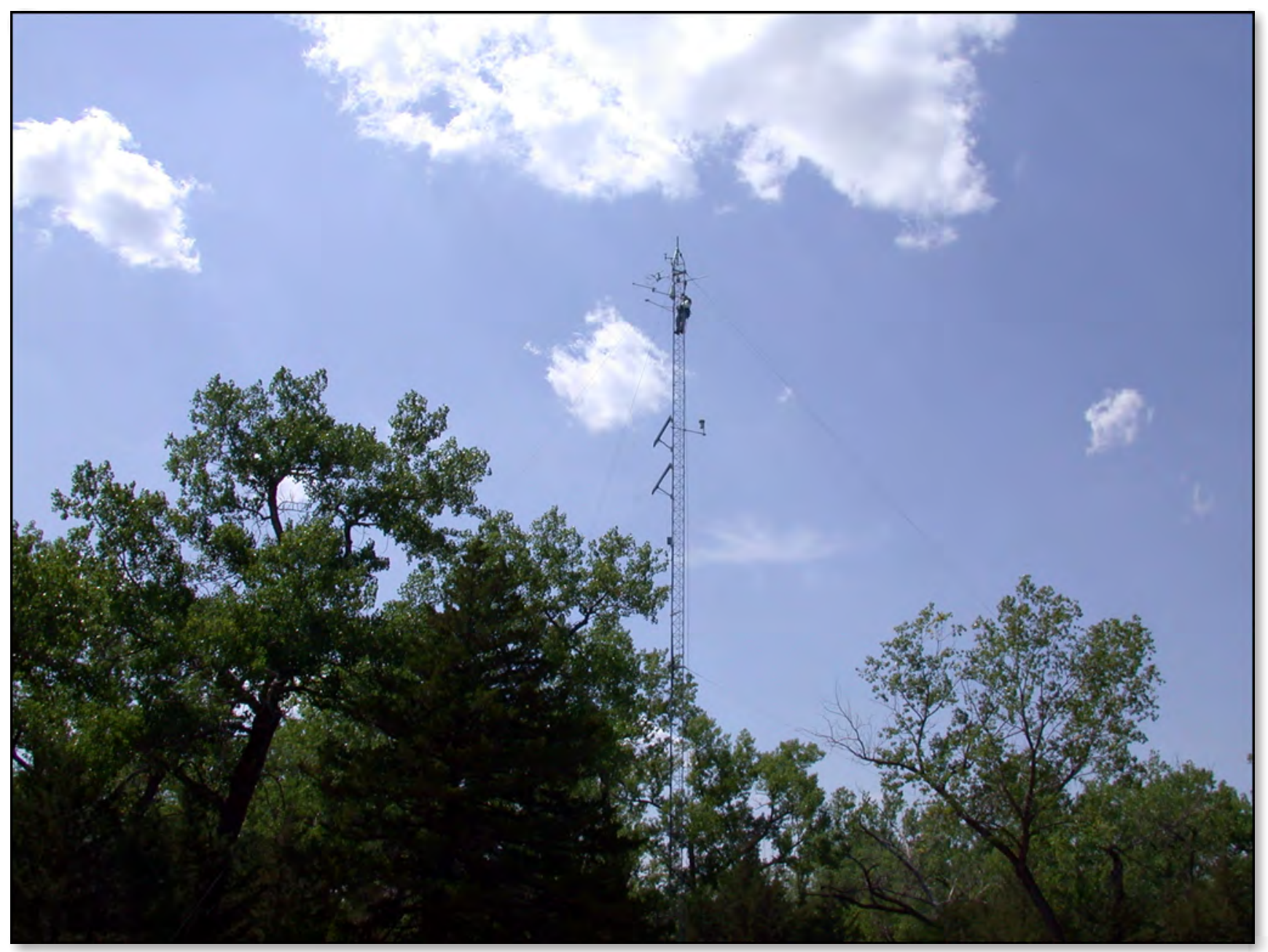

Scientific Investigations Report 2008-5228 
Front cover: U.S. Geological Survey personnel maintaining sensors atop a 27.4-meter tower in a riparian forest near Gothenburg, Nebraska, July 2002. 


\section{Evapotranspiration Rates of Riparian Forests, Platte River, Nebraska, 2002-06}

By Matthew K. Landon, David L. Rus, Benjamin J. Dietsch, Michaela R. Johnson, and Kathleen D. Eggemeyer

In cooperation with the Nebraska Platte River Cooperative Hydrology Study

Group and Central Platte Natural Resources District

Scientific Investigations Report 2008-5228 


\title{
U.S. Department of the Interior \\ KEN SALAZAR, SECRETARY
}

\author{
U.S. Geological Survey \\ Suzette M. Kimball, Acting Director
}

U.S. Geological Survey, Reston, Virginia: 2009

For product and ordering information:

World Wide Web: http://www.usgs.gov/pubprod

Telephone: 1-888-ASK-USGS

For more information on the USGS--the Federal source for science about the Earth, its natural and living resources, natural hazards, and the environment:

World Wide Web: http://www.usgs.gov

Telephone: 1-888-ASK-USGS

Any use of trade, product, or firm names is for descriptive purposes only and does not imply endorsement by the U.S. Government.

Although this report is in the public domain, permission must be secured from the individual copyright owners to reproduce any copyrighted materials contained within this report.

Suggested citation:

Landon, M.K., Rus, D.L., Dietsch, B.J., Johnson, M.R., and Eggemeyer, K.D., 2009, Evapotranspiration rates of riparian forests, Platte River, Nebraska, 2002-06: U.S. Geological Survey Scientific Investigations Report 2008-5228, 65 p. 


\section{Contents}

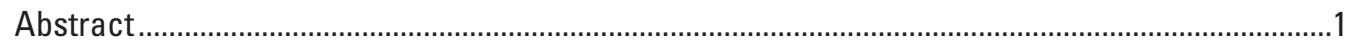

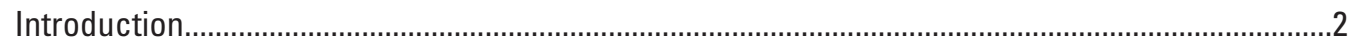

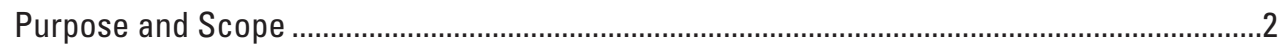

Description of the Platte River Basin in Nebraska..................................................................

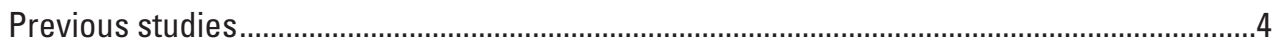

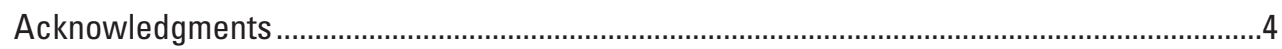

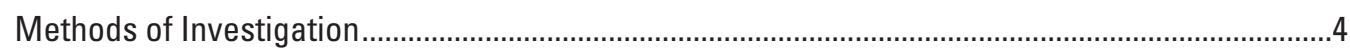

Site Selection and Characterization ...............................................................................

Footprint and Forest Area Analysis ...........................................................................

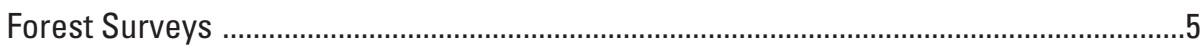

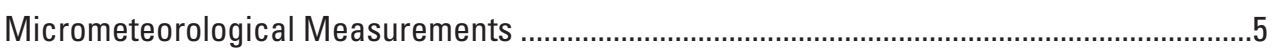

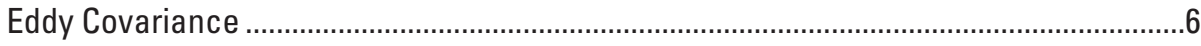

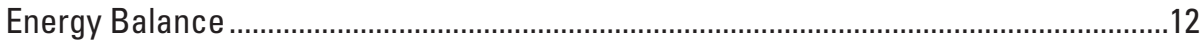

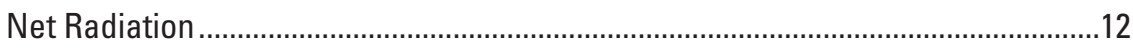

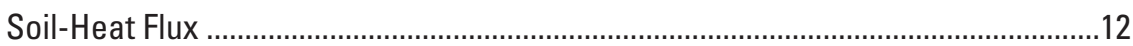

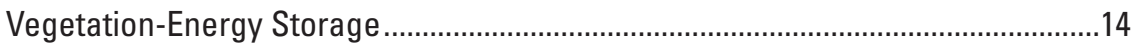

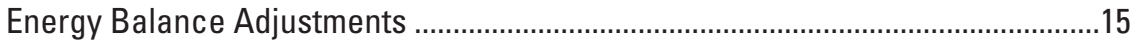

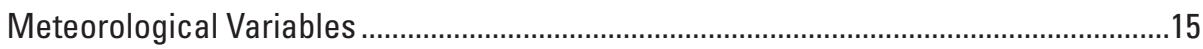

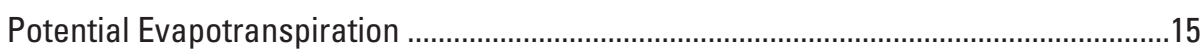

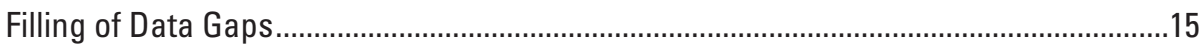

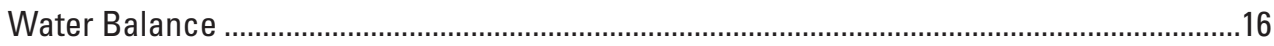

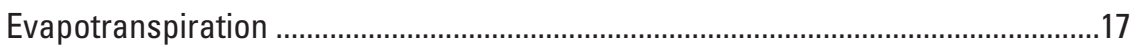

Precipitation and Canopy Interception .......................................................................17

Precipitation and Throughfall Measurement............................................................17

Accounting for Canopy Interception in the Water Balance .......................................17

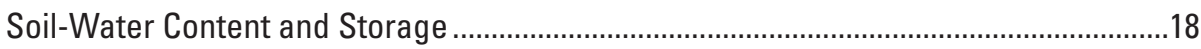

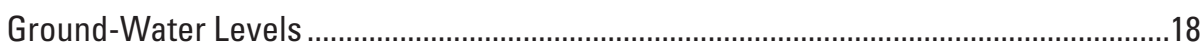

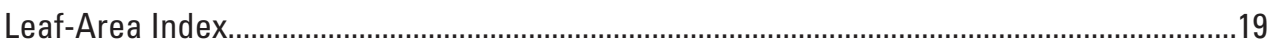

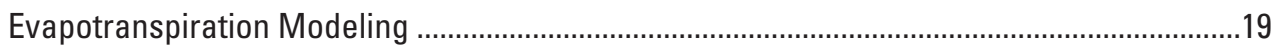

Sap Flux .

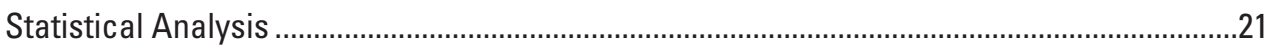

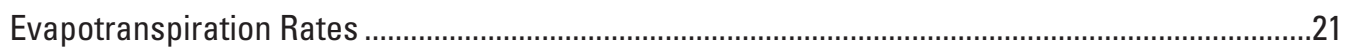

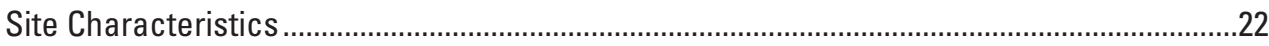

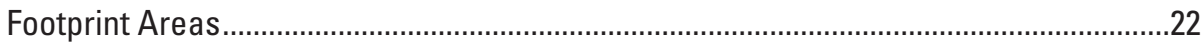

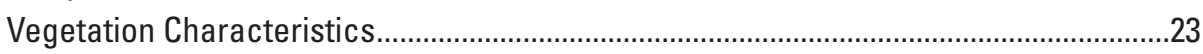

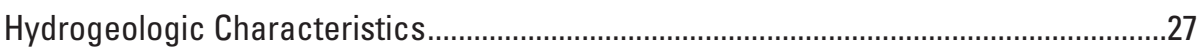

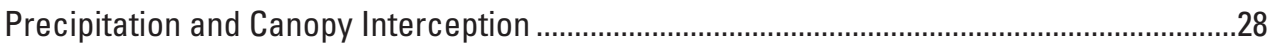

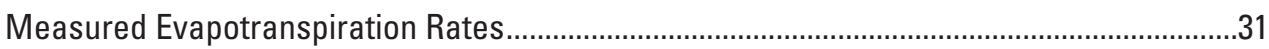

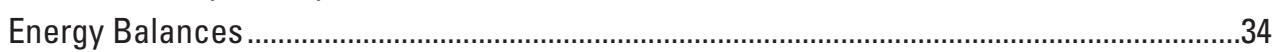

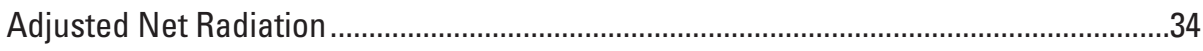

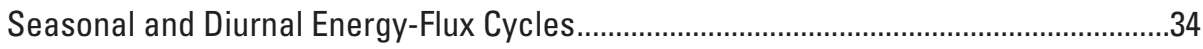

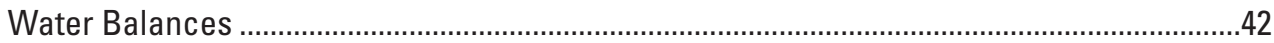


Simulation of Evapotranspiration Rates..............................................................................

Environmental Factors Affecting Evapotranspiration Rates ..................................................4

Simple Linear Regressions.......................................................................................4

Multiple Linear Regressions ......................................................................................

Evapotranspiration Responses to Seasonal Energy and Hydrologic Fluctuations.........50

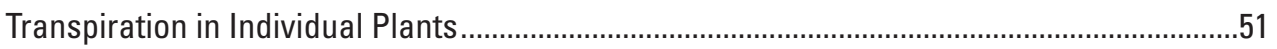

Extrapolating Evapotranspiration Rates Beyond the Study Sites...........................................54

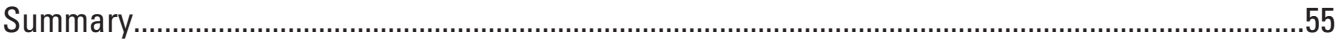

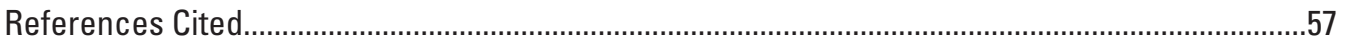

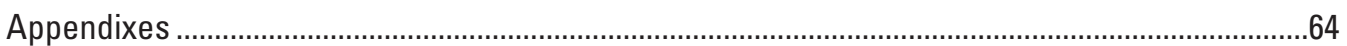

\section{Figures}

1. Map showing location of riparian forest evapotranspiration study sites near Odessa and Gothenburg, Nebraska, and distribution of riparian forests along

the Platte River.

2-3. Aerial photographs showing-

2. Data collection locations and probable flux source areas for micrometeorological instrumentation on towers at study sites near Odessa and Gothenburg, Nebraska.

3. Areal layout of instrumentation near the towers at study sites near Odessa and Gothenburg, Nebraska

4-5. Photographs showing-

4. Selected micrometeorological instrumentation used at study sites

5. Instrumentation used for measurements of surface or subsurface conditions at study sites.

6. Graph showing relation of source strength with distance upwind from a measurement point 26.1 meters above land surface for end-member atmospheric conditions

7. Map showing distribution of land cover and fraction of total area in each category at study sites near Odessa and Gothenburg, Nebraska

8-21. Graphs showing-

8. Tree diameter and sapwood thickness for selected trees and shrubs at study site near Odessa, Nebraska

9. Seasonality of average leaf-area index of riparian forests at study sites near Odessa and Gothenburg, Nebraska, 2002-04.

10. Vertical profile of grain-size distribution of study sites near Odessa and Gothenburg, Nebraska.

11. Daily, monthly measured and normal, and annual measured and normal precipitation for study sites near Odessa and Gothenburg, Nebraska, 2002-06.

12. Relations between precipitation and throughfall at study sites near Odessa and Gothenburg, Nebraska, 2002-06. 
13. Daily, monthly, and annual evapotranspiration rates for study sites near Odessa and Gothenburg, Nebraska, 2002-06...

14. Relations between net radiation measured with different net radiometers at study site near Odessa, Nebraska, March 2004-May 2005.

15. Monthly mean energy fluxes for study sites near Odessa and Gothenburg, Nebraska, 2002-06...

16. Diurnal patterns of median energy fluxes based on March 2002 to December 2004 data for June-August and December-February at study sites near Odessa and Gothenburg, Nebraska.

17. Relations among annual water-balance terms for study sites near Odessa and Gothenburg, Nebraska, 2002-06.

18. Average crop coefficients for riparian forests at study sites near Odessa and Gothenburg, Nebraska, 2002-05.

19. Simple linear regressions of daily evapotranspiration rates with vaporpressure deficit, solar radiation, air temperature, and leaf-area index at study sites near Odessa and Gothenburg, Nebraska, 2002-06.

20. Daily average transpiration rates for monitored trees and shrubs and aggregate evapotranspiration measured by eddy-covariance method, April through August 2004, at study site near Odessa, Nebraska

21. Relation of daily transpiration rates for monitored trees and shrubs with evapotranspiration determined from eddy covariance, April through August 2004, at study site near Odessa, Nebraska. 


\section{Tables}

1. Summary of instrumentation used and placement of sensors at study sites near Odessa and Gothenburg, Nebraska

2. Tree and shrub species instrumented with sap-flow devices during April through August 2004, at the study site near Odessa, Nebraska.

3. Summary of vegetation and hydrogeologic characteristics of study sites near Odessa and Gothenburg, Nebraska

4. Summary of annual precipitation and interception at study sites near Odessa and Gothenburg, Nebraska, 2002-06

5. Summary of monthly mean energy fluxes for April 2002 to April 2006 at riparian forest study site near Odessa, Nebraska

6. Summary of monthly mean energy fluxes for April 2002 to April 2006 at riparian forest study site near Gothenburg, Nebraska

7. Annual water-balance results for riparian forest study sites near Odessa and Gothenburg, Nebraska, April 1, 2002, to March 31, 2006.

8. Average crop coefficients for riparian forest study sites near Odessa and Gothenburg, Nebraska, 2002-05

9. Comparison of evapotranspiration simulated with 15 -day average and monthly crop coefficient models to actual evapotranspiration at riparian forest study sites near Odessa and Gothenburg, Nebraska

10. Results of simple linear regressions of daily evapotranspiration with potentially explanatory independent variables for study sites near Odessa and Gothenburg, Nebraska, 2002-06

11. Results for multiple linear-regression models of daily evapotranspiration as a function of potentially explanatory independent variables for study sites near Odessa and Gothenburg, Nebraska, 2002-06

12. Transpiration rates in individual plants determined from thermal dissipation probes and aggregate evapotranspiration rates determined from eddycovariance methods for days with complete transpiration data, April to August 2004, riparian forest study site near Odessa, Nebraska. 


\section{Conversion Factors}

SI to Inch/Pound

\begin{tabular}{|c|c|c|}
\hline Multiply & By & To obtain \\
\hline \multicolumn{3}{|c|}{ Length } \\
\hline centimeter $(\mathrm{cm})$ & 0.3937 & inch (in.) \\
\hline millimeter (mm) & 0.03937 & inch (in.) \\
\hline meter $(\mathrm{m})$ & 3.281 & foot $(\mathrm{ft})$ \\
\hline kilometer (m) & 0.6215 & mile (mi) \\
\hline \multicolumn{3}{|c|}{ Area } \\
\hline square meter $\left(\mathrm{m}^{2}\right)$ & 0.0002471 & acre \\
\hline hectare (ha) & 2.471 & acre \\
\hline square centimeter $\left(\mathrm{cm}^{2}\right)$ & 0.001076 & square foot $\left(\mathrm{ft}^{2}\right)$ \\
\hline square meter $\left(\mathrm{m}^{2}\right)$ & 10.76 & square foot $\left(\mathrm{ft}^{2}\right)$ \\
\hline \multicolumn{3}{|c|}{ Volume } \\
\hline milliliter (mL) & 0.03382 & ounce, fluid (fl. oz) \\
\hline liter $(\mathrm{L})$ & 33.82 & ounce, fluid (fl. oz) \\
\hline cubic meter $\left(\mathrm{m}^{3}\right)$ & 264.2 & gallon (gal) \\
\hline cubic centimeter $\left(\mathrm{cm}^{3}\right)$ & 0.06102 & cubic inch $\left(\mathrm{in}^{3}\right)$ \\
\hline cubic meter $\left(\mathrm{m}^{3}\right)$ & 0.0008107 & acre-foot (acre-ft) \\
\hline \multicolumn{3}{|c|}{ Flow rate } \\
\hline cubic centimeter per second $\left(\mathrm{cm}^{3} / \mathrm{s}\right)$ & 0.06102 & cubic inch per second $\left(\mathrm{in}^{3} / \mathrm{s}\right)$ \\
\hline centimeter per second $(\mathrm{cm} / \mathrm{s})$ & 0.3937 & inch per second (in/s) \\
\hline millimeter per day $(\mathrm{mm} / \mathrm{d})$ & 0.03937 & inch per day (in/d) \\
\hline millimeter per year (mm/yr) & 0.03937 & inch per year (in/yr) \\
\hline \multicolumn{3}{|c|}{ Mass } \\
\hline kilogram (kg) & 2.205 & pound avoirdupois (lb) \\
\hline \multicolumn{3}{|c|}{ Pressure } \\
\hline kilopascal (kPa) & 0.1450 & pound per square inch $\left(\mathrm{lb} / \mathrm{ft}^{2}\right)$ \\
\hline \multicolumn{3}{|c|}{ Density } \\
\hline gram per cubic centimeter $\left(\mathrm{g} / \mathrm{cm}^{3}\right)$ & 62.4220 & pound per cubic foot $\left(\mathrm{lb} / \mathrm{ft}^{3}\right)$ \\
\hline kilogram per cubic meter $\left(\mathrm{kg} / \mathrm{m}^{3}\right)$ & 0.06243 & pound per cubic foot $\left(\mathrm{lb} / \mathrm{ft}^{3}\right)$ \\
\hline \multicolumn{3}{|c|}{ Energy } \\
\hline Joule $(\mathrm{J})$ & 0.239 & Calorie (cal) \\
\hline \multicolumn{3}{|c|}{ Power } \\
\hline Watt (W) & 0.239 & Calorie per second (cal/s) \\
\hline
\end{tabular}

Temperature in degrees Celsius $\left({ }^{\circ} \mathrm{C}\right)$ may be converted to degrees Fahrenheit $\left({ }^{\circ} \mathrm{F}\right)$ as follows:

${ }^{\circ} \mathrm{F}=\left(1.8 \mathrm{x}^{\circ} \mathrm{C}\right)+32$

Temperature in degrees Fahrenheit $\left({ }^{\circ} \mathrm{F}\right)$ may be converted to degrees Celsius $\left({ }^{\circ} \mathrm{C}\right)$ as follows:

${ }^{\circ} \mathrm{C}=\left({ }^{\circ} \mathrm{F}-32\right) / 1.8$

Temperature in Kelvin (K) may be converted to degrees Celsius ( ${ }^{\circ} \mathrm{C}$ ) as follows:

${ }^{\circ} \mathrm{C}=\mathrm{K}-273.15$

Horizontal coordinate information is referenced to the North American Datum of 1983 (NAD 83)

Altitude, as used in this report, refers to distance above an arbitrary datum. 


\section{Abbreviations}

$\begin{array}{ll}\text { COHYST } & \text { Platte River Cooperative Hydrology Study } \\ \text { DTW } & \text { Depth to the ground-water table } \\ \text { EBC } & \text { Energy balance closure } \\ \text { EBR } & \text { Energy balance ratio } \\ \text { ET } & \text { Evapotranspiration } \\ \text { GWET } & \text { ET derived directly from ground water } \\ \text { LAI } & \text { Leaf-area index } \\ \text { MLR } & \text { multiple-linear regression } \\ \text { NSE } & \text { Coefficient of efficiency } \\ \text { PET } & \text { Potential evapotranspiration } \\ \text { R } & \text { Coefficient of determination } \\ \text { Rn-2 } & \text { Two-component net radiometer } \\ \text { Rn-4 } & \text { Four-component net radiometer } \\ \text { RSE } & \text { Standard error of the residuals } \\ \text { SLR } & \text { Simple-linear regression } \\ \text { TDP } & \text { Thermal-dissipation probe } \\ \text { TF } & \text { Canopy throughfall gutter } \\ \text { USGS } & \text { U.S. Geological Survey } \\ \text { UZ } & \text { Unsaturated-zone vertical profile }\end{array}$

\section{Symbols}

$\alpha$

$A_{\text {canopy }}$

$A_{\text {sapwood }}$

$B_{i}$

$C_{i}$

$C_{m}$

$C_{\text {o }}$

$\mathrm{C}_{\mathrm{s}}$

$C_{w}$

d

D

$\Delta T_{s}$ $\triangle G W$

$\triangle P S$

$\triangle P S_{i}$

$\triangle P W$

$\Delta S$

$\Delta S W$

$\Delta T_{i}$

$\Delta T_{\text {sap }}$
Priestley-Taylor coefficient

Area of the ground underneath the tree canopy

Sapwood area

Unit volume of component $i$

Specific-heat capacity of component $i$

Volumetric specific-heat capacity of the mineral component of the soil

Volumetric specific-heat capacity of the organic component of the soil

Volumetric specific-heat capacity of the soil layer

Volumetric-specific-heat capacity of water

Thickness of the soil for which calculations are being performed

Vapor-pressure deficit

Change in soil temperature in the upper $8 \mathrm{~cm}$ of soil

Change in ground-water storage

Change in the storage of energy in the biomass

Change in energy storage of component $i$, where $i$ represents tree trunks, branches, or leaves

Change in plant-water storage

Change in storage of heat in the upper $8 \mathrm{~cm}$ of soil

Change in soil-water storage

Change in temperature of component $i$

Sap-temperature difference 


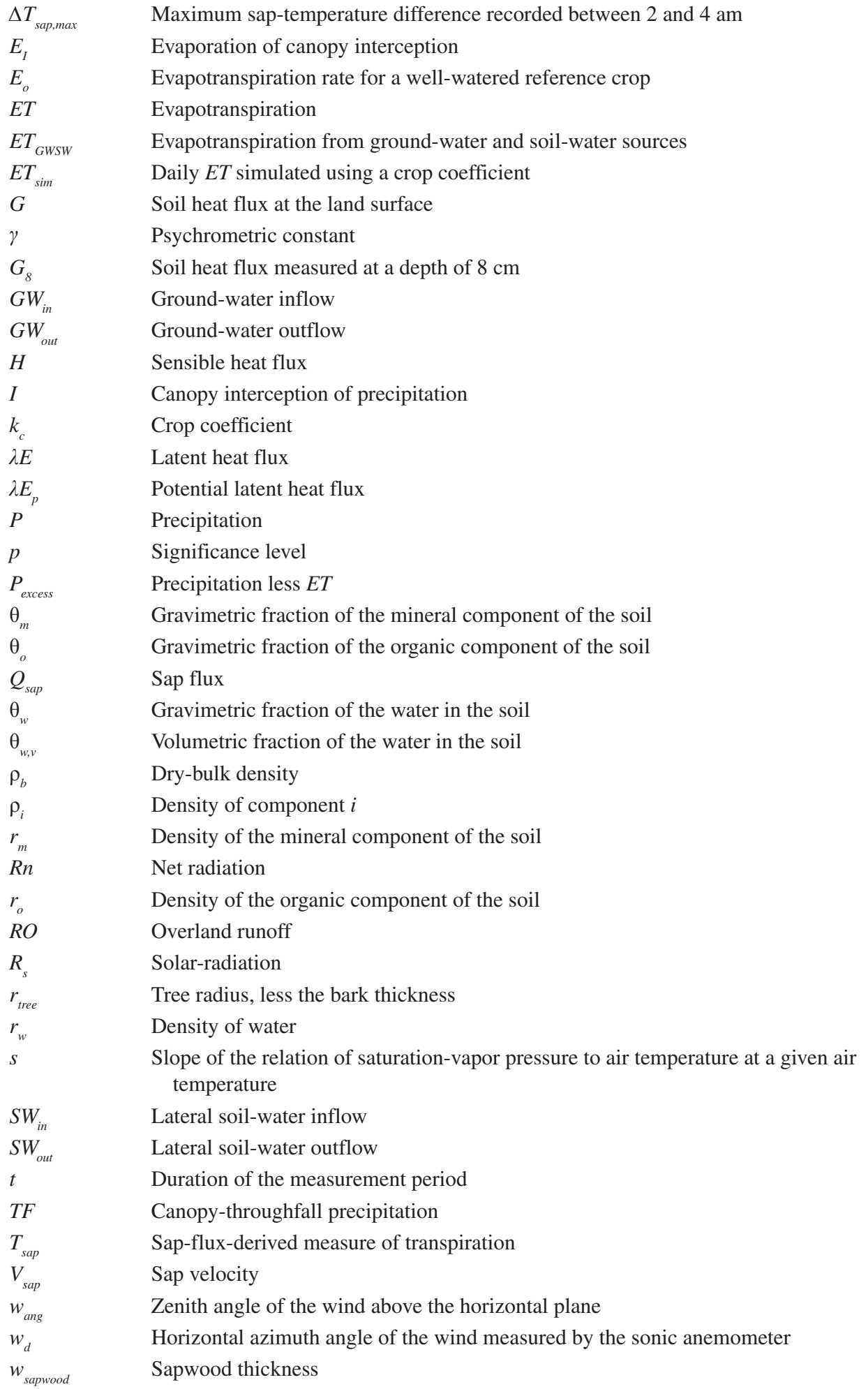





\title{
Evapotranspiration Rates of Riparian Forests, Platte River, Nebraska, 2002-06
}

\author{
By Matthew K. Landon, David L. Rus, Benjamin J. Dietsch, Michaela R. Johnson, and Kathleen D. Eggemeyer
}

\section{Abstract}

Evapotranspiration (ET) in riparian areas is a poorly understood component of the regional water balance in the Platte River Basin, where competing demands have resulted in water shortages in the ground-water/surface-water system. From April 2002 through March 2006, the U.S. Geological Survey, Nebraska Platte River Cooperative Hydrology Study Group, and Central Platte Natural Resources District conducted a micrometeorological study of water and energy balances at two sites in central Nebraska near Odessa and Gothenburg to improve understanding of ET rates and factors affecting them in Platte River riparian forests. A secondary objective of the study was to constrain estimates of groundwater use by riparian vegetation to satisfy ET consumptive demands, a useful input to regional ground-water flow models.

Both study sites are located on large islands within the Platte River characterized by a cottonwood-dominated forest canopy on primarily sandy alluvium. Although both sites are typical of riparian forests along the Platte River in Nebraska, the Odessa understory is dominated by deciduous shrubs, whereas the Gothenburg understory is dominated by eastern redcedars. Additionally, seasonal ground-water levels fluctuated more at Odessa than at Gothenburg. The study period of April 2002 through March 2006 encompassed precipitation conditions ranging from dry to wet.

This study characterized the components of the water balance in the riparian zone of each site. ET was evaluated from eddy-covariance sensors installed on towers above the forest canopy at a height of 26.1 meters. Precipitation was measured both above and below the forest canopy. A series of sensors measured soil-moisture availability within the unsaturated zone in two different vertical profiles at each site. Changes in ground-water altitude were evaluated from piezometers. The areal footprint represented in the water balance extended up to 800 meters from each tower.

During the study, ET was less variable than precipitation. Annual ET fluctuated about 7 percent from the 4-year mean, ranging from about 514 to 586 millimeters per year (551 on average) at the Odessa site and 535 to 616 millimeters per year (575 on average) at the Gothenburg site. Conversely, annual precipitation fluctuated by about 35 percent from the 4-year mean, ranging from 429 to 844 millimeters per year at Odessa and 359 to 791 millimeters per year at Gothenburg. Of this precipitation, 14 to 15 percent was intercepted by the forest canopy before it could infiltrate into the soil.

For the 4-year period, annual ground-water recharge from the riparian measurement zone averaged 76 and 13 millimeters at Odessa and Gothenburg, respectively, to satisfy the water balance at each site. This indicates that, from an annual perspective, ground-water reductions caused by ET may be minimal. This effect varied somewhat and primarily was affected by fluctuations in precipitation. Ground-water discharge occurred during the driest study year (2002), whereas ground-water recharge occurred from 2003 to 2005. These results do not exclude ground water as an important source of water to riparian vegetation-especially to phreatophytes that have the capability of directly using water from the saturated zone-during periods of high ET in the summer, particularly during periods of lower than normal precipitation. However, the calculations indicate that, on an annual (or longer) netflux basis, ground-water use by riparian forests is likely to be balanced by periods of recharge from excess precipitation at other times of the year. In contrast to more arid settings, where scientific literature indicates that ground water may supply a large fraction of the water used for ET by riparian vegetation, precipitation along the Platte River of Nebraska was great enough — and generally greater than ET — that most or all of the annual ET demand was satisfied by available precipitation.

Crop coefficients developed for 15-day and monthly periods from the measured data predicted ET within 3.5 percent of actual annual ET; however, daily ET was underpredicted on days of increased ET and overpredicted on days of low ET. These crop coefficients can be used to extrapolate riparian-forest ET along the Platte River in conjunction with atmospheric data from other climate stations in central Nebraska.

Regression models of simple and multiple-linear relations between explanatory variables and ET indicated that the relation of ET to environmental factors was different on days with precipitation than on dry days. At Odessa, ET was affected by vapor-pressure deficit, solar radiation, leaf-area index, and depth to water regardless of precipitation conditions, but was also affected by air temperature on days without precipitation, suggesting energy limitations on ET on days without precipitation. At Gothenburg, ET was always a function of vaporpressure deficit, solar radiation, and leaf-area index, but, as 
with Odessa, air temperature also became important on days without precipitation.

Despite depths to ground water of less than 2 meters and phreatophytic vegetation, measured ET was substantially less than potential ET (based on the modified Penman method), consistent with plant-stomatal regulation of ET in response to environmental and meteorological factors. Although annual ET rates generally were similar, the two sites exhibited different intraannual soil-moisture regimes that had a corresponding effect on ET and vegetation vigor. Smaller seasonal declines in ground-water levels and a lack of understory shrubs at the Gothenburg site as compared to the Odessa site may explain why Gothenburg ET was comparatively greater later in the summer and was not dependent on depth to water (as identified by the multiple-linear regression model). These differences also may explain why, during years of increased precipitation, ET rates increased at Odessa but not at Gothenburg.

\section{Introduction}

An agreement between the Governors of Nebraska, Colorado, and Wyoming, and the U.S. Department of the Interior has established guidelines to increase in-stream flows within the Platte River in an effort to enhance the habitat of threatened and endangered species such as whooping cranes, piping plovers, and least terns (Platte River Endangered Species Partnership, 1997). In response to this agreement, a group of state agencies, local governmental units, and private organizations in Nebraska called the Platte River Cooperative Hydrology Study (COHYST) has been conducting hydrologic studies along the Platte River to develop scientifically supportable hydrologic data bases, analyses, and models. One of the goals of the COHYST effort is to better understand the ground-water resources and stream/aquifer interaction to fulfill a need to quantify river gains and losses from ground-water interaction. To quantify this interaction, COHYST constructed groundwater models of an area encompassing the Platte River in central Nebraska (fig. 1). A second phase of the study, begun in 2001, included studies to fill gaps in hydrologic understanding for the models. One of the top priorities for COHYST in the second phase was to better quantify evapotranspiration (ET) from riparian forest areas along the Platte River and its effects on the hydrologic system. In response, the U.S. Geological Survey (USGS), in cooperation with the COHYST Group and the Central Platte Natural Resources District, characterized ET rates at two riparian forest sites along the Platte River.

Rates of riparian forest ET are important to quantify because they have the potential to affect the regional water balance (Goodrich and others, 2000; Szilagyi and others, 2005). First, the area of riparian forest along the Platte River has expanded substantially from the 1930s to the 1960s (Johnson, 1994, 1997). Second, riparian forests are suspected to have increased ET rates because of the relatively shallow depth to ground water near stream channels in conjunction with the presence of phreatophytes-primarily cottonwood with some willow trees along the Platte River-that can directly utilize ground water for transpiration processes (Busch and others, 1992). In the context of this report, Platte River riparian forests represent the forest ecosystem located along the margins of the river as well as on the islands contained within the braided system.

Measurements of total ET rates and rates of ground-water use by riparian vegetation to satisfy ET consumptive demands are lacking in the region. Generally, ET is a key component in the water balance in Nebraska, second only to precipitation in magnitude (Szilagyi and others, 2005). Normal annual precipitation ranges from about 385 to 920 millimeters (mm) from west to east across the state (Gutentag and others, 1984; Szilagyi and others, 2003), whereas mean annual ET has been estimated to range from about 360 to $630 \mathrm{~mm}$ (Szilagyi and others, 2003). Despite the importance of riparian ET in the hydrologic cycle, little is known about its magnitude, seasonal and daily distributions, and the relation of ET to environmental variables.

ET derived directly from ground water (GWET) is a process important to include in regional ground-water flow models of the Platte River Basin in Nebraska (Luckey and Cannia, 2006; Luckey and others, 2006). Estimates of GWET rates are not as precise as total ET measurements because of the difficulty in distinguishing if water utilized by plants for transpiration or evaporating from soil is derived from precipitation or ground water. Poorly constrained estimates could produce errors or uncertainties in model results. However, estimates of GWET can be improved and constrained by accurate measurements of ET, precipitation, evaporation of intercepted precipitation, soil-water balance, and ground-water levels.

The objectives of the research reported herein were to estimate total ET and the GWET component in riparian forests along the Platte River. To do so, the study involved investigations of ET at two research sites in representative riparian settings. The investigations at each site included using eddycovariance and energy-balance techniques to determine total ET and determining relations of ET to selected environmental variables that commonly control ET rates. Measurements of precipitation through the canopy were used to estimate how much of total ET is comprised of evaporation of intercepted precipitation, thus providing an upper boundary of GWET estimates by subtracting interception evaporation from total ET. Additional constraints on GWET estimates were provided by calculations of annual-water balance in a representative volume enclosing the riparian system. Using these site-specific measurements, a crop-coefficient model was calibrated for use in estimating riparian ET elsewhere in the COHYST study area.

\section{Purpose and Scope}

The purpose of this report is to describe total ET rates measured using micrometeorological techniques at two ripar- 


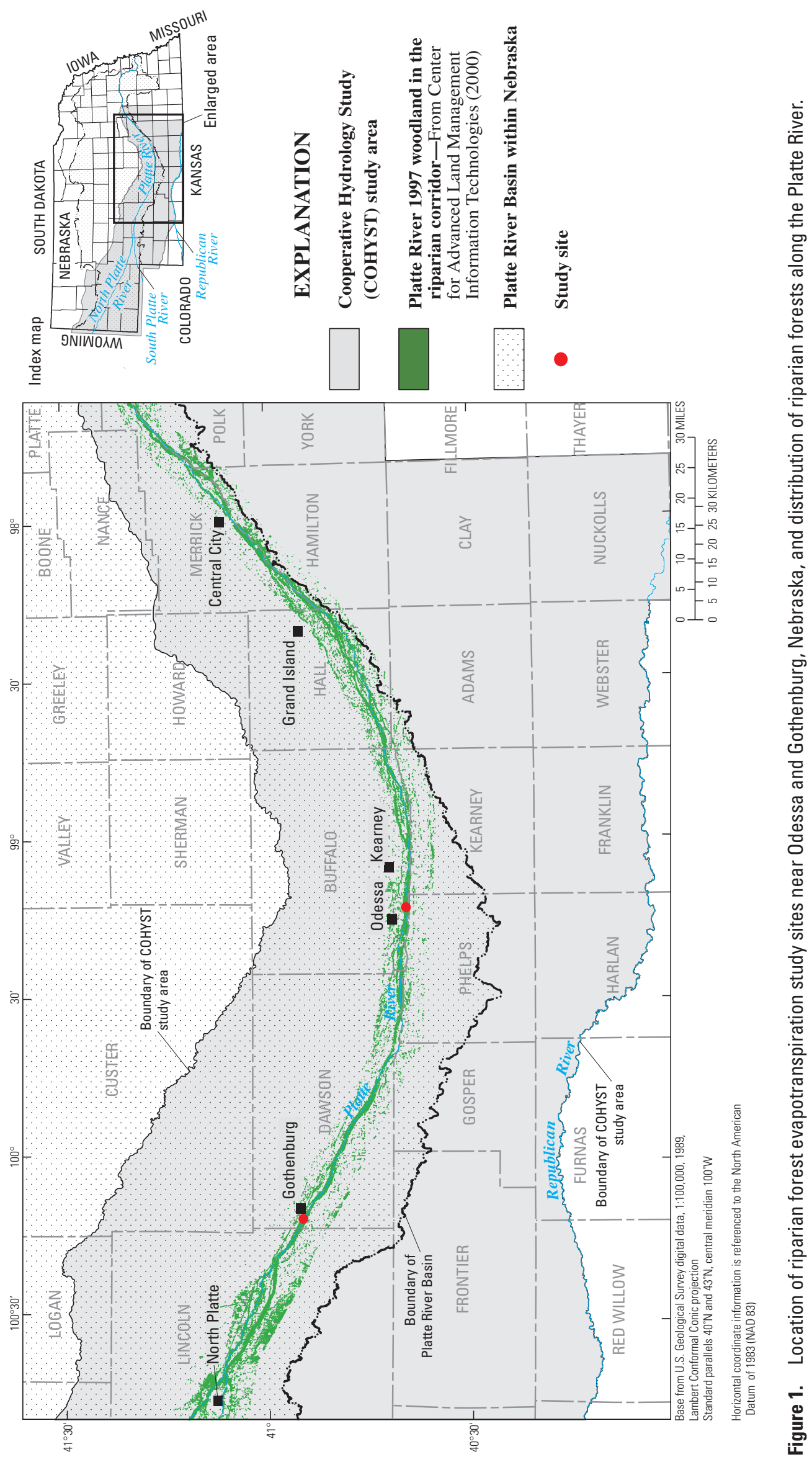


ian forest sites along the Platte River in central Nebraska during 2002-06. The ET rates were used as part of the annual water-balance calculations and in calibrating a crop-coefficient model used for simulating ET rates. The report also documents canopy interception at the two sites and how it was used to constrain the amount of transpiration utilizing ground water rather than precipitation sources. An analysis of environmental variables affecting ET rates is reported, followed by a special section detailing transpiration rates in individual plants. The report closes with a discussion of uncertainties, limitations, and extrapolation of the results to other locations.

\section{Description of the Platte River Basin in Nebraska}

The North and South Platte Rivers originate in the Rocky Mountains of Wyoming and Colorado and merge at North Platte, Nebraska, where the main stem of the Platte River flows east from that point. Flows in the Platte River are derived mainly from snowmelt runoff originating in the Rocky Mountains and surface runoff and ground-water discharge from the remaining areas of the basin, and are affected by storage, diversion, and irrigation return flows (Bentall and Shaffer, 1979; Gutentag and others, 1984).

Land use in the Platte River Basin varies longitudinally. The eastern and central parts of Nebraska predominantly are cultivated-agricultural land with increasing amounts of rangeland to the west (Center for Advanced Land Management Information Technologies, 2000; U.S. Geological Survey, 1999-2000). Riparian vegetation is restricted to lowlands located along the Platte River and its tributaries.

Forests and grasslands (including wet meadows) in the riparian zone are the predominant communities, but other categories include herbaceous, shrub, and emergent wetlands (Currier and others, 1985). Previous investigations have indicated that the area of riparian forest expanded substantially from the 1930s to the 1960s and stabilized thereafter (Johnson, 1994, 1997). As a result, the formerly wide, shallow, and braided channel of the Platte River changed to mostly wooded islands separated by a few relatively narrow, deepened channels. The increases in riparian forest cover have resulted at least in part from widespread changes in environmental conditions including fire suppression, bison removal, and water-resources development (Currier, 1982; Johnson, 1994). Water-resources development has included the construction of storage reservoirs that regulate river flows and utilize the river channel for water delivery to locations downstream (Currier, 1982; Johnson, 1994; Sidle and Faanes, 1997). As a result, Platte River flows can vary by location with respect to water diversion or return structures.

\section{Previous Studies}

Previous studies in and near the COHYST study area generally have estimated riparian ET from empirical formulas using meteorological data or from intermittent experiments; estimates have ranged widely (Tomanek and Ziegler, 1960; Weeks and Sorey, 1973; Nagel and Dart, 1980; Bureau of Reclamation, 1985; Eddy, 1995). The magnitude of the estimated riparian ET rates reported in previous studies in the region, ranging from about 500 to 1,300 millimeters per year (mm/yr), is poorly constrained.

Techniques exist for accurately measuring riparian ET using micrometeorological approaches. The eddy-covariance method has been used to successfully measure ET in numerous studies (Businger and others, 1967; Moore, 1986; Baldocchi and others, 1988; Stannard and others, 1994). This micrometeorological method has several advantages in comparison to other approaches such as lysimeters or regional water balances, by providing more areal integration and less site disruption than lysimeters, by eliminating the need to estimate other terms such as runoff in the water balance, and by allowing fine temporal resolution of less than 1 hour of ET patterns. These data and the models calibrated from those data provide insight into the relations between ET and environmental variables (Stewart, 1988; Stannard, 1993). Models also provide a tool for extrapolating results to other locations. For example, Jensen and others (1990) developed crop coefficients that reflect the ratio of a given crop ET with that of a reference ET estimated from nearby weather stations.

\section{Acknowledgments}

The authors thank the landowners, Gerald and Keith Trampe and Steve Potter, who provided access to their property, and Jim Gaskill for logistical assistance. The COHYST technical committee also is acknowledged for extensive input and support of this project. The authors also thank USGS researcher David Stannard for providing guidance and expertise from the project's conception to its conclusion.

\section{Methods of Investigation}

The sections below provide an overview of the approaches used in this study and provide references for more detailed descriptions. Methods used in selecting and characterizing study sites, collecting micrometeorological, waterbalance, leaf-area-index, and sap-flux data, and developing models of ET are described.

\section{Site Selection and Characterization}

The study sites were chosen on the basis of several selection criteria. Candidate selections were based upon large north-to-south riparian forest extent along the Platte River, a forest community generally representative of Platte River riparian forests, and physical site characteristics. After analysis of land-cover data to select candidate riparian forest sites, field 
reconnaissance verified that vegetation and site characteristics were within the range of those encountered in Platte River riparian areas. Thereafter, study sites were selected based upon landowner permission, site access, plans for future vegetation management, and representative vegetation characteristics. Site selection was completed during May-August, 2001, culminating in the final selection of study sites near Odessa and Gothenburg, Nebraska (fig. 1).

\section{Footprint and Forest Area Analysis}

To use micrometeorological techniques to measure fluxes from the targeted riparian areas rather than adjacent land uses, an adequately sized area of homogeneous riparian forest was necessary. Calculations of the footprint, or upwind area most likely to affect a flux measurement at a given height, were made using methods developed by Schuepp and others (1990). For computing preliminary footprint requirements, an average tree height of $18.3 \mathrm{~m}$ (meters) - based on riparian tree height data from the nearby Republican River in south-central Nebraska (Rand, 1973) — and hypothetical sensor height of $27.4 \mathrm{~m}$ were used. The footprint boundaries were calculated by assuming neutral conditions, in which the relative effect of buoyancy on fluxes is negligible as compared to the effect of wind. The footprint calculations also were dependent on the ratio of roughness length (a measure of the aerodynamic roughness of the canopy) to canopy height and the ratio of displacement height (or the height within the canopy at which aerodynamic drag cancels out wind momentum) to canopy height, which were assumed initially to be 0.08 and 0.75 , respectively, based on the mean of six forest ET studies (Stanhill, 1969; Leonard and Federer, 1973; Thompson, 1979; De Bruin and Moore, 1985; Gash, 1986; Bergen, 1987). The results of the preliminary calculations indicated that for neutral conditions, about 85 percent of the flux measured at a $27.4 \mathrm{~m}$ height originated within an upwind distance of $800 \mathrm{~m}$. The actual footprint was likely to be less than that because the largest ET rates occur during unstable conditions, when the footprint is smaller than during neutral conditions; however, to maintain a margin of safety, the initial estimate of the riparian forest area necessary to reflect fluxes from that vegetation was a circle with a radius of $800 \mathrm{~m}$.

Analysis of digital data for land cover (Center for Advanced Land Management Information Technologies, 2000), riparian vegetation types (Currier and others, 1985; Bureau of Reclamation, 1998), and infrared reflectance (aerial photographs) covering parts of the Platte River Basin in Nebraska (Bureau of Reclamation, 1999), indicated that 20 sites met the footprint criterion. Subsequently, nine candidate sites with the greatest densities of woodland vegetation (as compared to meadows or open water) were selected for further investigation.

Basic reconnaissance visits were made to the nine candidate sites to survey tree heights and species from roads bordering the sites. Based upon the reconnaissance data, the assumption of an average canopy height of about $18 \mathrm{~m}$ was considered justified; however, the reconnaissance data also indicated large variability, with tree canopy height ranging from about 14 to $23 \mathrm{~m}$. The canopy height variability indicated that the forests had a greater roughness length than previously assumed, thereby decreasing the footprint area. As a result, the preliminary selection criterion requiring at least $800 \mathrm{~m}$ of upwind riparian forest was conservative as compared to actual upwind source areas. As a result of this reconnaissance, as well as access limitations, four of the nine sites remained for further consideration.

\section{Forest Surveys}

Forest surveys of the four remaining candidate sites, including the two study sites selected, were completed during July and August 2001. Vegetation data were collected at 12 to 14 points along generally north-south transects spanning the entire width of the riparian forest area at each site. Along each transect, measurement points were spaced $100 \mathrm{~m}$ apart, and the point-centered quarter sampling method (Mueller-Dombois and Ellenberg, 1974; Fitzpatrick and others, 1998) was used to select the trees sampled. From the sampling point, the closest live tree in each of four quadrants was selected for description. Described trees were at least $2 \mathrm{~m}$ tall and had a diameter at breast height $(1.5 \mathrm{~m})$ of at least $3 \mathrm{~cm}$ (centimeters). For each quadrant, canopy closure was measured with a concave spherical densiometer following methods described by Platts and others (1987) and Fitzpatrick and others (1998); pointto-tree distance was measured with a cloth tape; the species of the tree was identified; the circumference of each sampled tree was measured using a cloth tape; the diameter at breast height and basal area were calculated from the field-measured circumference; tree heights were calculated using angles and distances measured with a clinometer and range finder (Rand, 1973); and any additional ancillary notes on understory vegetation composition and other observable features of note were recorded. In addition to the characteristics listed above, the vegetation data collected were used to compute the average canopy area per tree, density (number of individuals per area), species frequency, and relative densities and frequencies using formulas provided by Fitzpatrick and others (1998) and Rand (1973).

\section{Micrometeorological Measurements}

At each of the study sites, micrometeorological instrumentation was installed at a height of $26.1 \mathrm{~m}$ on a $27.4-\mathrm{m}$ tall tower, at the land surface, or in the subsurface. Because the cottonwood-dominated canopy was approximately $18.3-\mathrm{m}$ tall on average at both sites, the tower allowed for instrumentation to be placed at a height of about 1.5 times the canopy height, a typical design height for energy flux measurements (David I. Stannard, U.S. Geological Survey, oral commun., May 15, 2001). The instrumentation was installed in March 2002 and measurements continued until May 2006 (figs. 2, 3, 4; table 1). 
Instruments recorded continuously through the year to monitor dormant-season ET as well as growing-season ET.

Micrometeorological data were compiled every 30 minutes, transmitted daily by cellular-telephone telemetry, and reviewed at least once per week. Monthly site visits were made to clean and repair sensors as necessary, to collect additional samples such as soil cores for determining soil-water content and bulk density, to measure leaf-area index (LAI) using a hemispherical-photographic system, and to download data loggers recording ground-water levels, unsaturated-zone temperature profiles, and plant sap flux. Details of the data collection and analysis are described in the sections that follow.

\section{Eddy Covariance}

Total ET was determined from micrometeorological measurements using the eddy-covariance technique (Businger and others, 1967; Moore, 1986; Baldocchi and others, 1988; Stannard and others, 1994). Eddy covariance measures fluxes along all three Cartesian axes (vertical, or $\mathrm{z}$, and horizontal, or $\mathrm{x}$ and $\mathrm{y}$ ), with a focus on the vertical fluxes in scenarios where the footprint area is homogeneous. This technique was selected because it has been used successfully to measure actual ET for forest and shrub canopies (Stewart, 1988; Stannard, 1993; Nagler and others, 2005), which usually have considerable roughness. Because of the large fluctuations in vertical velocity associated with increased roughness in the forest canopy, eddy covariance is expected to produce more accurate results than techniques that rely on vertical gradients (Kanemasu and others, 1979), such as the Bowen ratio method, a commonly applied and less expensive micrometeorological technique used for vegetation of more uniform height.

Sensors pertinent to evaluating ET from the eddy-covariance technique (sonic anemometer and krypton hygrometer; table 1) were deployed. These sensors took measurements every 0.1 seconds that were then compiled for 30-minute periods to record mean fluxes of water (in the form of latent heat) and energy (in the form of sensible heat) from the vegetated land surface. Water fluxes were direct measures of ET. Energy fluxes were used in conjunction with other sensors to determine how closely the energy balance approached closure, thus providing a quality-assurance check on the data.

Before the data could be used to evaluate energy-balance closure or to fill gaps in the data record, coordinate-rotation adjustments and atmospheric corrections had to be applied to the raw eddy-covariance data. To achieve the ideal conditions of the eddy-covariance method-where the mean verticalturbulent flux is the result of advective diffusion from the underlying surface- the mean vertical wind velocity must be zero (Baldocchi and others, 1988); however, apparent non-zero vertical wind-velocity components can result from imperfectly leveled eddy-covariance sensors or from non-horizontal upwind surfaces. Therefore, coordinate rotation typically is performed to transform the data into a natural coordinate system (Kaimal and Finnigan, 1994) in which each 30-minute mean wind velocity is parallel to the underlying surface. In more complex terrain, the planar-fit coordinate system (Paw U and others, 2000; Wilczak and others, 2001) may be preferable to natural coordinates because it reduces errors and biases associated with over-rotation (Massman and Lee, 2002; Lee and others, 2004). Although the land surfaces at both sites were comparatively flat, the intermittent pattern of trees and open areas resulted in an aerodynamically complex terrain that warranted the use of planar-fit coordinates. Planar-fit techniques correct the mean wind velocity for much longer periods (in this case, the 4-year study period) to be parallel to the underlying surface. For this study, this was accomplished by manually fitting a sinusoidal curve to the raw data (Wilczak and others, 2001). The derived equations were:

Near Odessa, Nebraska:

$$
w_{\text {ang }}=0.56+0.57 \cos \left(\frac{\pi}{180}\left(w_{d}+75\right)\right)
$$

Near Gothenburg, Nebraska:

$$
w_{\text {ang }}=0.05+1.94 \cos \left(\frac{\pi}{180}\left(w_{d}+220\right)\right)
$$

where

$$
\begin{aligned}
& w_{\text {ang }} \quad \text { is the zenith angle of the wind above the } \\
& \text { horizontal plane, in degrees; and } \\
& w_{d} \quad \text { is the horizontal azimuth angle of the wind } \\
& \text { measured by the sonic anemometer, in } \\
& \text { degrees. }
\end{aligned}
$$

The resulting equation for $w_{\text {ang }}$ at each site was then used in equations described by Baldocchi and others (1988) for calculating rotated turbulent-flux covariances between wind and krypton hygrometer voltage and between wind and air temperature. Covariances necessary to calculate rotated eddy-covariance measurements were not stored before February 6, 2003; therefore, coordinate rotations were not made to data collected before this date. The omission of coordinate rotations to flux data collected before February 6, 2003, is expected to have negligible impact because the rotation adjustment for later periods had a small (less than a 2-percent change in annual energy balance closure) effect on the estimated turbulent fluxes.

Adjustments were made to the rotated latent- and sensible-heat fluxes to account for atmospheric effects. Corrections for air-density fluctuations caused by heat and water-vapor transfer followed the techniques of Webb and others (1980). The sensitivity of the krypton hygrometer to oxygen and the resulting effect on latent-heat-flux measurements (Tanner and Greene, 1989; Sumner, 1996) were taken into account. Because air temperature was determined from sonic measure- 
(A) Odessa study site
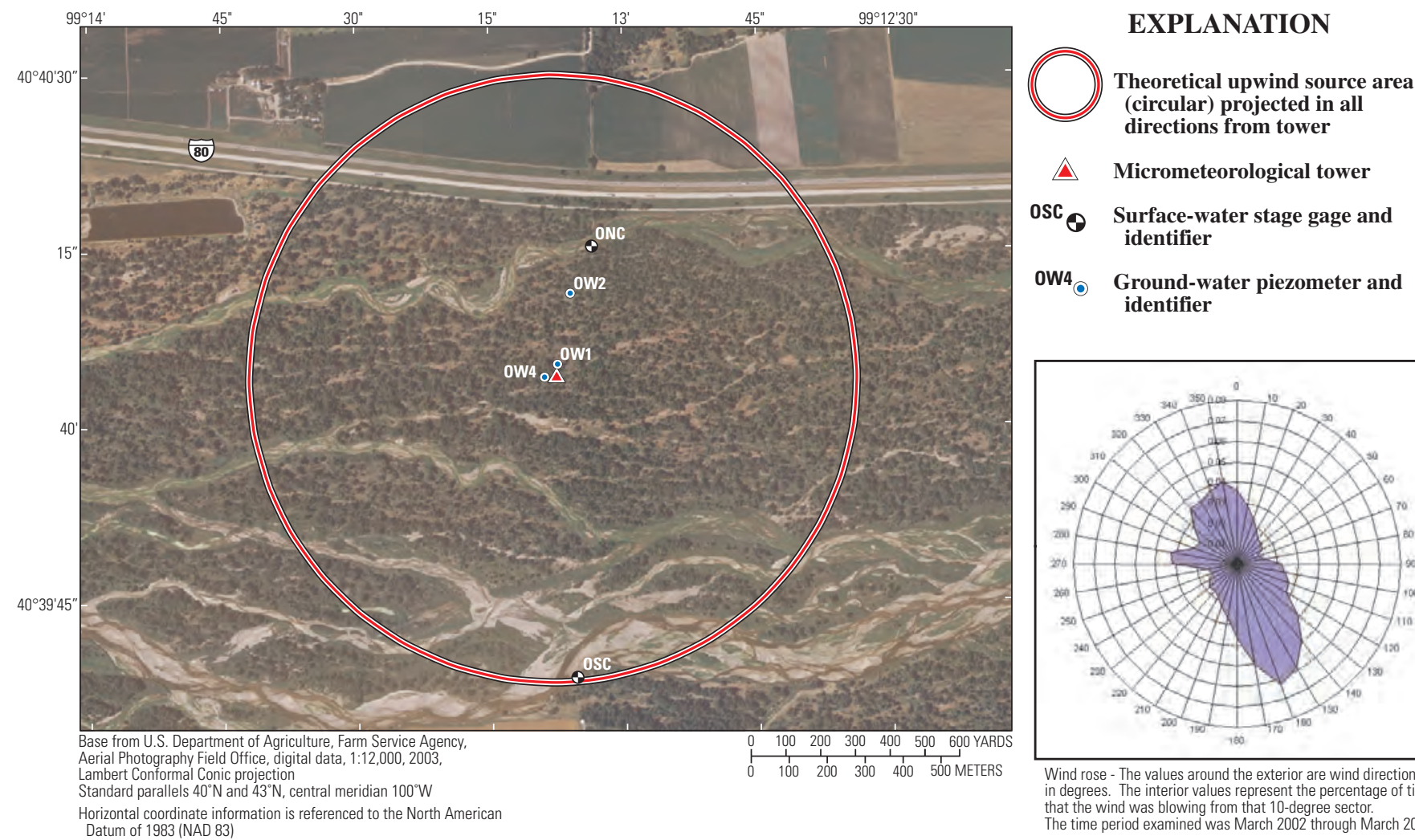

\section{(B) Gothenburg study site}
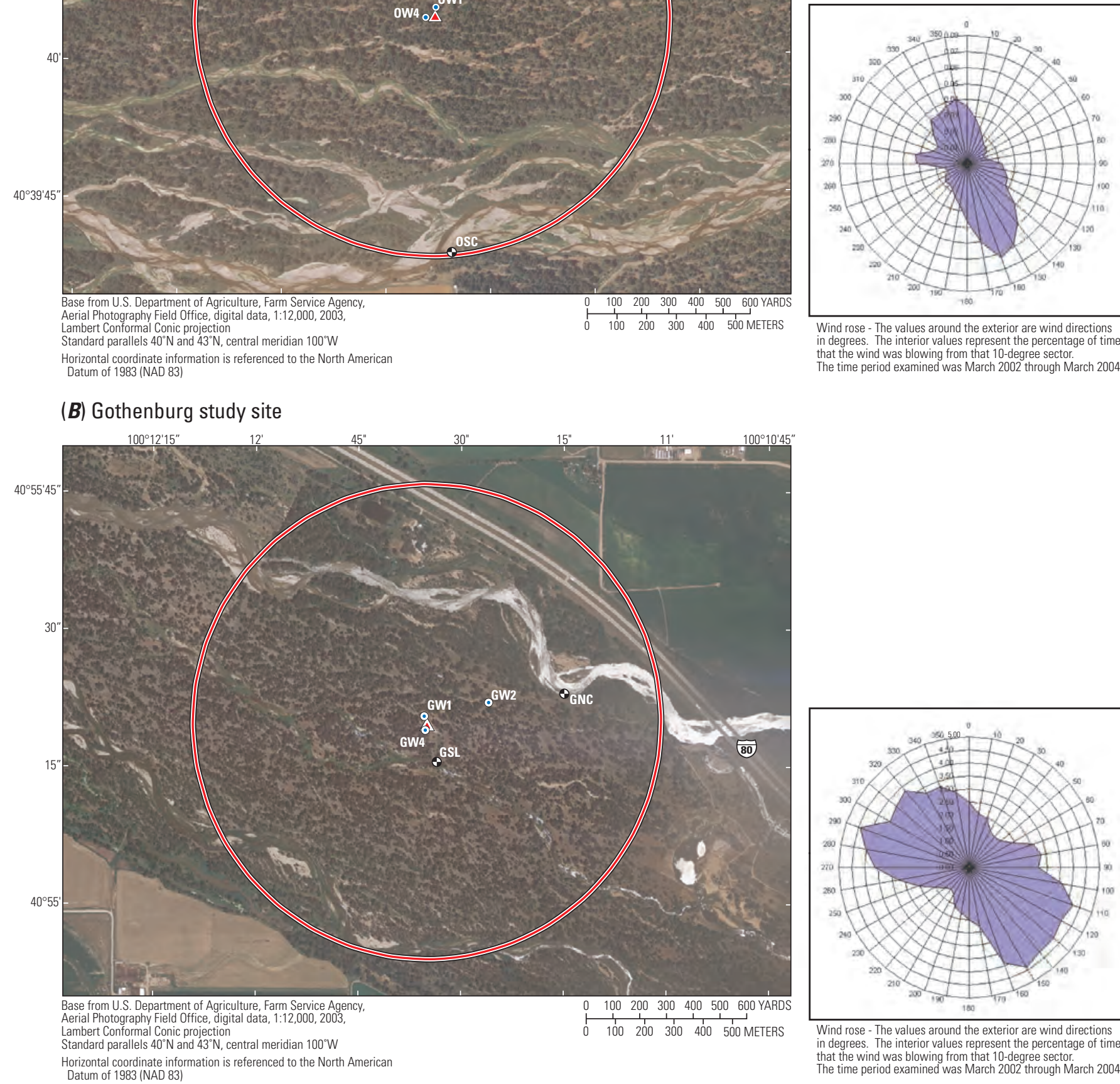

Wind rose - The values around the exterior are wind directions in degrees. The interior values represent the percentage of tim The time period examined was March 2002 through March 2004

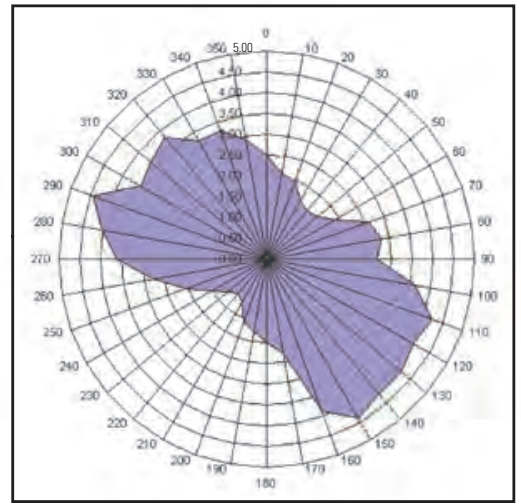

Wind rose - The values around the exterior are wind directions in degrees. The interior values represent the percentage of time

The time period examined was March 2002 through March 2004.

Figure 2. Data collection locations and probable flux source areas for micrometeorological instrumentation on towers at study sites near Odessa and Gothenburg, Nebraska. 
(A) Odessa study site

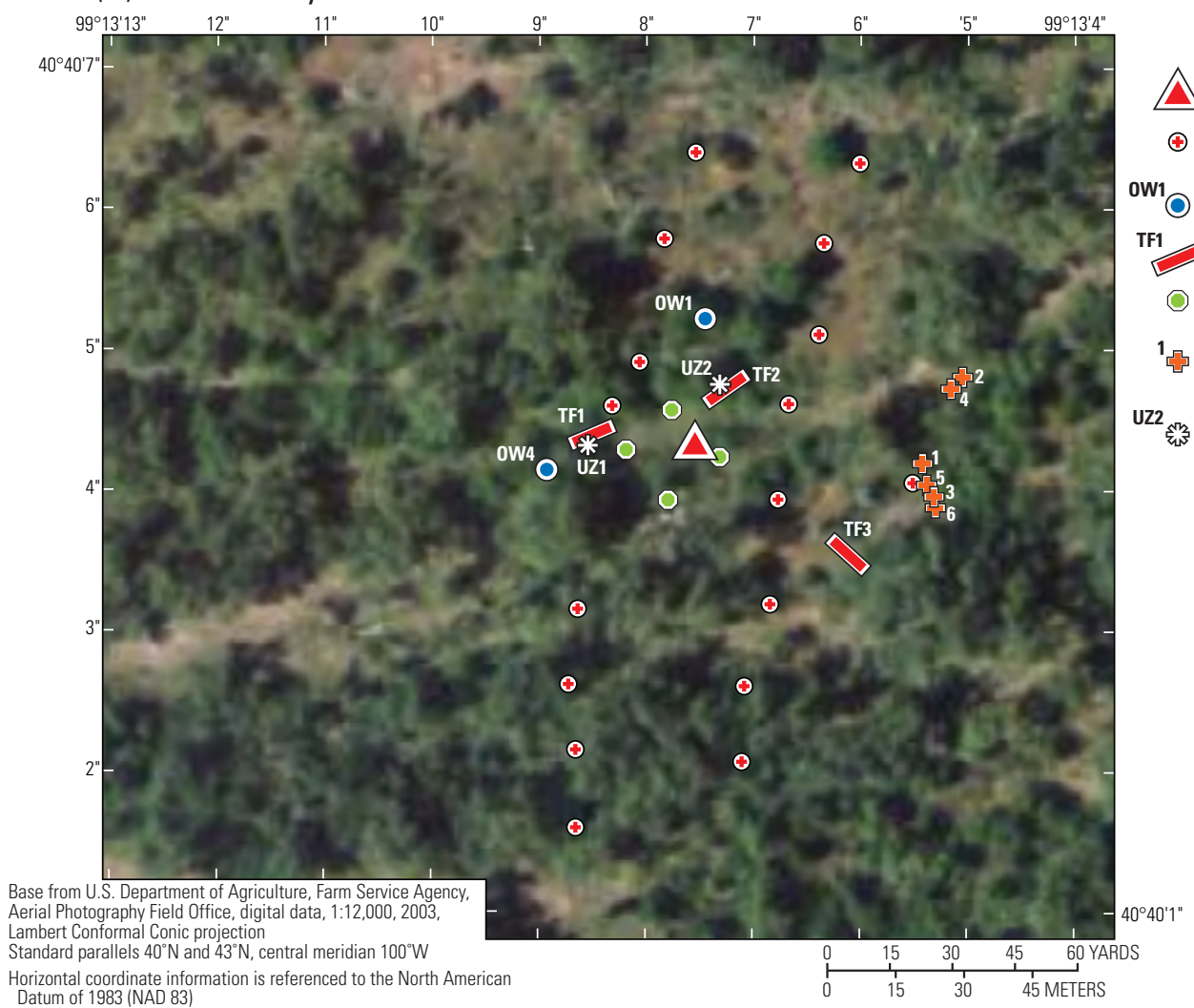

Datum of 1983 (NAD 83)

(B) Gothenburg study site

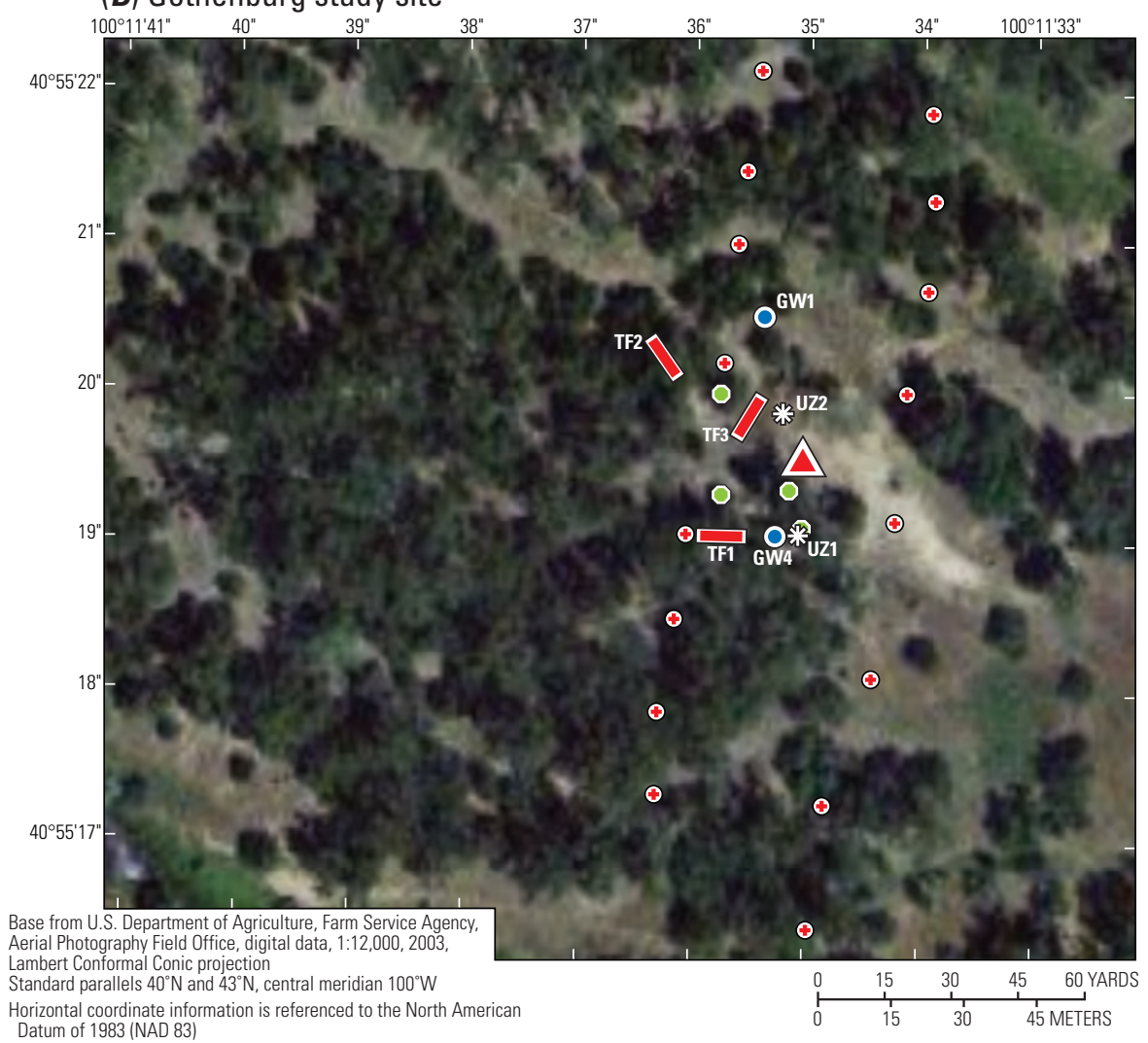

\section{EXPLANATION}

Micrometeorological tower

(†) Leaf-area-index measurement site

Ground-water piezometer and identifier

TF1 Throughfall gage and identifier

Tree-trunk temperature measurements

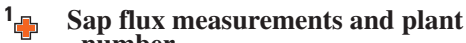
number

Unsaturated zone vertical profile (soil-water content, heat flux, temperature) and identifier

Figure 3. Areal layout of instrumentation near the towers at study sites near Odessa and Gothenburg, Nebraska. 
Micrometeorological measuring instruments

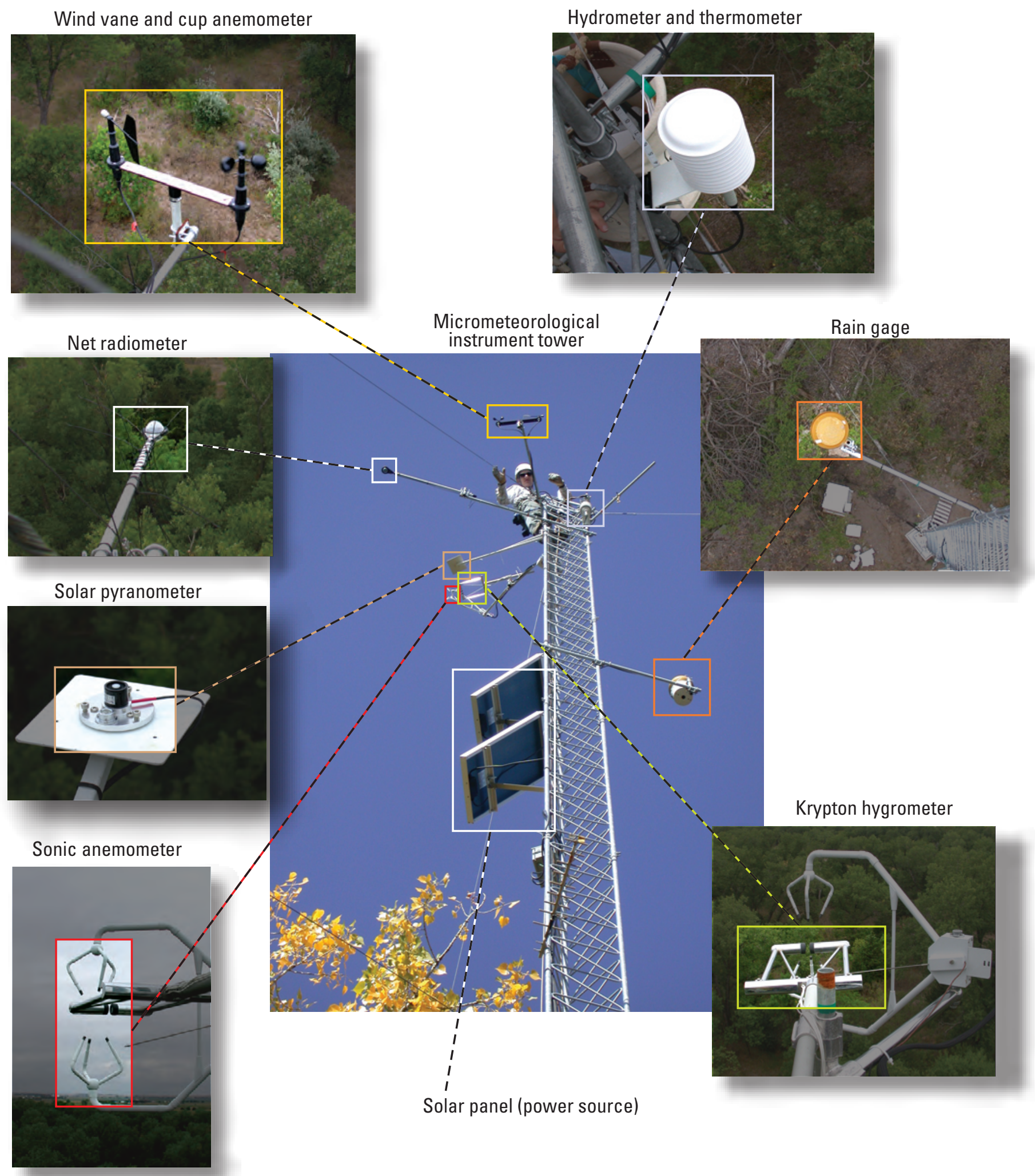

Figure 4. Selected micrometeorological instrumentation used at study sites. 


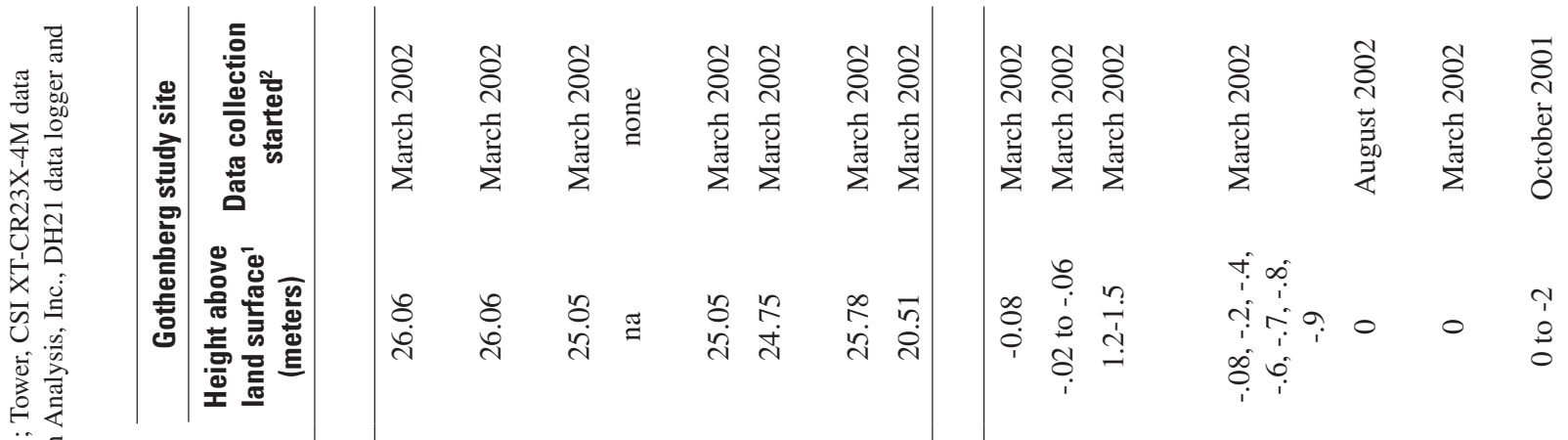

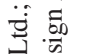

空言

.

总

రิ

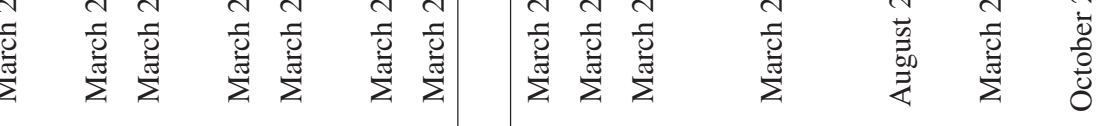

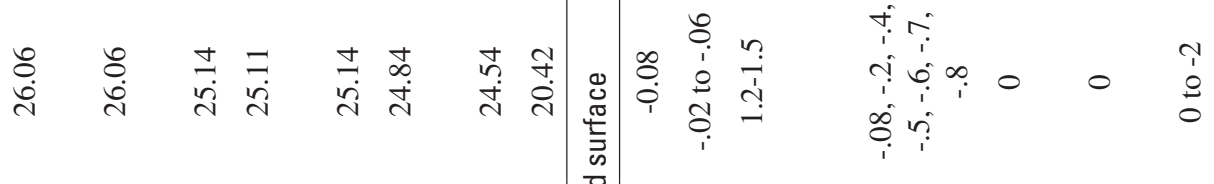




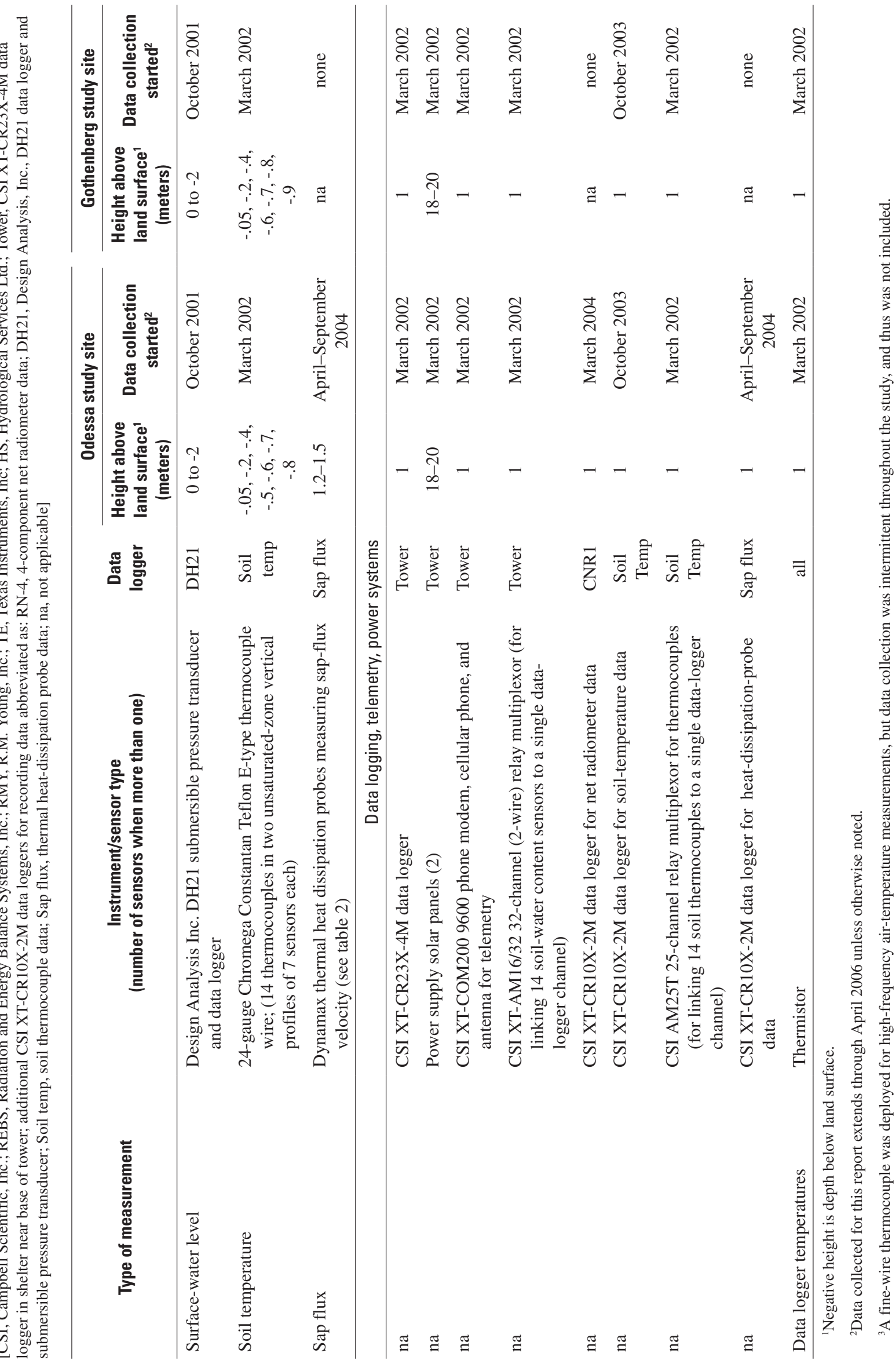


ments, the resulting effect on sensible-heat-flux measurements was adjusted following Schotanus and others (1983).

\section{Energy Balance}

ET determined using eddy covariance was combined with data on other energy-balance variables to calculate energybalance closure (Nichols, 1993; Stannard and others, 1994; Unland and others, 1998; Laczniak and others, 1999). Assessment of energy-balance closure (EBC) was used to evaluate the accuracy of the ET calculations and was determined from the energy-balance equation:

$$
R n-G-\triangle P S=\lambda E+H
$$

where

$$
\begin{aligned}
R n & \text { is net radiation; } \\
G & \text { is the soil-heat flux; } \\
\Delta P S & \text { is the change in the storage of energy in the } \\
& \text { biomass; } \\
\lambda E & \text { is the latent-heat flux; and } \\
H & \text { is the sensible-heat flux. }
\end{aligned}
$$

All terms are in watts per square meter $\left(\mathrm{W} / \mathrm{m}^{2}\right)$. Inequality in the equation above is referred to as the EBC. The energy-balance equation was solved for 30-minute, daily, monthly, and annual periods. In addition, equation 3 was used to calculate the unitless ratio of turbulent flux to available energy, or the energy balance ratio (EBR):

$$
E B R=\frac{\lambda E+H}{R n-G-\Delta P S}
$$

The EBR provided a relative measure of data quality by comparing to unity (or an EBR of one), and also was used in adjusting energy terms for energy-balance closure during gap-filling procedures described in the "Filling of Data Gaps" section in this report. $\lambda E$ and $H$ were determined from the eddy-covariance system previously described. The remaining terms were estimated from additional sensor arrays as described later in this report.

\section{Net Radiation}

Net radiation $(R n)$ primarily was measured using a twocomponent net radiometer (Rn-2) (table 1) deployed throughout the study period at each tower. The windshields of the net radiometer were inspected on every site visit and replaced as needed. Adjustment for the effects of wind speed on $R n$ were made concurrently with the data collection (Campbell Scientific, Inc., 1996a).

A four-component net radiometer ( $\mathrm{Rn}-4)$ (table 1) was installed at the Odessa site beginning in March 2004 for the duration of the study. The Rn-4 includes additional sensors to separately measure upward and downward short-wave and long-wave radiation, and may measure long-wave radiation components more accurately (Campbell Scientific, Inc., 2007) than the model Rn-2. Because of resource limitations, only one Rn-4 was purchased and was deployed at the Odessa site at the same height and about $0.88 \mathrm{~m}$ away from the $\mathrm{Rn}-2$ on the south side of the tower. The data from the two net radiometers at the Odessa site after March 2004 were compared to investigate the effects of long-wave radiation on the energy balance. After determining that EBC was improved with the $\mathrm{Rn}-4$, the net radiation values from the $\mathrm{Rn}-2$ recorded before March 2004 at Odessa, and for the entire period at Gothenburg, were corrected to estimate the $R n$ that would have been measured from a Rn-4. These corrected $R n$ values were estimated by developing linear regression models of $R n$ measurements from the Rn-4 with those from the Rn-2 for the data collected after March 2004. Separate regression models were computed for daytime and nighttime conditions.

\section{Soil-Heat Flux}

Soil-heat flux $(G)$ was calculated as the weighted average of soil-heat-flux measurements from two unsaturated-zone vertical profiles_- UZ1 and UZ2 (fig. 3) —at each site. At Odessa, UZ1 was beneath a cottonwood canopy, and UZ2 was beneath a shrub canopy with no forest overstory. At Gothenburg, UZ1 was located beneath a cottonwood and eastern redcedar canopy, and UZ2 was located in a grassy meadow with no forest overstory. Weighting of each profile into a site average was determined by estimating the relative extent of vegetation corresponding to each profile within the theoretical source area (footprint) for the tower (using aerial photographs). At each location, soil-heat flux was calculated following the techniques of Campbell Scientific, Inc. (1999):

$$
\begin{gathered}
G=G_{8}+\Delta S \\
\Delta S=\frac{\Delta T_{s} \times d \times C_{s}}{t}
\end{gathered}
$$

where

$$
\begin{aligned}
& G \quad \text { is the soil-heat flux at the land surface, in } \\
& \mathrm{W} / \mathrm{m}^{2} \text {; } \\
& G_{8} \quad \text { is the heat flux measured at a depth of } 8 \mathrm{~cm} \\
& \text { using a Campbell Scientific, Inc., model } \\
& \text { HFT3 soil-heat-flux plate (table 1; fig. 5), } \\
& \text { in } \mathrm{W} / \mathrm{m}^{2} \text {; } \\
& \Delta S \quad \text { is the change in storage of heat in the upper } \\
& 8 \mathrm{~cm} \text { of soil, in } \mathrm{W} / \mathrm{m}^{2} \text {; } \\
& \Delta T_{s} \quad \text { is the change in soil temperature in the upper } \\
& 8 \mathrm{~cm} \text { of soil during the measurement } \\
& \text { period, in Kelvin (K); } \\
& d \quad \text { is the thickness of the soil for which the } \\
& \text { calculations are being performed, } 0.08 \mathrm{~m} \text {; }
\end{aligned}
$$




\section{Surface/subsurface measurements}

Sap flux

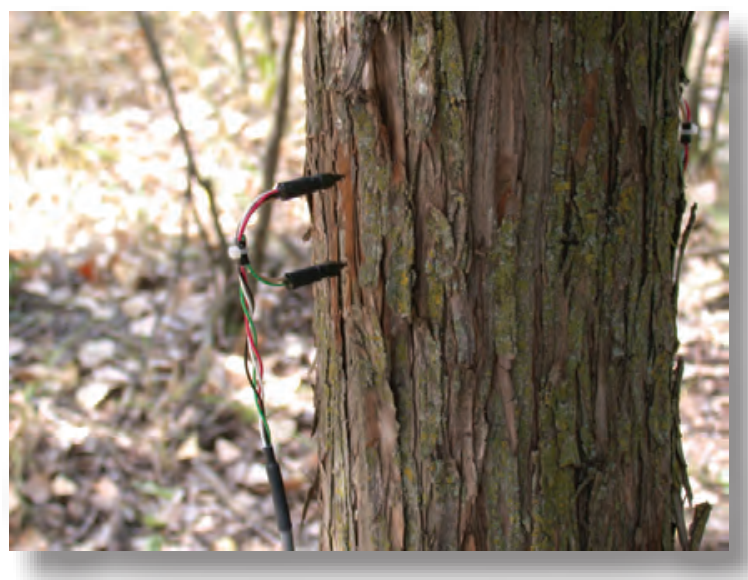

Leaf-area index

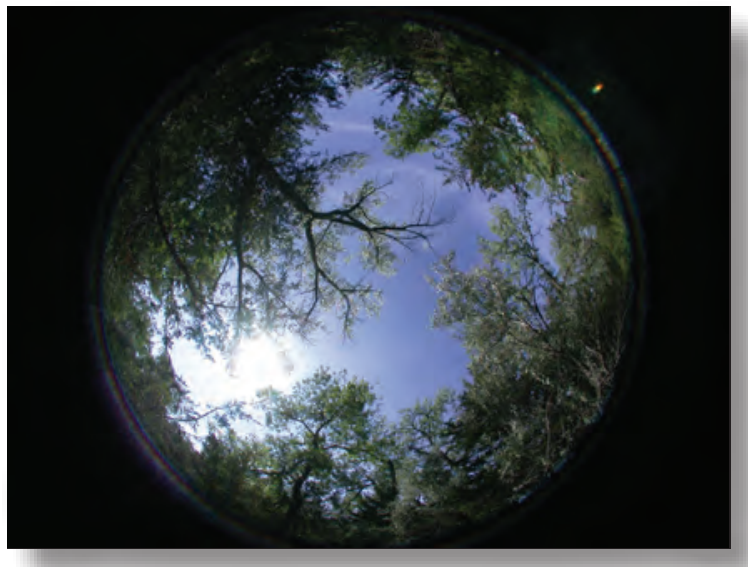

Throughfall/interception

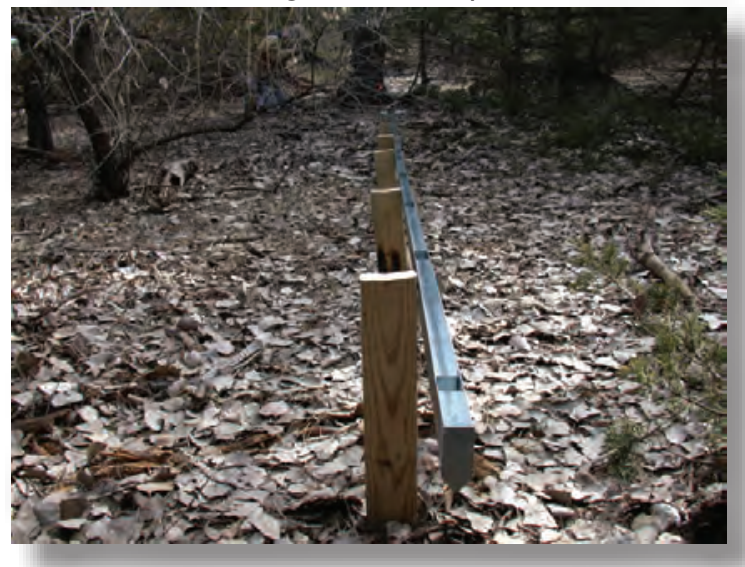

Soil-heat flux/soil temperature

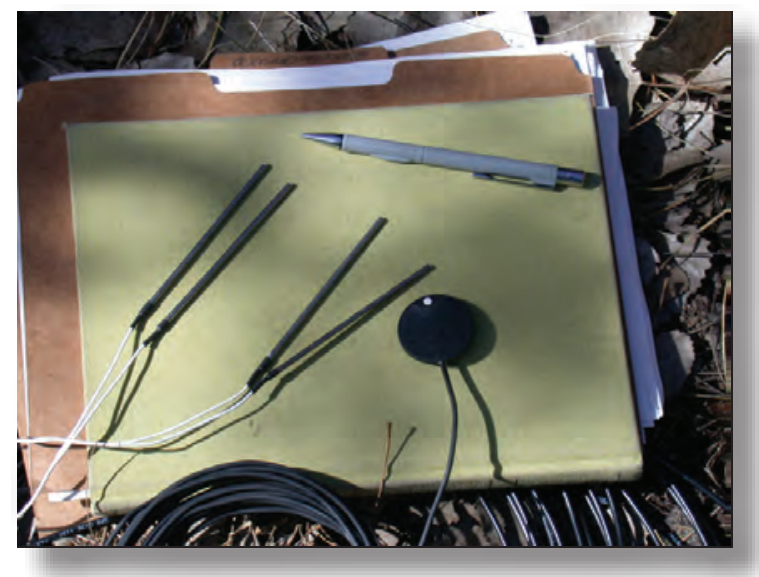

Soil-water content

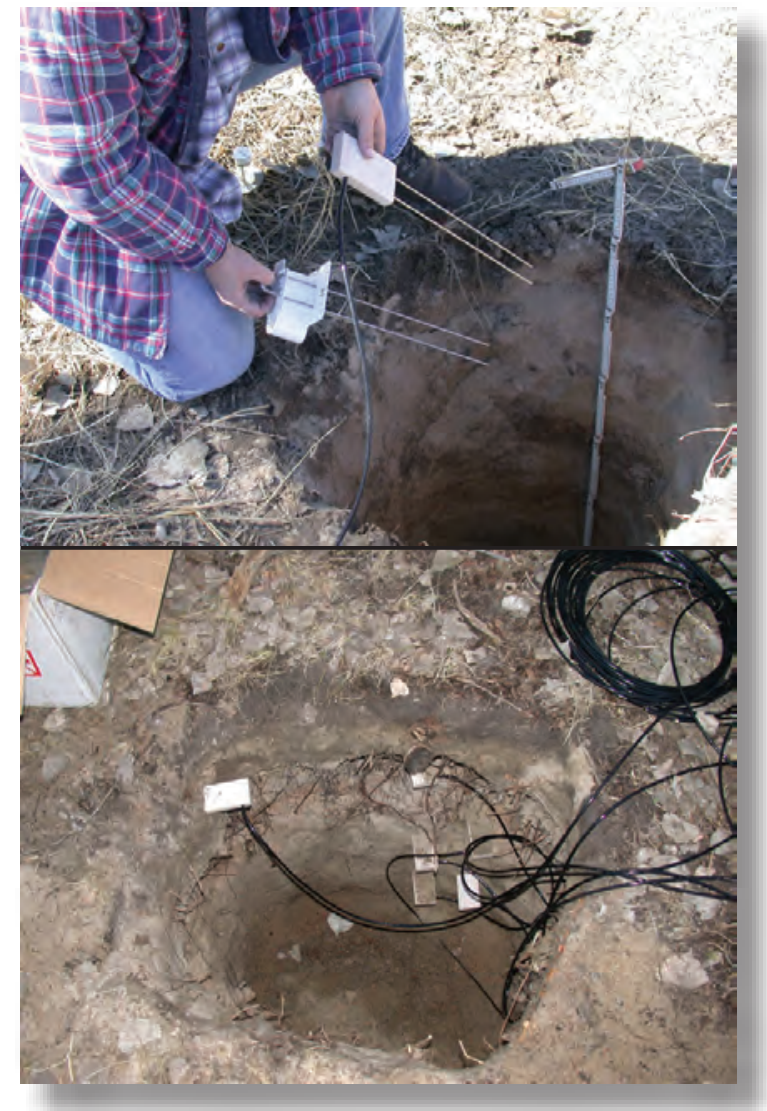

Figure 5. Instrumentation used for measurements of surface or subsurface conditions at study sites. 
$C_{s} \quad$ is the volumetric specific-heat capacity of the soil layer, in Joules per cubic meter per Kelvin $\left(\mathrm{J} /\left(\mathrm{m}^{3} \mathrm{~K}\right)\right)$; and

$t$ is the duration of the measurement period, 1,800 seconds.

A Campbell Scientific (Logan, Utah) model TCAV averaging soil thermocouple (table 1) array was used to measure $\Delta T_{s}$ and consisted of two sets of thermocouples installed 2 and $6 \mathrm{~cm}$ deep on either side of the soil-heat-flux plate (fig. 5) installed horizontally at $8 \mathrm{~cm}$ depth. Values of the volumetric specificheat capacity $\left(C_{s}\right)$ were calculated using the DeVries equation (Hillel, 1980):

$$
C_{s}=\rho_{b}\left(C_{m} \frac{\theta_{m}}{\rho_{m}}+C_{o} \frac{\theta_{o}}{\rho_{o}}+C_{w} \frac{\theta_{w}}{\rho_{w}}\right)
$$

where

$\rho_{b} \quad$ is the median dry-bulk density determined from 11 to 13 soil samples per profile, in kilograms per cubic meter $\left(\mathrm{kg} / \mathrm{m}^{3}\right)$;

$C_{m} \quad$ is the volumetric specific-heat capacity of the mineral component of the soil, $2.13 \times 10^{6}$ $\mathrm{J} /\left(\mathrm{m}^{3} \mathrm{~K}\right)$ (Hillel, 1980);

$\theta_{m} \quad$ is the gravimetric fraction of the mineral component of the soil determined from three samples per profile, in $\mathrm{kg}$ of minerals per kg of soil;

$\rho_{m} \quad$ is the assumed density of the mineral component of the soil, 2,650 kg/m ${ }^{3}$ (Hillel, 1980);

$C_{o}$ is the volumetric specific-heat capacity of the organic component of the soil, $2.5 \times 10^{6} \mathrm{~J} /$ $\left(\mathrm{m}^{3} \mathrm{~K}\right)$ (Hillel, 1980);

$\theta_{o} \quad$ is the gravimetric fraction of the organic component of the soil determined from three samples per profile, in $\mathrm{kg}$ of organics per $\mathrm{kg}$ of soil;

$\rho_{o} \quad$ is the assumed density of the organic component of the soil, 1,300 kg/m ${ }^{3}$ (Hillel, 1980);

$C_{w} \quad$ is the volumetric-specific-heat capacity of water, $4.19 \times 10^{6} \mathrm{~J} /\left(\mathrm{m}^{3} \mathrm{~K}\right)$ (Hillel, 1980);

$\theta_{w} \quad$ is the gravimetric fraction of the water in the soil, in $\mathrm{kg}$ of water per $\mathrm{kg}$ of soil, and calculated from

$$
\theta_{w}=\theta_{w, v} / \rho_{b}
$$

$\rho_{w} \quad$ is the density of water, $1,000 \mathrm{~kg} / \mathrm{m}^{3}$ (Hillel, 1980); and

$\theta_{w, v} \quad$ is the volumetric fraction of the water in the soil measured continuously at each profile using a Campbell Scientific model CS615 water-content reflectometer installed to provide an integrated measurement for $0-8 \mathrm{~cm}$ deep, in cubic meters of water per cubic meter of soil.

\section{Vegetation-Energy Storage}

The changes in energy storage in tree trunks, tree branches, and leaves $(\triangle P S)$ were expected to be small relative to the other terms in eq. 3 , but it was still included in the energy-balance analysis. Previous studies determined that $\triangle P S$ had a negligible effect on the energy balance, especially at timescales longer than a day (Bossung and others, 2003), and the term is not always included in energy-balance studies (Sumner, 1996; Bastiaanssen and others, 1998). However, some practitioners have determined it to be important at daily timescales (Samson and Lemeur, 2001; Meyers and Hollinger, 2004; Gu and others, 2007). $\triangle P S$ was calculated from air and tree-trunk temperature measurements for each 30-minute period. Air temperature was assumed to represent leaf temperature. Tree-trunk temperature was measured as the mean temperature measured at eight points located at depths one-half the radii of four representative trees. Tree-branch temperatures were estimated as the mean of the air and tree-trunk temperatures. Changes in these temperatures were used to estimate the changes in vegetation-energy storage using a summation of the definite integral defined by McCaughey and Saxton (1988):

$$
\Delta P S=\sum \Delta P S_{i}=\sum \frac{\Delta T_{i} C_{i} \rho_{i} \mathrm{~B}_{i}}{t}
$$

$$
\begin{aligned}
& \text { where } \\
& \triangle P S_{i} \quad \text { is the change in energy storage of component } \\
& i \text {, where } i \text { represents tree trunks, branches, } \\
& \text { or leaves, in } \mathrm{W} / \mathrm{m}^{2} \text {; } \\
& \Delta T_{i} \quad \text { is the change in temperature of component } i, \\
& \text { in } \mathrm{K} \text {; } \\
& C_{i} \quad \text { is the specific-heat capacity of component } i \text {, in } \\
& \mathrm{J} /(\mathrm{kg} \mathrm{K}) \text {; } \\
& \rho_{i} \quad \text { is the density of component } i \text {, in } \mathrm{kg} / \mathrm{m}^{3} \text {; } \\
& B_{i} \quad \text { is the unit volume of component } i \text {, in } \\
& \text { cubimeters per square meter }\left(\mathrm{m}^{3} / \mathrm{m}^{2}\right) \text {; and } \\
& t \text { is the duration of the measurement period, } \\
& 1,800 \text { seconds. }
\end{aligned}
$$

Heat capacities and densities of the trunks were estimated by measuring or estimating the heartwood and sapwood fractions of the trunk; assigning specific-heat capacities and densities to wood $\left(C_{\text {wood }}=1,760 \mathrm{~J} /(\mathrm{kg} \mathrm{K}), \rho_{\text {wood }}=700 \mathrm{~kg} / \mathrm{m}^{3}\right)$ and water $\left(C_{\text {water }}=4,190 \mathrm{~J} /(\mathrm{kg} \mathrm{K}), \rho_{\text {water }}=1,000 \mathrm{~kg} / \mathrm{m}^{3}\right)$ using the values of Hodgman and Holmes (1941); and assuming volumetricmoisture contents for heartwood, sapwood, and leaves of $0.05,0.35$, and 0.50 cubic meters of water per cubic meter of vegetation, respectively. Trunk volume was determined from 
forest-survey measurements of tree height, diameter, and areal density (trees per hectare) for each site. Branch volume was assumed to be one-half of the trunk volume. Leaf volume at maximum leaf out was assumed to be one-half of the trunk volume, and the seasonal cycle of leaf volume was represented by applying a ratio of measured-leaf area (integrating several individual plants and species) for a given period with the maximum-measured-leaf area. Simple approaches were used to quantify many of these terms, producing considerable uncertainty with these assumptions. However, because $\triangle P S$ is typically small relative to the other variables in an open system such as a riparian forest (Samson and Lemeur, 2001), this uncertainty probably has a negligible effect on the energy balance at seasonal or annual timescales.

\section{Energy-Balance Adjustments}

Previous investigations have described that long-term average energy-balance ratio values typically are in the range of 0.7 to 1.0 for energy balance investigations (Moore, 1986; Sumner, 1996; Aubinet and others, 2000; Twine and others, 2000). For this study, initial analyses of 2002 to 2003 data collected using the 2-component net radiometer indicated EBR values around 0.83 . Possible explanations for the discrepancy between measured turbulent fluxes and measured available energy include several factors (Sumner, 2001) but can be summarized as resulting from underestimation of the turbulent fluxes using the eddy-covariance method (Moore, 1986; Twine and others, 2000; Barr and others, 2006), or overestimation of $R n$ using a Rn-2 (David I. Stannard, U.S. Geological Survey, written commun., 2004), as a result of underestimated long-wave radiation components (Field and others, 1992). In the case of the latter mechanism, better long-wave radiation measurement has the effect of improving the daily EBC by decreasing daily $R n$; therefore, a four-component netradiometer equipped to more accurately measure long-wave radiation was deployed at the Odessa site after March 2004 (table 1). $R n$ values from this sensor systematically were less than those from the existing Rn-2; therefore, it was evident that $R n$ had been systematically overestimated, thereby resulting in a long-term average EBR less than 1. After correcting all $R n$ data in relation to the Rn-4 values, the long-term (April 1, 2002-March 31, 2005) EBR was 0.89 at both sites, an improvement in energy balance closure.

Adjustments to energy-balance terms routinely are made as part of micrometeorological investigations to correct for the effects of this inherent lack of energy balance closure (Twine and others, 2000). To account for the assumed overestimation of $R n$ by the Rn-2, the $R n$ data were adjusted downward by multiplying by long-term EBR ( 0.89 at both sites). The adjusted $R n$ data were considered the final values that were used in the analyses and reported in the appendixes.

It should be noted that a long-term EBR less than 1 could be the result of a combination of underestimated-turbulent fluxes and overestimated $R n$. Because the relative contribution of each was unknown, upper bounds of $\lambda E$ and $H$ were esti- mated by dividing the measured values by the long-term mean EBR; however, these upper bounds served only as a reference and were not used in the analyses.

\section{Meteorological Variables}

Additional meteorological variables were either measured or calculated to relate environmental conditions to ET rates at the study sites. Air temperature, relative humidity, solar radiation, wind speed, and wind direction (table 1; fig. 4) were measured every 10 seconds and averaged for each 30-minute period. The saturation-vapor pressure was calculated from air temperature using the equations of Lowe (1977). The vapor pressure was calculated from the relative-humidity measurements and saturation-vapor-pressure calculations (Campbell and Norman, 1998). Vapor-pressure deficit $(D)$ is a good measure of the drying potential of air and often is an important variable affecting ET rates (Jarvis, 1976; Stewart, 1988; Stannard, 1993). $D$ was calculated as the difference between the saturation-vapor pressure and vapor pressure.

\section{Potential Evapotranspiration}

Potential evapotranspiration (PET) - the vapor flux that would occur from a well-watered short green crop (Rosenberg and others, 1983) — was calculated at the study sites. Winter and others (1995) demonstrated that the Priestley-Taylor equation (Priestley and Taylor, 1972) produced similar results as the Penman-Monteith equation, but was computationally less demanding. The equation took the form:

$$
\lambda E_{p}=\alpha\left(\frac{s}{s+\gamma}\right)(R n-G-\Delta P S)
$$

where

$$
\begin{array}{cl}
\lambda E_{p} & \text { is the potential latent-heat flux, in } \mathrm{W} / \mathrm{m}^{2} ; \\
\alpha & \text { is the Priestley-Taylor coefficient, } 1.26 \\
& \text { (Priestley and Taylor, 1972); } \\
s & \text { is the slope of the relation of saturation-vapor } \\
\text { pressure to air temperature at a given air } \\
\text { temperature, computed using the equations } \\
\text { of Jensen and others }(1990), \text { in kilopascals } \\
\text { per degree Celsius }\left(\mathrm{kPa} /{ }^{\circ} \mathrm{C}\right) ;
\end{array}
$$

\section{Filling of Data Gaps}

Eddy-covariance data were either missing or discarded for approximately 11 percent of the study period. Gaps in these data can occur for a number of reasons, including condensation on either the windows of the krypton hygrometer or the transducers of the sonic anemometer; sensor or data-logger 
failure; other problems such as debris on sensors; and data not meeting quality standards, such as data spikes. Gaps in eddycovariance data are common (Falge and others, 2001), and had to be filled to develop daily, monthly, and annual values of ET and other micrometeorological variables. Typically, these gaps were filled using either linear interpolation or a form of the energy equation (eq. 3) modified to account for the long-term mean $\mathrm{EBR}\left(\mathrm{EBR}_{\text {mean }}\right)$ (eq. 4):

$$
E B R_{\text {mean }}(R n-G-\Delta P S)=\lambda E+H
$$

where all terms are previously defined.

Most of the gaps (66 percent) were caused by condensation on the krypton hygrometer or sonic anemometer that produced over-range values in $\lambda E$ and $H$. In these situations, $\lambda E$ typically was estimated as the product of $\lambda E_{p}$ and $E_{B R}$ mean $H$ was then estimated to be the residual needed to balance the energy equation (eq. 10). For a small subset of gaps corresponding to short (less than 2 hours) and small (less than $1 \mathrm{~mm}$ ) precipitation events, linear interpolation between measured data was used to estimate data for the missing time periods.

Some gaps were caused by instrumentation failure or maintenance-related down time. In these instances, gaps less than 6 hours typically were filled using linear interpolation. In some cases, perceived trends in the data-such as the nonlinearity between nighttime values and daytime peaks-were applied to estimate data within missing periods. For extended periods of missing data, other approaches were used. For example, a sensor malfunction at the Odessa site caused the removal of $\lambda E$ values from September to December 2002. For this and similar periods, $\lambda E$ was estimated as the residual needed to balance the energy equation (eq. 10). During some of these extended $\lambda E$ gaps, values of $H$ also were missing for shorter periods typically corresponding to mid-day periods of rising $\lambda E$ and $H$. In these situations, $H$ was linearly interpolated before $\lambda E$ could be calculated from the energy equation. For periods where none of the energy-equation variables were available at a site (less than 1 percent of the study period), missing data for a given variable were estimated using linearregression equations of one site with the other that were developed from periods of measured data.

\section{Water Balance}

A water-balance approach was used to estimate the part of ET derived from ground water. In addition to the measured ET rates, measurements of precipitation, soil-water storage, and ground-water storage were included. These were used to estimate the remaining term in the water balance, net-groundwater flow to or from the riparian forest area, which served as a surrogate for the presence of aquifer recharge or GWET. In addition to their application to the water balance, precipitation, soil-water content, and ground-water level were explored as explanatory variables for predicting ET rates.

The annual water balance was estimated for a representative volume extending vertically from a height of $26.1 \mathrm{~m}$ above land surface - corresponding to the eddy-covariance sensors - to about $3 \mathrm{~m}$ below land surface (into the saturated zone). Horizontally, the representative volume is considered to represent the riparian island where the tower is located, between flowing river channels to the north and south, and extending out $800 \mathrm{~m}$ from the tower to the east and west along the island, corresponding to the calculated footprint for the tower. The water-balance equation was a function of the inputs, the outputs, and the changes in storage (Healy and others, 2007) within the representative volume:

$$
\begin{gathered}
P+S W_{\text {in }}+G W_{\text {in }}=E T+S W_{\text {out }}+G W_{\text {out }}+R O \\
+\Delta S W+\Delta G W+\Delta P W+\text { error }
\end{gathered}
$$

where

$\begin{array}{cl}P & \text { is the precipitation; } \\ S W_{\text {in }} & \text { is the lateral soil-water inflow; } \\ G W_{\text {in }} & \text { is the ground-water inflow; } \\ E T & \text { is the evapotranspiration; } \\ S W_{\text {out }} & \text { is the lateral soil-water outflow; } \\ G W_{\text {out }} & \text { is the ground-water outflow; } \\ R O & \text { is the overland runoff; } \\ \Delta S W & \text { is the change in soil-water storage; } \\ \Delta G W & \text { is the change in ground-water storage; } \\ \Delta P W & \text { is the change in plant-water storage; and } \\ \text { error } & \text { is the residual term including errors in other } \\ & \quad \text { terms in the equation and other sources of } \\ & \text { error. }\end{array}$

All terms are expressed in $\mathrm{mm} / \mathrm{yr}$ corresponding to a water volume on a unit-area basis.

For these study sites, several of the terms in equation 11 were relatively unimportant, and were thus omitted. Surfacewater flow $(R O)$ into or out of the representative volume was assumed to be negligible based on the sandy soils and flat topography. Lateral flow of soil water into $\left(S W_{i n}\right)$ or out of $\left(S W_{\text {out }}\right)$ the representative volume and changes in plant water storage $(\triangle P W)$ also were assumed to be negligible. As a matter of practicality, the error also was assumed to be insignificant. The resulting water-balance equation was then rearranged to isolate ground-water inflow and outflow:

$$
G W_{\text {in }}-G W_{\text {out }}=E T-P+\Delta S W+\Delta G W
$$

where all terms are previously defined.

This approach was applied annually, with annual periods defined as April 1 of a given calendar year to March 31 of the following calendar year. 


\section{Evapotranspiration}

To include ET in the water balance, the latent-heat flux $(\lambda E)$ measured using micrometeorological techniques was converted from units of power for a given area $\left(\mathrm{W} / \mathrm{m}^{2}\right)$ to units of water flux for a given area (cubic millimeters of water per square millimeter per second, reducing to millimeters of water per second). This was done by dividing $\lambda E$ by the latent-heat of vaporization $(\lambda)$ — calculated from air temperature following Jensen and others (1990) — and by the density of water. The resulting value represented an ET rate associated with vegetation within the footprint area.

\section{Precipitation and Canopy Interception}

Because of the importance of precipitation to the water balance, total precipitation and throughfall precipitation (the precipitation not intercepted by canopy vegetation) were both measured. Canopy interception was then calculated as the difference between total and throughfall precipitation, or, when rearranged:

$$
P=I+T F
$$

where

$$
\begin{aligned}
& \text { I is the canopy interception of precipitation, in } \\
& \mathrm{mm} \text {; and } \\
& \text { TF is the canopy-throughfall precipitation, in } \\
& \mathrm{mm} .
\end{aligned}
$$

\section{Precipitation and Throughfall Measurement}

Throughfall precipitation was measured underneath the canopy using gutter systems that drained into rain gages (Davie, 2003). At each site, a series of three gutters were installed (fig. 3) beneath a relatively dense canopy (TF1), beneath a relatively less dense canopy (TF2), and in an open meadow with no overlying canopy (TF3). Each gutter was 9.1 $\mathrm{m}$ long, $2.5 \mathrm{~cm}$ wide, $6.4 \mathrm{~cm}$ deep (fig. 5), and was installed at a 4-percent slope that drained into a tipping-bucket rain gage (Hydrological Services, Sydney, Australia, model TB4, table 1) installed below ground surface in an 18.9-L (liter) bucket.

For comparison to the gutter systems, a fourth tippingbucket rain gage (Model TE525WS; Campbell Scientific, Inc., 2008) was installed at a height of approximately $20.5 \mathrm{~m}$ on each tower. Precipitation measured in all three throughfall gages generally was greater than precipitation measured in the tower gage. It was suspected that precipitation in the tower gage was negatively biased with respect to the throughfall gages for two reasons: Wind speed and turbulence were greater at the tower gage, thereby reducing the effective area of the gage, and the throughfall gages had a collection area approximately 7.1 times larger than the tower gage so that the design of the throughfall gages permitted them to measure small amounts of precipitation more accurately. As a result, the tower gages were operated throughout the study to have an additional source of precipitation data, but generally were not used for estimating precipitation totals.

Field tests of the throughfall and tower rain gages were done annually to verify that the rain gages accurately measured precipitation. Tests were conducted by delivering a known volume of water to the rain gage for 20 to 70 minutes. For 31 rain-gage tests conducted during 2002 to 2005, the rain gages recorded 90 to 110 percent of the volume of water added with a median of 102 percent.

Precipitation data generally were excluded if any of the following criteria were met: The air temperature was below freezing; the recorded precipitation appeared to be associated with snow or ice melt; the recorded precipitation was associated with gage maintenance during the time of a site visit; or the precipitation was recorded in a gage that was partially clogged. All rain gages and throughfall gutters were inspected on monthly site visits. Observations of clogged gages were recorded in field notes, and then the debris was removed. In addition, periods of clogging generally were evident from the recorded data as reduced totals or substantially delayed responses compared to gages that were operating normally.

Once anomalous data were removed, the maximum daily value from the four gages at each site was used as the best estimate of total precipitation at each site for periods without freezing conditions. The daily-total precipitation for each site was compared to daily precipitation measured at nearby weather stations at Gothenburg and Kearney (High Plains Regional Climate Center, 2006). These weather stations were located approximately 4 to 19 kilometers $(\mathrm{km})$ away from the Gothenburg and Odessa study sites, respectively, leading to differences in the amounts and timing of precipitation. During non-winter months, monthly precipitation values at the study sites were approximately 27 and 30 percent larger than at the weather stations at Gothenburg and Odessa, respectively. Annual and monthly precipitation data for each site also were compared to 30-year normal precipitation data for 1961 to 1990 at the weather stations. Because the weather stations also recorded precipitation during freezing conditions, the daily precipitation from the weather stations was used as the daily estimate of precipitation for days in which the air temperature was below freezing. Although spatial differences were likely between the study sites and the weather stations, the rain gages at the study sites were not equipped to accurately monitor frozen precipitation. The effect of these differences on the annual water balance is expected to be lessened because a relatively small part (less than 15 percent; High Plains Regional Climate Center, 2006) of the annual precipitation occurs during November through February.

\section{Accounting for Canopy Interception in the Water Balance}

Using measurements of canopy interception, distinctions between water fluxes associated with the evaporation of intercepted water and fluxes associated with ET processes utilizing soil-water and ground-water sources could be made. 
By making the assumption that all intercepted precipitation returned to the atmosphere by evaporation, the ET term could be expanded by:

$$
E T=E_{I}+E T_{G W S W}
$$

where

$$
\begin{gathered}
E_{I} \quad \begin{array}{c}
\text { is the evaporation of canopy interception- } \\
\text { assumed to equal I, in mm; and }
\end{array} \\
E T_{G W S W} \quad \begin{array}{c}
\text { is the evapotranspiration from ground-water } \\
\text { and soil-water sources, in mm. }
\end{array}
\end{gathered}
$$

By substituting equations 13 and 14 into equation 12 and relying on the assumption that $I$ and $E_{I}$ fluxes were of equal magnitude but in the opposite direction, the water balance was modified to constrain the ET flux:

$$
G W_{\text {in }}-G W_{\text {out }}=E T_{G W S W}-T F+\Delta S W+\Delta G W
$$

where all terms are previously defined.

This equation resulted in the same value for $\left(G W_{\text {in }}-G W_{\text {out }}\right)$ as equation 12 , but was used to exclude fractions of precipitation and ET affected by canopy interception.

\section{Soil-Water Content and Storage}

Soil-water contents were monitored to determine changes in soil-water storage and to relate those changes to ET. Volumetric soil-water content $\left(\theta_{w, v}\right)$ was measured every 30 minutes using model CS615 water-content reflectometers (Campbell Scientific, 1996b) at seven depths in unsaturated-zone vertical profiles at each site (table 1; figs. 3, 5). At Odessa, reflectometers were installed at $8,20,40,50,60,70$, and $80 \mathrm{~cm}$ below land surface. At Gothenburg, reflectometers were installed at $8,20,40,60,70,80$, and $90 \mathrm{~cm}$ below land surface. One profile (UZ1) was located close to a cottonwood tree to characterize $\theta_{w, v}$ within a tree-root system. The other profile (UZ2) was located away from trees to characterize $\theta_{w, v}$ in non-forested areas. At Odessa, the UZ2 profile was located in an area of mostly dogwood shrub cover with grass and forb ground cover. At Gothenburg, the UZ2 profile was located in an open meadow with moderate grass cover. The two profile settings were intended to represent the primary vegetation conditions at each site. Soil-water storage was calculated at each UZ profile by integrating the measured soil-moisture contents from all seven depths. Soil-water storage was then estimated across the entire footprint by assuming a uniform soil thickness above the aquifer materials and assigning UZ-derived values to corresponding vegetation types (forested and nonforested) distributed throughout the footprint area.

Several soil samples were collected for particle-size analysis, $\rho_{b}$ (bulk density), and $\theta_{w}$ (gravimetric-soil-water content) from each of the profiles. Particle-size samples were collected at each reflectometer depth in March 2002. Within $5 \mathrm{~m}$ of each profile, a series of soil-core samples were collected from each reflectometer depth between July 2002 and September 2004 for $\rho_{b}$ and $\theta_{w}$ analyses. Three soil samples from the upper $10 \mathrm{~cm}$ were collected at each of the profiles and analyzed for organic carbon content. All soil analyses were performed using standard techniques (Natural Resources Conservation Service, 2004) by the University of Nebraska-Lincoln Soil and Plant Analytical Laboratory.

The reflectometers report $\theta_{w, v}$ using default-calibration curves developed for typical soils having clay contents less than 30 percent (Campbell Scientific, 1996b). Attempts were made to develop custom-calibration curves for each reflectometer. The laboratory $\theta_{w}$ results from the soil samples of each profile were converted to $\theta_{w, v}$ values, and then compared to the corresponding reflectometer measurements. Although results varied for different reflectometers, these comparisons generally indicated that the default-calibration curves performed as well as customized calibrations. As a result, the default curves were used.

\section{Ground-Water Levels}

Ground-water levels were measured to determine changes in ground-water storage and for the purpose of evaluating depth to water as an explanatory factor affecting ET. The change in annual ground-water storage was determined as the product of the change in the height of the saturated zone within the control volume and the specific yield of the aquifer. The specific yield was estimated as the porosity (calculated from the average $\rho_{b}$ of the sediment below $80 \mathrm{~cm}$ at each site, which was observed to represent shallow aquifer sediment).

At each site, three shallow piezometers (wells) and one surface-water stage gage were installed along a transect from near the center of the vegetated island to the northern river channel (fig. 2). The river gage primarily was installed so that the effects of fluctuations in river levels on ground-water levels could be identified.

The wells were temporary shallow piezometers with slotted 7.6-cm-diameter polyvinyl chloride that were installed using a hand auger to about $2 \mathrm{~m}$ deep during the fall of 2001. Submersible-pressure transducers and data loggers recorded water levels every 30 minutes in the river-stage gage, in one well close to the tower, and in one well approximately equidistant between the tower and the river. Water levels were measured manually during site visits to determine if the recorded water levels were accurate. The median deviation of manual and recorded water levels was $0.57 \mathrm{~cm}$. The maximum deviation between measured and recorded water levels was $6.6 \mathrm{~cm}$. On rare occasions when deviations between manual and recorded water levels were more than $1.5 \mathrm{~cm}$, the water level recorded by the pressure transducer was reset to reflect the measured value. Typically, water levels are adjusted by prorating the measured deviation from one site visit to the next and shifting the recorded water level accordingly (Freeman 
and others, 2004). However, these shifts were only deemed necessary if seasonal changes in ET were sensitive to changes in depth to water on the scale of these deviations. As described later in the Environmental Factors Affecting Evapotranspiration Rates section, the depth to ground water was often an inconclusive explanatory factor, and visual inspection of the data suggested that changes in ground-water depth of $20 \mathrm{~cm}$ or less had little effect on ET. Therefore, the recorded water levels for the preceding period were not shifted to reflect the measured water levels.

\section{Leaf-Area Index}

Leaf-area index (LAI) is a key forest characteristic that is important to measure for ET studies because the abundance of green leaves in the canopy affects transpiration rates (Chen and others, 1997; Hall and others, 2003). At each site, LAI data were collected at 16 fixed stations spaced $20 \mathrm{~m}$ apart in two 8-station transects and oriented approximately north to south (fig. 3). Measurements were made at least six times each year between April and October of 2002 to 2004. LAI was calculated from analysis of hemispheric-digital photographs (Ringold and others, 2003; Kelley and Krueger, 2005). Hemispheric images were collected with automatic exposure and high contrast using a wide-angle (fisheye) lens mounted on a leveled camera oriented to magnetic north (fig. 5). The photos were collected from a height of $0.8 \mathrm{~m}$ above land surface at each LAI-measurement station. LAI estimates were derived from the images using standard techniques offered in Hemiview (version 2.1) software (Delta-T Devices, Ltd., 1999).

The LAI data were considered a proxy for seasonal variations in live vegetation for use as an explanatory variable for ET rates. Considerable research has been done on methods for determining LAI, of which hemispheric photos represent one of the preferred techniques (Chen and others, 1997; Hall and others, 2003).

Approximately monthly measurements of LAI during 2002 to 2004 were used to interpolate daily LAI values between measurements. For 2005 to 2006, when LAI was not measured, an average of the 2002 to 2004 values for each day of the year was used.

\section{Evapotranspiration Modeling}

The ET data collected were used to simulate riparian forest ET for the purposes of extrapolating the results beyond the two sites and improving the understanding of factors upon which ET is dependent. Daily crop coefficients $\left(k_{c}\right)$ for riparian forests were determined so that riparian ET can be estimated in similar forests elsewhere in the COHYST study area using climatic data from weather stations. Although the crop-coefficient technique is commonly associated with agricultural production, $k_{c}$ values have been developed for more natural cover such as wetlands (Allen and others, 1998) and fallowed fields (Bidlake, 2002). Nonetheless, a $k_{c}$ for a riparian forest may include additional uncertainty beyond that typically associated with the technique. Measured ET values were also regressed with explanatory variables to identify factors that may be affecting ET.

Measured $E T$ rates at the study sites were compared to reference $E T$ rates calculated from data at nearby weather stations to estimate $k_{c}$ for riparian forests. For daily periods, riparian forest $k_{c}$ was calculated following the techniques of Jensen and others (1990):

$$
k_{c}=\frac{E T}{E_{o}}
$$

where

$$
\begin{gathered}
k_{c} \quad \text { is the empirical-crop coefficient for riparian } \\
\text { forests in the study area, dimensionless; } \\
E T \quad \text { is the evapotranspiration rate for riparian } \\
\text { forests in the study area, in millimeters of } \\
\text { water per day (mm/d); and } \\
E_{o} \quad \begin{array}{c}
\text { is the evapotranspiration rate for a well- } \\
\text { watered reference crop, in } \mathrm{mm} / \mathrm{d} .
\end{array}
\end{gathered}
$$

$E_{o}$ provides an ET standard that incorporates climate effects and ET from surfaces other than the reference crop in the same area. $E_{o}$ values were downloaded from the High Plains Regional Climate Center (2006) and are calculated using a modified Penman-evapotranspiration method with a wind function for a reference crop of alfalfa. The Odessa $E T$ data were compared to $E_{o}$ values from the Kearney weather station (High Plains Regional Climate Center, 2006), located about $19 \mathrm{~km}$ northeast of the site. The Gothenburg ET data were compared to $E_{o}$ from the Gothenburg weather station, located about $4 \mathrm{~km}$ north of the site.

Daily mean $k_{c}$ values were computed for three complete years of data (April 1, 2002, to March 31, 2005). Because daily mean $k_{c}$ values varied considerably, 15-day and monthly mean $k_{c}$ values also were computed. $E T$ data from the fourth year of study (April 1, 2005, to March 31, 2006) were compared to $E T$ rates simulated from $k_{c}$ to evaluate the crop-coefficient models.

\section{Sap Flux}

To characterize the transpiration rates of the major tree and shrub species, sap-flux measurements were made on a subset of individual trees and shrubs (table 2). Thermaldissipation probes (TDP) were used to estimate sap velocities from sap-temperature differences following the techniques of Granier (1987). Sap velocity refers to the speed of sap measured at a point in the stem (Clearwater and others, 1999). The sap flux is then calculated as the product of the sap velocity and the cross-sectional area of the stem that can transmit sap (sapwood). Because of limited resources, sap-flux measure- 
Table 2. Tree and shrub species instrumented with sap-flow devices during April through August 2004, at the study site near Odessa, Nebraska.

[TDP-XX, Thermal dissipation probe -XX millimeters long]

\begin{tabular}{ccccccccc}
\hline $\begin{array}{c}\text { Plant } \\
\text { number } \\
\text { (fig. 3) }\end{array}$ & $\begin{array}{c}\text { Tree or } \\
\text { shrub }\end{array}$ & $\begin{array}{c}\text { Distance } \\
\text { from } \\
\text { data logger } \\
\text { (meters) }\end{array}$ & $\begin{array}{c}\text { Direction } \\
\text { from } \\
\text { data } \\
\text { logger }\end{array}$ & $\begin{array}{c}\text { Tree diameter } \\
\text { (centimeters) }\end{array}$ & Instrument & $\begin{array}{c}\text { Side of } \\
\text { tree } \\
\text { where } \\
\text { installed }\end{array}$ & $\begin{array}{c}\text { Depth of } \\
\text { thermocouple } \\
\text { in tree } \\
\text { (millimeters) }\end{array}$ & $\begin{array}{c}\text { Thickness } \\
\text { of } \\
\text { sapwood } \\
\text { (millimeters) }\end{array}$ \\
\hline 1 & Dogwood & 1.5 & northeast & 2.5 & TDP-10 & south & 5 & $1.5-4.6^{\mathrm{a}}$ \\
$2^{\mathrm{b}}$ & Dogwood & 23.5 & northeast & 2.5 & TDP-10 & south & 5 & $1.5-4.6^{\mathrm{a}}$ \\
3 & $\begin{array}{c}\text { Eastern } \\
\text { redcedar }\end{array}$ & 6.1 & south & 15.2 & TDP-30 & north & 15 & $19-27^{\mathrm{c}}$ \\
& Eastern & 6.1 & south & 15.2 & TDP-30 & south & 15 & $19-27^{\mathrm{c}}$ \\
& redcedar & & & & & & & 23 \\
4 & Green ash & 19.8 & northeast & 11.0 & TDP-30 & north & 15 & 26 \\
& Green ash & 19.8 & northeast & 11.0 & TDP-30 & south & 15 & $28^{\mathrm{d}}$ \\
& Cottonwood & 3.0 & south & 22.9 & TDP-30 & east & 15 & $28^{\mathrm{d}}$ \\
& Cottonwood & 3.0 & south & 22.9 & TDP-30 & west & 15 & $37^{\mathrm{d}}$ \\
& Cottonwood & 7.9 & south & 61.0 & TDP-50 & east & 25 & $37^{\mathrm{d}}$ \\
\hline
\end{tabular}

a Sapwood thickness determined from three nearby dogwoods.

${ }^{\mathrm{b}}$ Because of unrealistic variability in measured sap velocity, data from this dogwood were considered erroneous.

${ }^{c}$ Sapwood thickness determined from two nearby eastern redcedars of similar diameter.

d Sapwood thickness determined as the average of two cores.

ments were done only at the Odessa site during 2004. Several assumptions are implicit in using this method, including: sap velocity is uniform in sapwood of known area; plant-water storage is negligible relative to transpiration; there is an instantaneous response of sap velocity to the environmental factors driving transpiration; measured-temperature differences are a function of sap flux and not of thermal gradients caused by solar or atmospheric heating in the stem; the temperature is evenly distributed along the length of the probe; and the empirical relation of Granier (1987) between sap velocity and temperature difference applies to tree species measured in this study (Granier, 1987; Granier and others, 1994; Clearwater and others, 1999).

Fourteen TDP probes were installed in four trees and two shrubs at the Odessa site in September 2003 (fig. 3). Although the system was powered by three 60 -watt solar panels, power limitations during relatively low solar input conditions during September 2003 to March 2004 resulted in collection of few continuous data during this period. Nearly continuous data were collected during April to August 2004; thereafter, the sap-velocity measurement system was largely inoperable because of power limitations and undetermined electrical malfunctions.

The TDP probes were installed at breast height on 1 or 2 sides of the monitored trees, depending upon trunk size, so that average-sap velocities could be calculated from measurements in different parts of the trunk (Clearwater and others,
1999; Ewers and Oren, 2000). Three different lengths of TDP probes were installed, ranging from 10 to $50 \mathrm{~mm}$ long (table 2). Sap velocity was calculated from the expression of Granier (1987):

$$
V_{\text {sap }}=0.0119\left(\frac{\Delta T_{\text {sap, mas }}-\Delta T_{\text {sap }}}{\Delta T_{\text {sap }}}\right)^{1.231}
$$

where

$$
\begin{aligned}
& V_{\text {sap }} \text { is the sap velocity, in centimeters per second, } \\
& \text { for a 30-minute period; } \\
& \Delta T_{\text {sap,max }} \quad \text { is the maximum sap-temperature difference } \\
& \text { recorded between } 2 \text { and } 4 \text { am-used to } \\
& \text { represent conditions of no sap flux, in }{ }^{\circ} \mathrm{C} \text {; } \\
& \text { and } \\
& \Delta T_{\text {sap }} \quad \text { is the sap-temperature difference for an } \\
& \text { individual probe measured every minute } \\
& \text { and averaged during a 30-minute period, in } \\
& { }^{\circ} \mathrm{C} \text {. }
\end{aligned}
$$

When probes extended into non-conducting xylem, values of $\Delta T_{\text {sap }}$ were corrected using the method of Clearwater and others (1999). In cases where two sides of a tree were monitored (table 2), a composite $V_{\text {sap }}$ value was calculated as the average of velocities computed from both probes. 
The depths and thickness of the bark, cambium, sapwood, and heartwood (non-conducting xylem) were identified from color differences in tree cores collected following sap-velocity monitoring. Cores were collected from monitored trees and additional trees and shrubs selected to characterize the full range of trunk diameters. Twenty-three cores were collected from 16 individuals. The sapwood area was calculated by assuming that the plant stem was perfectly cylindrical, and that the sapwood thickness (an average of 2 to 4 measurements around the tree) was uniform:

$$
A_{\text {sapwood }}=\left(\pi r_{\text {tree }}^{2}\right)-\left(\pi\left(r_{\text {tree }}-w_{\text {sapwood }}\right)^{2}\right)
$$

where

$$
\begin{aligned}
& A_{\text {sapwood }} \text { is the sapwood area, in square centimeters } \\
&\left(\mathrm{cm}^{2}\right) ; \\
& \pi \text { is } 3.14 ; \\
& r_{\text {tree }} \text { is the tree radius, less the bark thickness, in } \\
& \mathrm{cm} \text {; and } \\
& w_{\text {sapwood }} \text { is the sapwood thickness, in cm. }
\end{aligned}
$$

Sap flux was then calculated from:

$$
Q_{\text {sap }}=V_{\text {sap }} A_{\text {sapwood }}
$$

where

$$
\begin{aligned}
& Q_{\text {sap }} \quad \text { is the sap flux, in cubic centimeters per } \\
& \text { second }\left(\mathrm{cm}^{3} / \mathrm{s}\right) \text {. }
\end{aligned}
$$

The sap flux is a direct measure of the volumetric transpiration rate of an individual plant. To facilitate comparison to the ET rates measured on a unit-area basis from the micrometeorological measurements, the sap-flux values were scaled up to the canopy areas of the monitored plants using:

$$
T_{\text {sap }}=\frac{Q_{\text {sap }}}{A_{\text {canopy }}}
$$

where

$$
\begin{gathered}
T_{\text {sap }} \quad \begin{array}{l}
\text { is the sap-flux-derived measure of } \\
\text { transpiration, in centimeters per second } \\
(\mathrm{cm} / \mathrm{s}) ; \text { and }
\end{array} \\
A_{\text {canopy }} \quad \text { is the area of the ground underneath the tree } \\
\text { canopy, in } \mathrm{cm}^{2} .
\end{gathered}
$$

This equation spreads the volumetric sap flux measured in the sapwood area uniformly to the area of the canopy of the tree measured. It is assumed that the rooted area, from which water is withdrawn from the subsurface to satisfy transpiration, was similar to the canopy area (Ewers and others, 2002).

Whereas several investigators have used $T_{\text {sap }}$ to scale transpiration rates to the stand scale, this scaling was not performed for this study because of limited resources to devote to measuring transpiration rates of additional tree species and sizes. Rather, the $T_{\text {sap }}$ data were used to estimate transpiration rates in a subset of important species to assess their possible relative contribution to ET from the riparian forest as a whole.

\section{Statistical Analysis}

Simple-linear regression (SLR) and multiple-linear regression (MLR) analysis of ET with potential explanatory variables used methods described by Helsel and Hirsch (2002). Statistical analyses were performed using the S-PLUS statistical package, version 6.1 (Insightful Corporation, 2002). The SLR models were used to identify potential explanatory variables that may have affected ET. A t-test was used to evaluate whether the regression coefficients were significantly different from zero. For hypothesis testing, the significance level $(p)$ was compared to a threshold value of 5 percent to evaluate whether the relation was statistically significant $(p<$ 0.05). Significant relations were further evaluated using the coefficient of determination $\left(\mathrm{R}^{2}\right)$. All investigated variables and their regression residuals were graphed as scatter plots and probability plots - to evaluate the normality of residuals - to check for obvious violation of the assumptions underlying ordinary least-square linear regressions.

Once identified by SLR analysis, the significant variables were included in two sets of MLR models. The first model was developed for comparison between study sites and constrained the MLR analysis to a consistent set of variables. The second model set was developed to determine the array of variables that best explain $E T$ without sacrificing model significance through over-specification of parameters. The array of variables was identified using step-wise MLR analysis (Helsel and Hirsch, 2002). The performance of the MLR model was evaluated using the F-statistic and corresponding probability, the standard error of the residuals (RSE), and the coefficient of efficiency (NSE) (Nash and Sutcliffe, 1970). Because ET is likely affected by several factors, SLR and MLR models explaining a large part of the ET response were not expected. Rather, the diagnostic values were used for relative comparisons between various models.

\section{Evapotranspiration Rates}

To provide perspective when evaluating the ET rates and annual water balances at each study site, the footprint, vegetation, and hydrogeologic attributes of the sites are characterized. In the sections that follow, measured precipitation and canopy interception are described to define moisture inputs to the study sites and to estimate possible evaporation from canopy interception as a component of total ET. Subsequently, ET rates determined from micrometeorological measurements are discussed. Energy balances are then described to assess the quality of the ET measurements and the seasonal dynam- 
ics of energy fluxes. Annual water balances are discussed to constrain estimates of GWET. A crop-coefficient model for simulating $E T$ rates, comparison of simulated and measured $E T$ rates, and relations of measured $E T$ rates to environmental factors are described. Comparisons of transpiration rates measured in individual plants using sap-flux techniques are then compared to $E T$ rates determined from micrometeorological techniques to assess the possible relative contribution of transpiration from different plants to total ET. The final section of this report describes factors to consider in extrapolating the results of the study.

The period of data collection from April 2002 through March 2006 constituted four complete annual periods, and is hereinafter referred to as the study period. For ease of understanding and because energy and water fluxes were expected to be relatively small from January through March, annual periods are referred to by the calendar year associated with April through December. Daily mean or total values for selected micrometeorological variables are shown in appendix 1 at the back of this report. Although most variables were recorded every 30 minutes, these data were processed and aggregated into daily averages or totals for the purposes of understanding ET rates on daily to annual time scales and the factors affecting them. Given that 4 years of record are included in the study, analyzing daily data greatly simplified the analyses compared to 30-minute data. Daily data are presented in appendixes 1 and 2 .

\section{Site Characteristics}

Although both sites included small patches of nontargeted land covers, greater than 85 percent of the measured fluxes were being produced from riparian forests at most times. The canopy at both sites was characterized by cottonwoods of similar height, but the Gothenburg understory was dominated by eastern redcedars, whereas the Odessa understory was more diverse and included dogwood shrubs. Soils at both sites coarsened with depth, and typically consisted of sand and fine gravel interbedded with thin silt horizons. The presence of irrigation-supply water in the Gothenburg river channel resulted in a fundamental difference in the groundwater conditions between the two sites.

\section{Footprint Areas}

Footprint calculations and analysis of land-cover data indicated that at least 85 percent of the fluxes measured by the eddy-covariance sensors originated from areas of riparian forest. In the following paragraphs, the land-cover characteristics within each footprint area measured by the eddy-covariance sensors are described.

During neutral conditions-associated with negligible buoyant heat flux relative to wind effects -85 percent of the cumulative energy fluxes measured at the height of eddycovariance sensors ( $26.1 \mathrm{~m}$ above land surface) originated within $800 \mathrm{~m}$ of the tower (fig. 6). During unstable conditions-in which buoyant heat flux is substantial relative to wind effects-more than 95 percent of the cumulative fluxes measured at a height of $26.1 \mathrm{~m}$ originated from within $800 \mathrm{~m}$ of the tower (fig. 6). Refined-footprint calculations that estimated atmospheric stability as a function of measured fluxes, wind speed, and roughness using equations of Brutsaert (1982) indicated that even under very unstable conditions, footprints were intermediate between the neutral and unstable curves; therefore, most measured energy fluxes are likely to originate from intermediate upwind distances within the riparian forest zone.

At both study sites, land cover in the theoretical-footprint area within $800 \mathrm{~m}$ of the towers was dominated by woody vegetation but interspersed with open areas (figs. 2 and 7). The open areas had no tree canopy and primarily were grasses and forbs with or without shrubs. These relatively low-density riparian forests intermixed with open areas are characteristic of the forests along the Platte River (Currier and others, 1985; Bureau of Reclamation, 1998).

At Odessa, woody vegetation (55.8 percent) and open areas (21.0 percent) accounted for 76.8 percent of the area within $800 \mathrm{~m}$ of the tower (fig. 7A). Although the edge of the riparian forests was only $500 \mathrm{~m}$ north of the tower, northern winds occurred (fig. $2 A$ ) primarily during winter periods, when minimal ET was expected or measured. For this reason, the close proximity of the northern riparian-forest boundary was expected to have minimal effect on fluxes and energy balances measured at the tower. Besides the woody vegetation and open areas, there is cropland located in the northern part of the footprint area and several Platte River channels lying along easterly paths in the footprint area (fig. 7A). The largest channel was about $100 \mathrm{~m}$ wide-one-half of which was wetted through most of the year-and was located about $600 \mathrm{~m}$ south and east of the tower. Other channels generally were less than $50 \mathrm{~m}$ wide, were mostly dry except for narrow channels with small flows and wetland vegetation, and were bounded by riparian forests. Winds from the southeast were dominant (fig. $2 A$ ) particularly during the summer when most ET occurred. It is recognized that the river channels may have had minor effects on measured fluxes and energy balances at the towers because of the presence of considerable river-channel area upwind of the tower to the southeast. When winds were from the southeast, between 6 and 20 percent of the cumulative normalized flux (fig. 6) was predicted to originate from the river channel $600 \mathrm{~m}$ away. Although it is expected that the river channels had a minor effect on measured fluxes at the tower, their presence within the footprint is a minor source of uncertainty in the data at Odessa.

At the Gothenburg study site, the combination of woody vegetation (40.6 percent) and open areas (49.9 percent) accounted for 90.5 percent of the area within $800 \mathrm{~m}$ of the tower (fig. $7 B$ ). The remaining 9.5 percent was predominantly a thin sliver of cropland in the northeastern part of the footprint, and two river channels. Because the closest edge of the riparian area was approximately $650 \mathrm{~m}$ northeast of the 


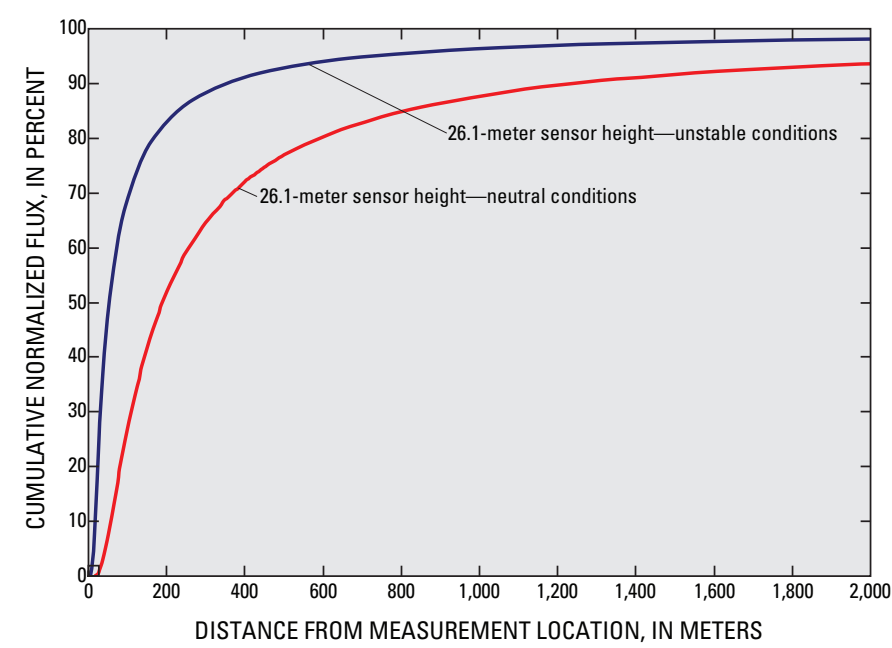

Figure 6. Relation of source strength with distance upwind from a measurement point 26.1 meters above land surface for endmember atmospheric conditions.

tower and winds blew infrequently from the northeast (fig. $2 B$ ), effects of the cropland to the northeast were expected to be insignificant. At less than $100 \mathrm{~m}$ wide, the northern river channel was the largest of the channels, was $400 \mathrm{~m}$ from the tower at its closest, and was bordered by forest. Moreover, the predominant wind directions at the Gothenburg site (fig. $2 B$ ) generally followed the riparian corridor of the Platte River. Consequently, effects of other land-cover types on the measurements at the Gothenburg tower were expected to be insignificant.

Because the land cover at both study sites consists of woody vegetation interspersed with open areas and some river channels, the water- and energy-balance measurements for this study characterize the riparian-vegetation community rather than just riparian trees. Riparian trees are a dominant component of the riparian-vegetation community, but forests in this study area have low density in comparison with many forests, and are characterized by relatively widely spaced trees with intervening open areas.

Some investigations have incorporated corrections for the estimated effects of non-target land uses within and adjacent to the flux-measurement footprint (Sumner, 2001). These corrections were not implemented for this study because non-target land uses (river channel, cropland) accounted for a small proportion of the estimated footprint, and ET rates associated with cropland were expected to be similar to those of riparian forests. For example, irrigated corn, which bordered the theoretical footprint at both sites, has an average ET rate of $690 \mathrm{~mm} /$ year in western Nebraska (Younts, 2002); this rate is similar to ET rates determined at the study sites (see Measured Evapotranspiration Rates section of this report). Open-water evaporation rates, approximated by calculated modified-Penman ET data available for weather stations (High Plains Regional Climate Center, 2006) were approximately twice that of riparian forests as determined in this study; however, because many of the river channels were dry, the area of open water in the channels was so small that even an evaporation rate double that of the riparian forests has an insignificant effect on total fluxes. For these reasons, corrections for estimated effects of non-target land covers were not made.

\section{Vegetation Characteristics}

Both study sites have a forest canopy, or overstory, dominated by cottonwoods (table 3 ). The canopy closure, meantree spacing, and density and height of cottonwoods were similar between the two sites. Canopy-closure measurements indicated that a vegetative canopy overlies slightly more than one-half of the landscape. In order of abundance, tree species with densities greater than 5 trees per hectare at the Odessa site were eastern cottonwood, green ash, eastern redcedar, red mulberry, willow, and Russian olive. At the Gothenburg site, tree species with densities greater than 5 trees per hectare were eastern redcedar, eastern cottonwood, and green ash.

The primary differences between the vegetation at the two sites was the greater abundance of eastern redcedars at the Gothenburg site and the presence of a shrub understory at the Odessa site that was absent at the Gothenburg site. Generally, the understory forest at Odessa was more diverse than at Gothenburg, with green ash, eastern redcedar, red mulberry, willow, and Russian olive composing a moderately dispersed secondary canopy between the top-level cottonwood canopy and the underlying shrub vegetation. The mean tree heights of green ash, eastern redcedar, mulberry, and willow were 7.5 to 8.5 $\mathrm{m}$, and $4.7 \mathrm{~m}$ for Russian olive, compared with a median tree height for cottonwood of $16.9 \mathrm{~m}$ (table 3 ). The shrub understory, which was dominated by roughleaf dogwoods (Cornus drummondii), was approximately 2 to $4 \mathrm{~m}$ tall and often was present in areas with tree cover and open areas with no tree cover. The shrubs were present across more than one-half of the landscape, but were not continuous. At the Gothenburg site, a shrub understory was absent, but eastern redcedars having a mean height of $7.2 \mathrm{~m}$ were present at a density approximately three times greater than the Odessa site (table 3 ). The Gothenburg eastern redcedars often were present in patches in which individual trees were densely spaced. These dense patches occurred in areas with and without overlying cottonwood canopy, but may prevent understory shrubs from gaining establishment. At both sites, the ground cover consisted of grasses and forbs in open areas and included some wetland plants in shallow depressions where the depth to water was less than for most of the landscape.

Qualitative comparisons of riparian-vegetation characteristics of the study sites with those from the regional literature (Rand, 1973; Johnson and others, 1976; Sedgewick and Knopf, 1989; Good, 1999) indicated that the sites were representative of regional riparian forests. Because of differences in characterization methods, quantitative comparisons were not possible. 


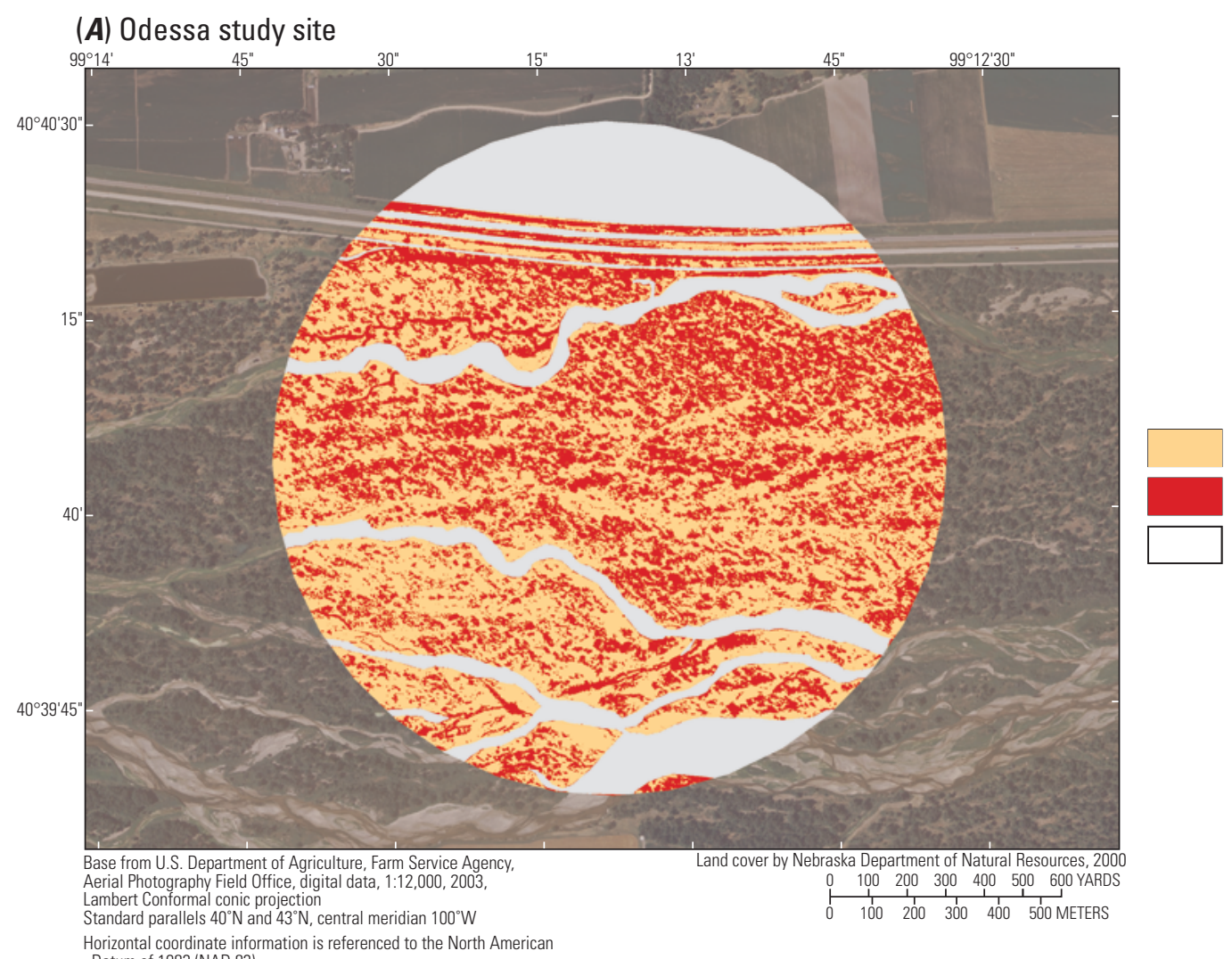

\section{EXPLANATION}

Odessa land cover

Open-21 percent

Woody vegetation- 55.8 percent

Other-23.2 percent

Horizontal coordinate information is referenced to the North American Datum of 1983 (NAD 83)

\section{(B) Gothenburg study site}

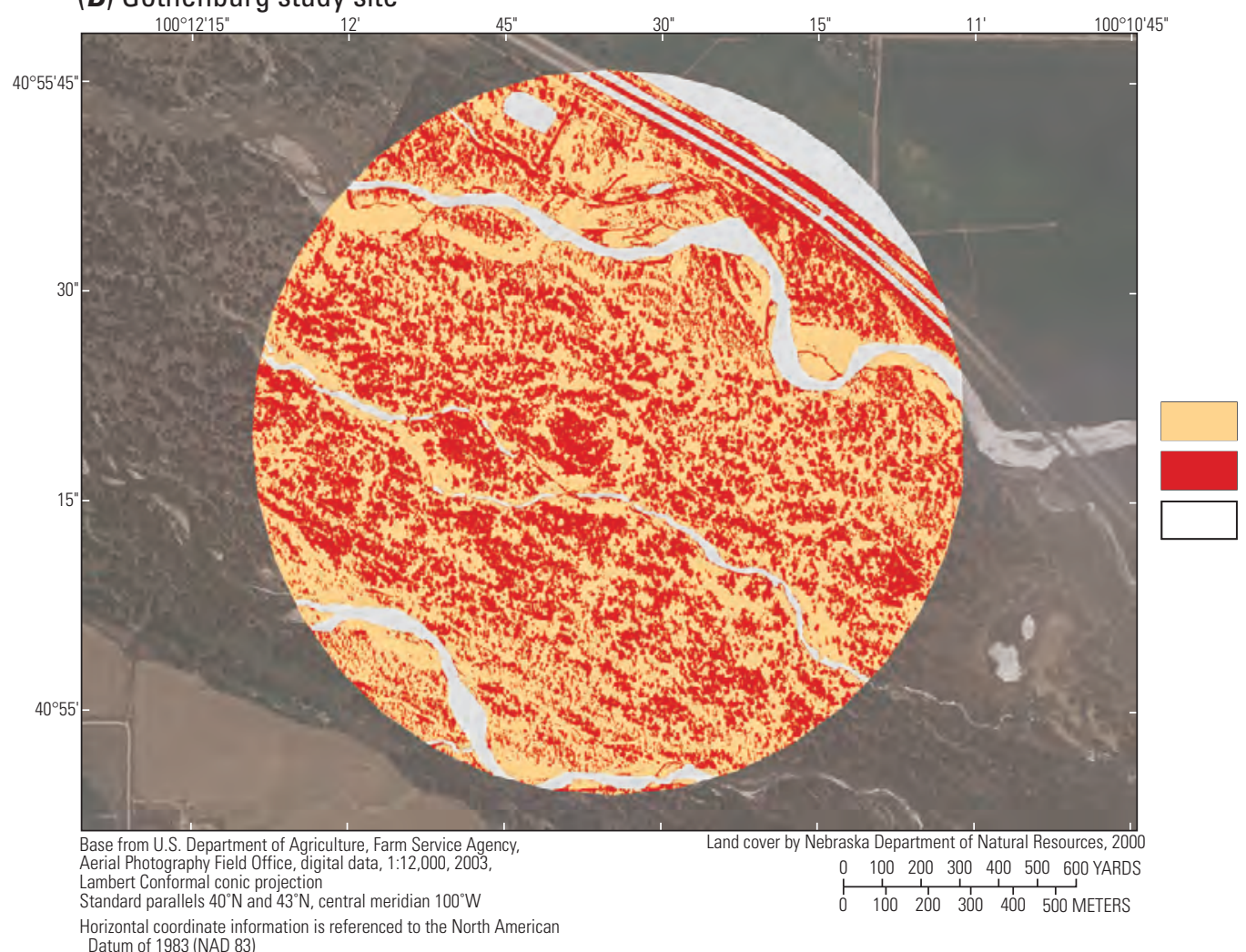

\section{EXPLANATION}

Gothenburg land cover

Open-49.9 percent

Woody vegetation-40.6 percent

Other-9.5 percent

Figure 7. Distribution of land cover and fraction of total area in each category at study sites near Odessa and Gothenburg, Nebraska. 
Table 3. Summary of vegetation and hydrogeologic characteristics of study sites near Odessa and Gothenburg, Nebraska.

[cm, centimeters]

\begin{tabular}{|c|c|c|}
\hline Site characteristics & Odessa & Gothenburg \\
\hline Overstory dominated by: & cottonwood & cottonwood \\
\hline Understory dominated by: & shrubs and grass & eastern redcedars and grass \\
\hline Mean canopy closure, percent & 56 & 52 \\
\hline Mean tree spacing, meters & 9.0 & 8.3 \\
\hline \multicolumn{3}{|l|}{ Density, trees per hectare ${ }^{a}$} \\
\hline All & 125 & 145 \\
\hline Eastern cottonwood (Populus deltoides) & 39 & 37 \\
\hline Eastern redcedar (Juniperus virginiana) & 27 & 80 \\
\hline Green ash (Fraxinus pennsylvanica) & 28 & 9 \\
\hline Willow (Salix spp.) & 7 & 4 \\
\hline Russian olive (Elaeagnus angustifolia) & 6 & 5 \\
\hline Red mulberry (Morus rubra) & 16 & 2 \\
\hline American elm (Ulmus americana) & 3 & 2 \\
\hline Ashleaf maple (boxelder) (Acer negundo) & 0 & 4 \\
\hline Number of tree species measurements & 184 & 144 \\
\hline Cottonwood tree height, median, meters & 16.9 & 16.9 \\
\hline Cottonwood height, number of measurements & 47 & 45 \\
\hline Typical early spring depth to water, $\mathrm{cm}$ & 90 & 110 \\
\hline 2002-04 water-level fluctuation, $\mathrm{cm}$ & 70 & 40 \\
\hline Stratigraphy & $\begin{array}{l}10-20 \mathrm{~cm} \text { sandy loam } \\
\text { overlying } \\
40-50 \mathrm{~cm} \text { fine sand } \\
\text { with silt layers over- } \\
\text { lying poorly sorted } \\
\text { sand and fine gravel }\end{array}$ & $\begin{array}{l}10-20 \mathrm{~cm} \text { sandy loam overlying } \\
40-50 \mathrm{~cm} \text { fine sand with silt } \\
\text { layers overlying poorly sorted } \\
\text { sand and fine gravel }\end{array}$ \\
\hline
\end{tabular}

${ }^{a}$ Density was derived from the point-centered quarter sampling method, which may have a negative bias in clustered populations (Batcheler, 1973) such as the riparian forests along the Platte River.

At Odessa, sapwood thickness determined from 23 tree cores in 4 species of trees and 1 species of shrub indicated that sapwood thickness generally increased with trunk diameter (fig. 8), as was generally expected on the basis of previous investigations (Meinzer and others, 2001). However, considering the large diameters of the four cottonwoods cored in comparison with the other species of trees cored, the sapwood thickness was less for cottonwoods than would have been expected from general relations between trunk diameter and sapwood thickness. Similar deviations from general relations between diameter at breast height and sapwood thickness have been noted in some other studies (Ewers and others, 2002). Although the data set is limited, the sapwood thickness in cottonwoods does not appear to increase with trunk diameter as much as in the green ash, eastern redcedar, and Russian olive, which had substantial increases in sapwood thickness for small increases in trunk diameter. These results imply that cottonwoods, despite their larger diameter compared to other tree species at the study sites, have relatively smaller proportions of sapwood as a percentage of total cross-sectional trunk area.

At Odessa, LAI values were about 1.03 to 1.40 during May through September (fig. 9A). The lowest LAI values of 0.36 occurred before leaf growth and reflected the presence of tree branches and conifers (primarily eastern redcedars). This baseline value is subtracted from growing-season values to represent seasonal vegetation growth. Late-April LAIs of 0.42 and 0.45 reflects partial leaf-out conditions by some species. Peak values occurred in July or August of each year. The seasonal pattern of LAI was characterized by large increases in LAI between late April and late May, transitioning to more 


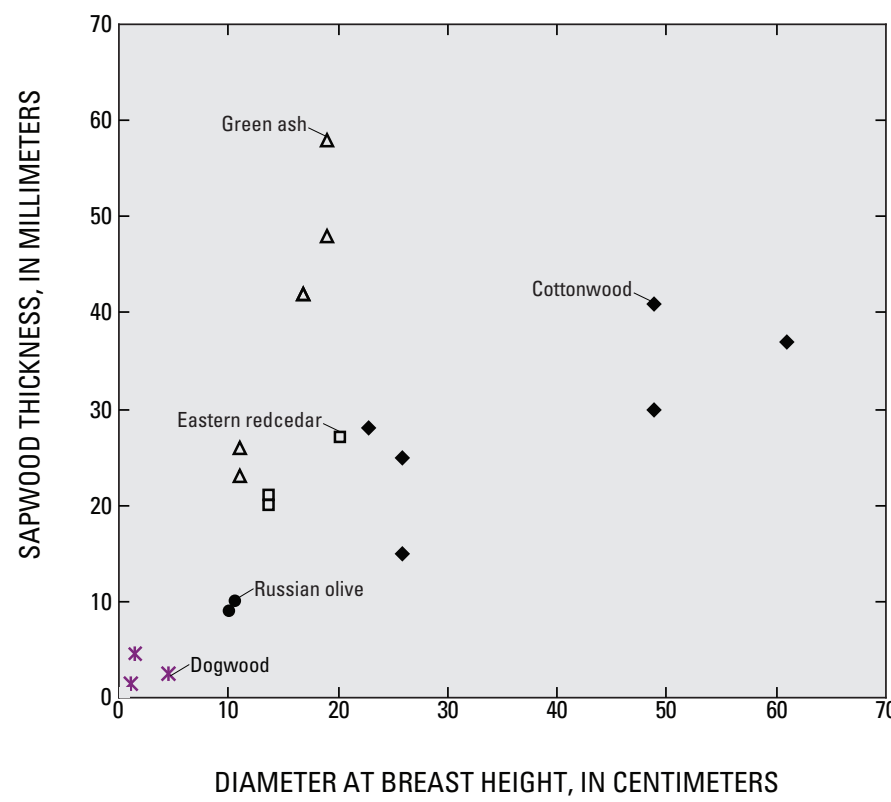

Figure 8. Tree diameter and sapwood thickness for selected trees and shrubs at study site near Odessa, Nebraska.

gradual increases until peak values were reached in July or August, followed by gradual declines to values measured in late September or early October, slightly before leaf drop.

Monthly variations in LAI at the Odessa site appear to have been affected by moisture availability. In 2002, LAI decreased from June to July, corresponding with dry conditions that caused visible water stress and dormancy in under- story shrubs. Rains in August caused noticeable improvements in vegetation vigor that may have been reflected in the increased LAI in August. In 2003, conditions during May to July were wetter than those in 2002 and LAI values were larger; however, dry conditions in August and September corresponded with lower monthly LAI in 2003 than during 2002. Rainfall in 2004 was closer to normal during the growing season, except for August, and LAI values generally were intermediate between the 2002 and 2003 values.

At Gothenburg, values of LAI were about 1.26 to 1.53 during May through September (fig. 9B). LAI values of 0.87 to 0.94 were measured in March and late April, probably reflecting pre-leaf-out conditions during dormancy. The larger dormant-LAI values at Gothenburg relative to Odessa probably were because of the greater abundance of coniferous eastern redcedars at the Gothenburg site. Annual peaks in Gothenburg LAI values occurred in June in 2002 and 2003 and in early August in 2004. Generally, the timing of seasonal rises and declines in LAI were similar at Gothenburg and Odessa; however, monthly variations in LAI were somewhat smaller at Gothenburg than at Odessa, particularly those associated with wet and dry periods during the summers of 2002 and 2003.

The increase in LAI during the growing season in comparison with dormant-season baseline values was less at Gothenburg, about 0.6, than at Odessa, about 1.0. This result implies that seasonal-leaf growth was greater at the Odessa site than at the Gothenburg site, consistent with the greater density of deciduous tree and shrub species at the Odessa site.

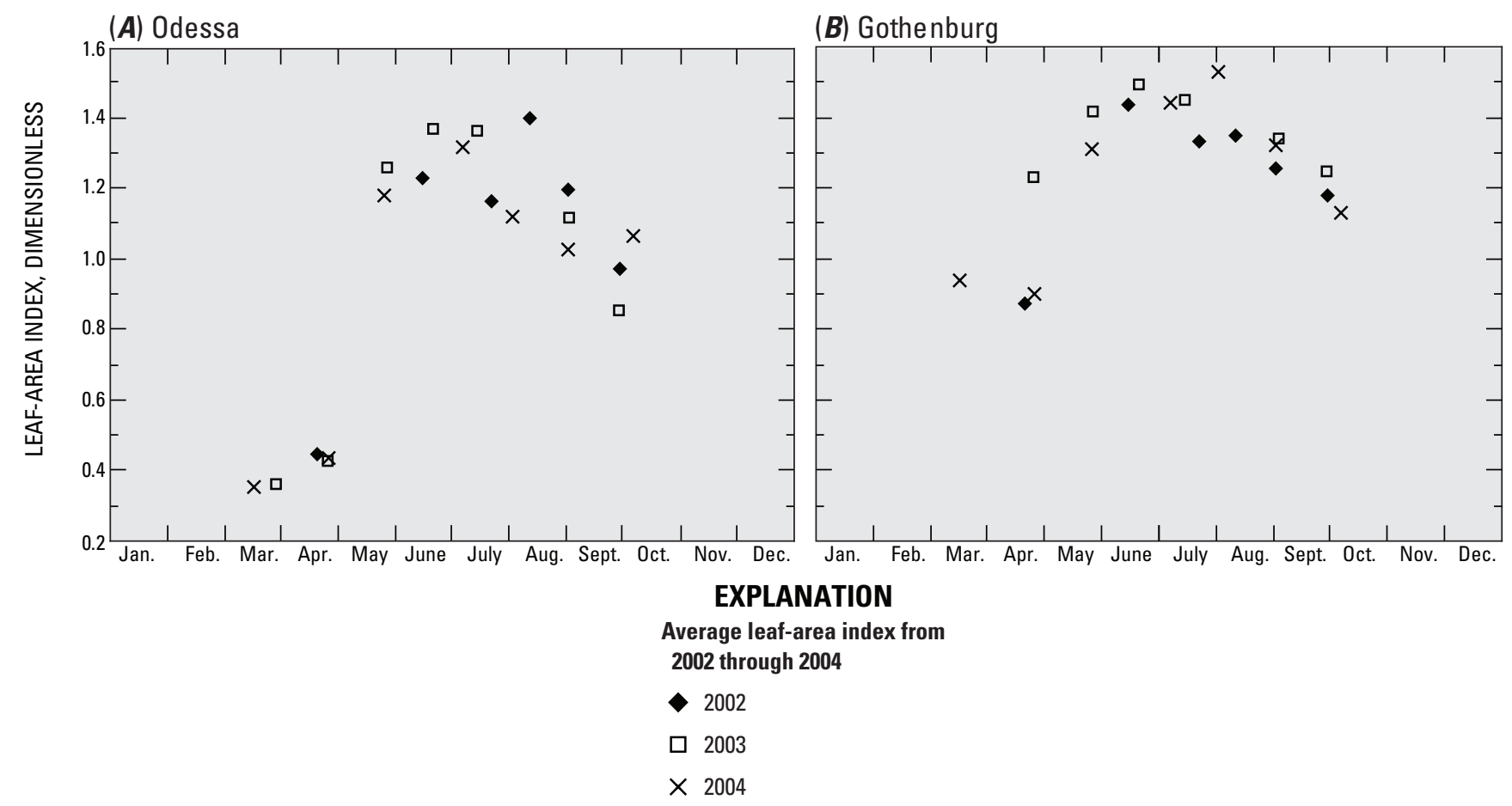

Figure 9. Seasonality of average leaf-area index of riparian forests at study sites near Odessa and Gothenburg, Nebraska, $2002-04$. 


\section{Hydrogeologic Characteristics}

At both study sites, the stratigraphy within $1 \mathrm{~m}$ of the surface coarsened with depth. Generally, the UZ vertical profiles consisted of a 10- to 20-cm-thick layer of sandy loam overlying a 40- to 50-cm-thick layer of fine sand interbedded with silt layers of variable thickness overlying a bottom layer of poorly sorted sand and fine gravel. Classified particle-size distributions from the UZ1 and UZ2 profiles are shown for each site in figure 10. At three of the four profiles (Odessa UZ1 and UZ2, Gothenburg UZ1), silt and clay contents were greater than 30 percent in the upper $20 \mathrm{~cm}$ but less than 1 percent at depths of $40 \mathrm{~cm}$ or more. The Gothenburg UZ2 profile was an exception, with less than 10 percent silt and clay in the upper $20 \mathrm{~cm}$. This profile was located in an open area with thin grass cover, and typically had lower soil-moisture contents than the other three profiles. At the time of sensor installation (in walls of trenches), silt horizons 5 to $10 \mathrm{~cm}$ thick were visible within sandy loam and fine-sand layers ranging from 12 to $50 \mathrm{~cm}$ deep in the different profiles. These silt horizons explained the silt and clay contents greater than 50 percent in soil samples collected from depths of $40 \mathrm{~cm}$ in the Gothenburg UZ2 profile and $20 \mathrm{~cm}$ in the Odessa UZ2 profile. Coarsening became particularly apparent at depths greater than $40 \mathrm{~cm}$. Samples from 40 to $90-\mathrm{cm}$ depths consisted of as much as 60 percent medium sand. Because of this coarser material, capillary rise of water into the unsaturated zone was expected to be small in comparison to soils having higher silt and clay contents (Hillel, 1980).

At Odessa, average values of $\rho_{b}$-based on 13 samples at each depth—generally increased with depth from 1.05 grams per cubic centimeter $\left(\mathrm{g} / \mathrm{cm}^{3}\right)$ at $5 \mathrm{~cm}$ to $1.74 \mathrm{~g} / \mathrm{cm}^{3}$ at $80 \mathrm{~cm}$, with similar values for both profiles. At the Gothenburg UZ1 profile, average values of $\rho_{b}$ generally increased with depth from $1.00 \mathrm{~g} / \mathrm{cm}^{3}$ at $5 \mathrm{~cm}$ to $1.88 \mathrm{~g} / \mathrm{cm}^{3}$ at $90 \mathrm{~cm}$. The surficial $\rho_{b}$ was comparatively larger at the Gothenburg UZ2 profile, with $\rho_{b}$ of $1.52 \mathrm{~g} / \mathrm{cm}^{3}$ at $5 \mathrm{~cm}$ increasing to $1.74 \mathrm{~g} / \mathrm{cm}^{3}$ at 90 $\mathrm{cm}$. Because organic matter has a lower density than mineral soils, the larger surficial $\rho_{b}$ at Gothenburg UZ2 most likely was the result of lower organic content in comparison to the other profiles. Based on three samples from the upper $10 \mathrm{~cm}$ at each profile, the average organic-carbon content was 6.3 percent at Odessa UZ1, 7.3 percent at Odessa UZ2, 12.1 percent at Gothenburg UZ1, and 3.0 percent at Gothenburg UZ2.

On average, the depth to water from the land surface (DTW) was slightly greater at the Gothenburg site than at the Odessa site. Typical DTW in early spring at the Odessa site was $90 \mathrm{~cm}$ compared to $110 \mathrm{~cm}$ at the Gothenburg site.

Ground-water levels typically peaked in April or May and then declined through September at both sites. Annual groundwater-level fluctuations of about $70 \mathrm{~cm}$ at the Odessa site were about $30 \mathrm{~cm}$ larger than fluctuations at the Gothenburg site.

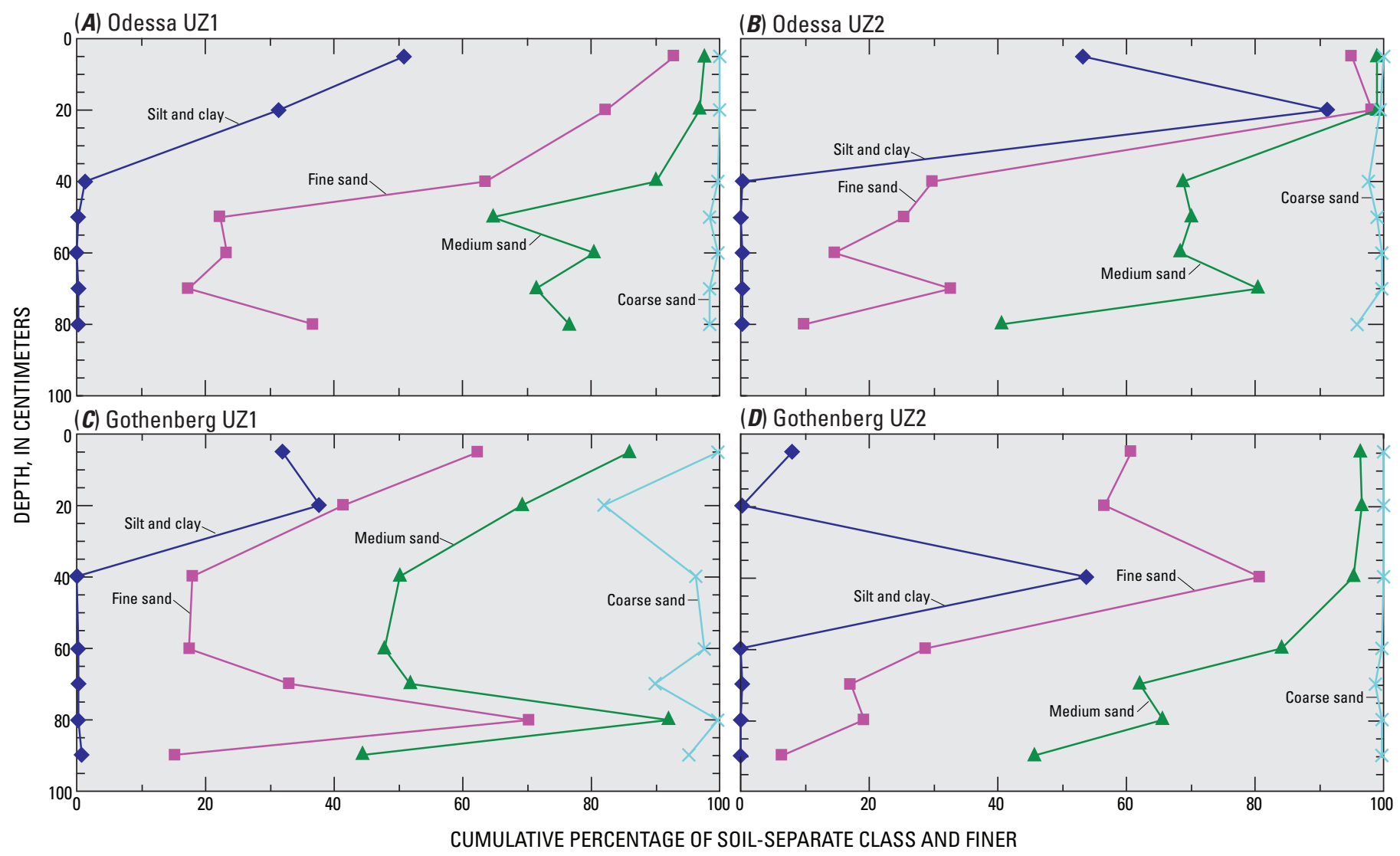

Figure 10. Vertical profile of grain-size distribution of study sites near Odessa and Gothenburg, Nebraska. 
The smaller declines at Gothenburg probably are the result of increased aquifer recharge from surface water as compared to Odessa. Because the north channel of the Platte River is used to route irrigation-supply water past the Gothenburg site, surface-water levels are more consistently maintained than at Odessa. During most of the year, water-level altitudes were highest in the GW1 piezometer, intermediate in the GW2 piezometer, and lowest in the river channel (GNC), indicating that the gradient for ground-water flow was toward the river channel. However, during the period of irrigation-water routing through the river channel from late June through early August, water-level altitudes were greater at GNC than in GW1 or GW2. At Odessa, ground-water levels fell by as much as $70 \mathrm{~cm}$ during the growing season, and water-level altitudes consistently were higher at the OW1 and OW2 piezometers than at the north channel of the Platte River (ONC) (fig. $2 A$ ). Unlike Gothenburg, the Platte River at Odessa is not used for irrigation-water routing and, as a result, no gradient reversal was observed that was similar to that at Gothenburg. Because of its presumed effect of artificially maintaining local groundwater levels, the presence of routed irrigation water in the river resulted in a fundamental difference in the ground-water conditions between the two sites.

\section{Precipitation and Canopy Interception}

At both sites, a wide range in daily, monthly, and annual precipitation occurred during the study period (fig. 11). This period encompassed a range of hydrologic conditions, including some periods of normal precipitation. Daily precipitation was characterized by many rainstorms of $25 \mathrm{~mm}$ or less with a few rainstorms greater than $25 \mathrm{~mm}$ accounting for a relatively large fraction of annual totals. The maximum daily precipitation occurred at Odessa, and was nearly $74 \mathrm{~mm}$ (fig. 11A, D).

Thirty-year average monthly precipitation for 1961 to 1990 (hereinafter referred to as normal monthly precipitation) (High Plains Regional Climate Center, 2006) varies seasonally. Normal monthly precipitation generally was similar between the study sites and varied from a minimum of about $10 \mathrm{~mm}$ in January to a maximum of about $100 \mathrm{~mm}$ in June (fig. $11 B, E$ ). Additionally, 66 percent and 69 percent of the normal annual precipitation occurred from May through September at Odessa and Gothenburg, respectively.

Monthly precipitation during the study period was more variable than normal (fig. $11 B, E$ ), resulting in relatively wet and relatively dry seasonal periods of 2 to 3 months long. Monthly departures from normal were calculated by subtracting the normal precipitation from the measured precipitation, with positive departures indicating relatively wet months and negative departures indicating relatively dry months. Of greatest hydrologic significance were consecutive months of substantial positive or negative departures. At both sites, the largest negative departures for consecutive months occurred during April through July 2002, and July through August 2003 (fig. $11 B, E$ ). The largest positive departures for consecutive months occurred during April through June of 2003, and May through June 2005 at the Odessa site (fig. 11B) and during June through July 2004 at the Gothenburg site.

For the four annual periods between 2002 and 2005, precipitation at both sites varied substantially from below normal in 2002 to substantially above normal in 2004, and approximately normal during 2003 and 2005 (fig. 11C, F). Annual precipitation ranged from 429 to $844 \mathrm{~mm}$ at the Odessa site, compared to a 30 -year average of $630 \mathrm{~mm}$. Annual precipitation at the Gothenburg site ranged from 359 to $791 \mathrm{~mm}$, compared to a 30-year average of about $560 \mathrm{~mm}$. Annual precipitation at Odessa always was greater than at Gothenburg, consistent with a general west-to-east increase in precipitation that occurs across Nebraska (Gutentag and others, 1984; Szilagyi and others, 2003). During the study period, annual precipitation at both sites varied by about 35 percent from its 4-year average.

Variations in annual precipitation primarily reflected wet and dry periods during May through September, when most precipitation occurred. These months also encompass most of the growing season that usually occurred between late April and mid-October. The substantial negative departure from normal in 2002 primarily reflected drier than normal conditions during April through July 2002. The substantial positive departure from normal in 2004 primarily reflected wetter than normal conditions during July through November 2004. The 2003 annual period had wetter than normal precipitation from May through July 2003, and drier than normal precipitation from July through August 2003. During the 2005 annual period, monthly departures from normal were not systematic.

Throughfall through the canopy at each site ranged from about 67 to 89 percent of precipitation (fig. 12; table 4). These percentages were derived from the ratio of mean throughfall and precipitation values at each gage when paired measurements were available. Simple linear-regression (SLR) models relating throughfall to precipitation during non-freezing conditions had $\mathrm{R}^{2}$ of 0.97 or greater, indicating a relatively strong relation between precipitation and throughfall over the measured range of rainfall intensities and amounts. The SLR models for the throughfall gages all had small, negative intercepts, which may reflect either uncertainty in the data or physical factors such as the storage capacity of the canopy, which can result in zero throughfall for small precipitation events. Because the SLR intercepts were relatively small in comparison to the measured data, comparisons between sites were made using the SLR slopes. All of the slopes were less than one, indicating throughfall was less than precipitation; however, there were a few rainstorms (fig. 12) where throughfall exceeded precipitation. These rainstorms could reflect scenarios where vegetation channeled raindrops toward the gutters or may be undetected rain-gage malfunctions. At the Odessa site, greater amounts of throughfall occurred in the shrub-dominated gage two-as indicated by a slope of 0.878 (fig. 12B) — than gage one-as indicated by a slope of 0.773 (fig. 12A)-located beneath the canopy of a large cottonwood tree. At the Gothenburg site, greater amounts of throughfall 

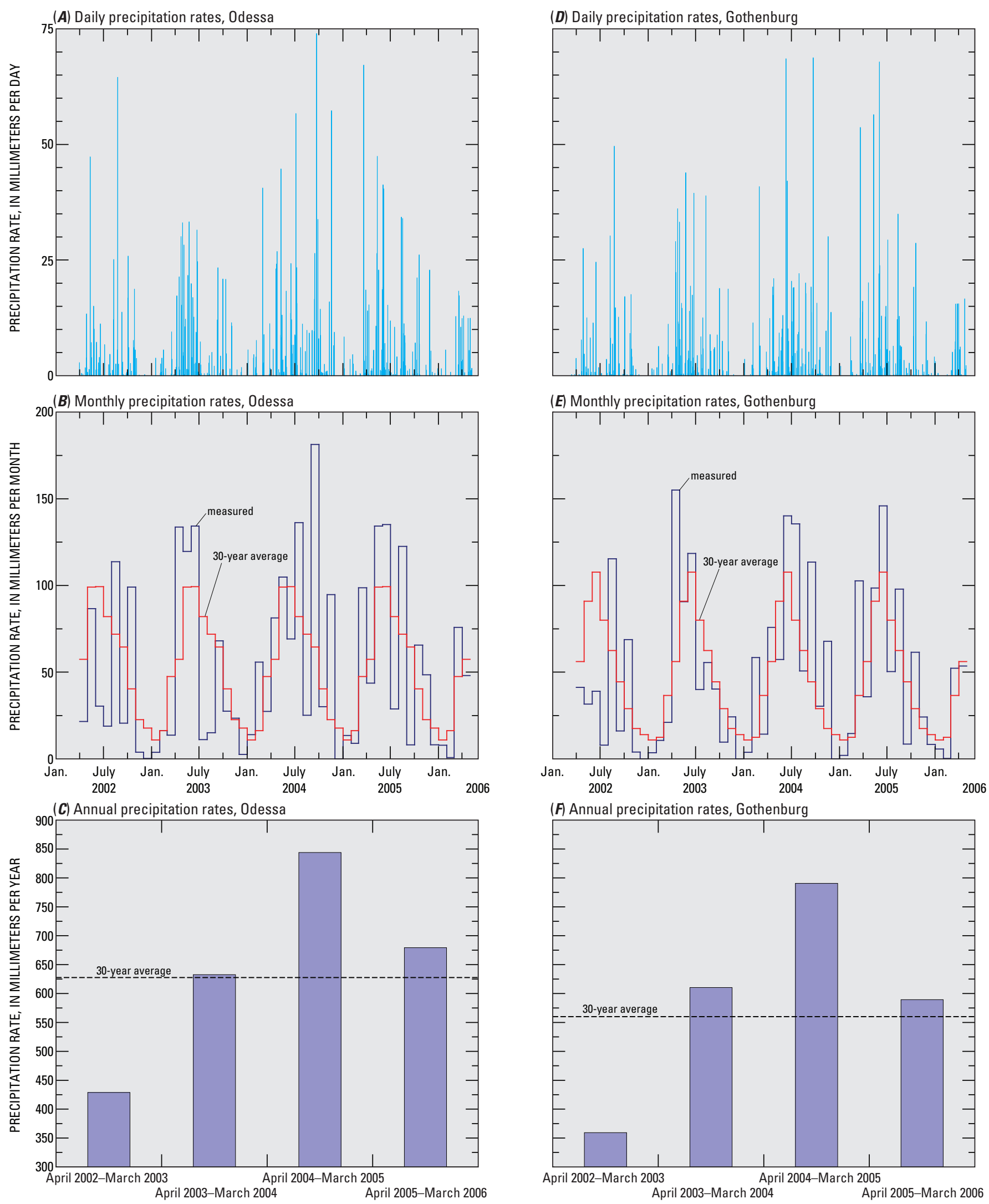

Figure 11. Daily, monthly measured and normal, and annual measured and normal precipitation for study sites near Odessa and Gothenburg, Nebraska, 2002-06. (Normal precipitation from High Plains Regional Climate Center, 2006) 

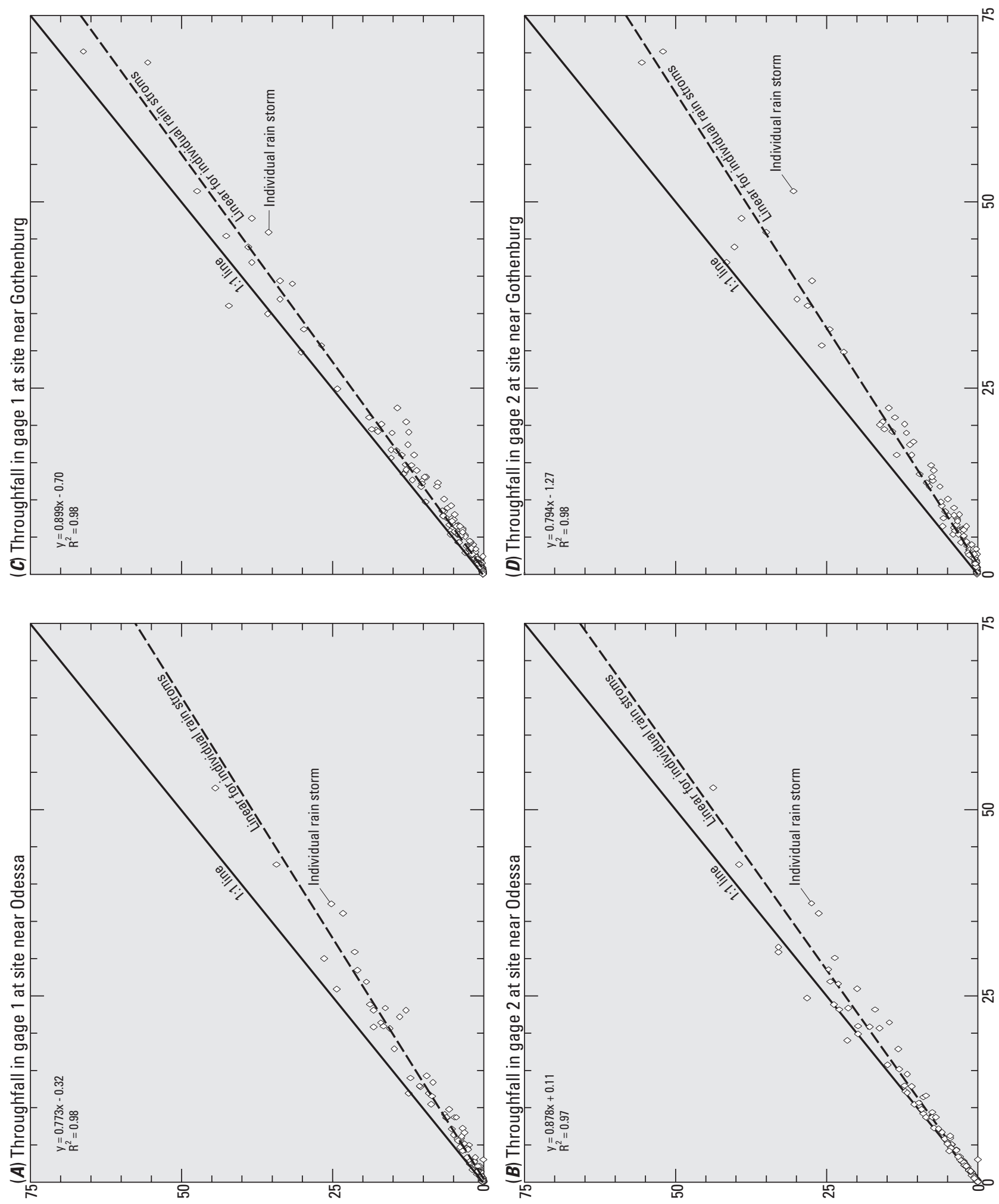

WYOLS NIVY y

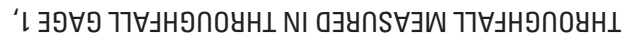

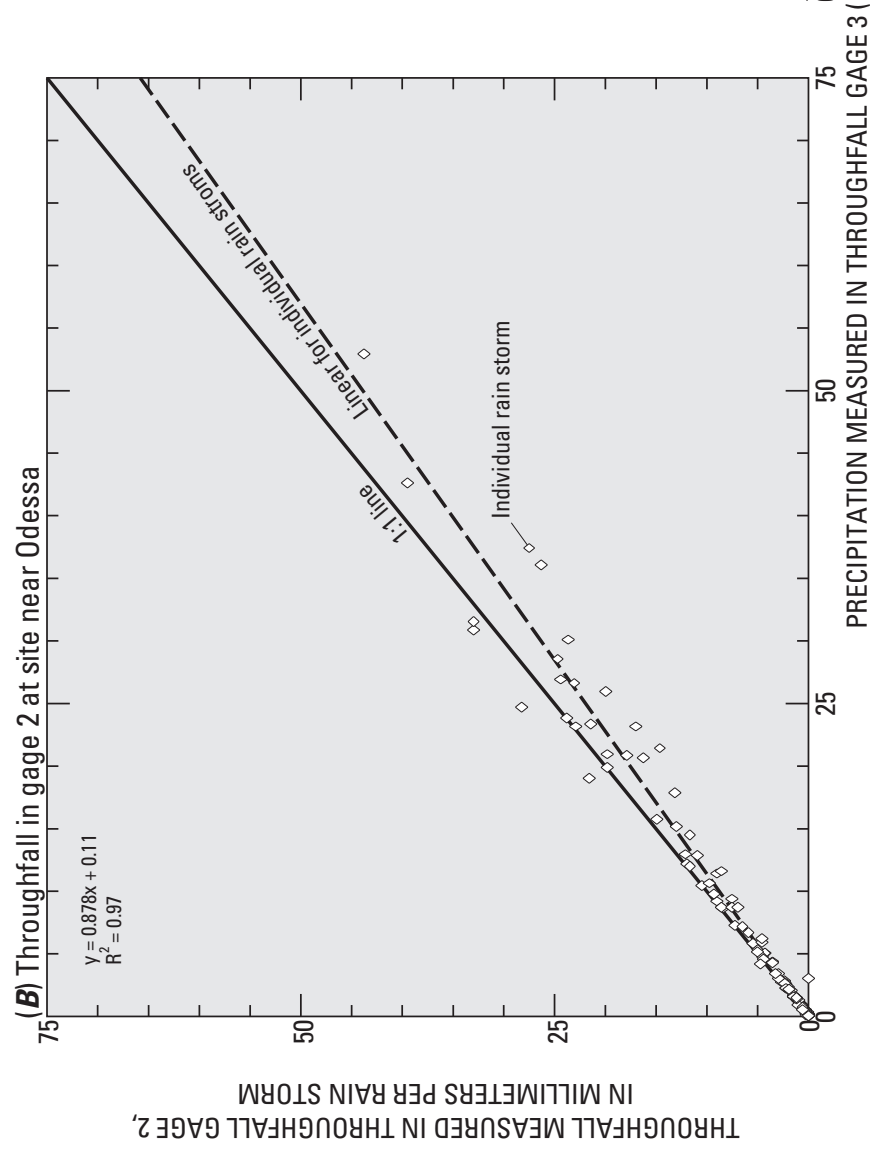

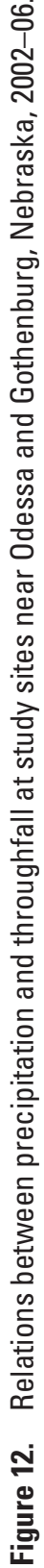


occurred through the cottonwood and Russian olive trees at gage one-as indicated by a slope of 0.899 (fig. 12C) - than the relatively low-hanging canopy of several eastern redcedar trees at gage two - as indicated by a slope of 0.794 (fig. 12D).

Interception of precipitation by the plant canopy (hereinafter referred to as interception) was calculated as the difference between precipitation and throughfall. This calculation is a maximum estimate of interception because some water could reach the ground surface through stemflow, the flow of precipitation down plant surfaces to the ground. Although not measured in this study, the fraction of stemflow for forests varies widely as a function of many factors, and has been determined to account for 5 to 15 percent of precipitation (Levia and Frost, 2003). Thus, these estimates of evaporation of intercepted water represent an upper boundary of possible values.

Estimates of area-weighted interception-calculated by allocating the interception determined at the two canopyaffected throughfall gages to the distribution of vegetation cover in the theoretical footprint-were both 13 percent of precipitation at the two sites (table 4). These calculations were based on the assumptions that interception determined from SLR for throughfall gages 1 and 2 (fig. 12) each represented one-half of the woody vegetation areas shown in figure 7; interception in areas of open or other land cover (fig. 7) was 5 percent of precipitation - one-half of the minimum interception of 10 percent measured in throughfall gages beneath tree or shrub canopies; and the vegetation cover within $800 \mathrm{~m}$ of the tower, shown in figure 7 , was representative of the study sites. Sensitivity analyses, done by varying the assumed interception for open vegetation cover and changing area weights within reasonable boundaries, indicated that uncertainties in these parameters resulted in estimates of area-weighted interception ranging from about 10 to 16 percent. It is likely that area-weighted interception lies within this range.

Most intercepted water is likely to evaporate into the atmosphere on time scales of one day or less (Savenije, 2004). For the purposes of this study, it was assumed that all intercepted water evaporated from the canopy.

The estimated interception values for Platte River riparian forests appear to be reasonable in comparison with literature values. Studies of interception indicate it is typically 10 to 30 percent of precipitation, and can be as much as 50 percent of the rainfall (Calder, 1990; Liu, 1997). Evaporation of intercepted water in the forest canopy has been determined to be a substantial component of total ET in some studies (Savenije, 2004). For example, Grelle and others (1997) determined that interception evaporation composed 20 percent of total ET in a coniferous forest in Scandinavia. Because the riparian forests along the Platte River have a relatively low areal density of deciduous plants (table 3 ), it is reasonable that interception and evaporation of intercepted water are in the lower range of values appearing in the literature.

\section{Measured Evapotranspiration Rates}

Measured ET rates were compiled on daily, monthly, and annual timescales (fig. 13). The ET values indicated a clear seasonal trend at both sites but exhibited subtle differences with respect to annual maximums and the dependence on precipitation.

Daily ET rates determined from eddy-covariance data ranged from -0.7 to about $7.5 \mathrm{~mm} / \mathrm{d}$ (appendix 1; appendix 2). From June through August, daily ET rates typically varied between 2.5 and $5.0 \mathrm{~mm} / \mathrm{d}$. Daily ET rates from December through February often were less than $0.5 \mathrm{~mm} / \mathrm{d}$. On average, the daily ET rates for the study period were $1.51 \mathrm{~mm} / \mathrm{d}$ at the Odessa site, and $1.56 \mathrm{~mm} / \mathrm{d}$ at the Gothenburg site.

Monthly ET rates ranged from less than $20 \mathrm{~mm}$ per month from November through February to a maximum of about $130 \mathrm{~mm}$ per month during summer (June, July, August) months (fig. $13 B, E)$. In $3(2002,2003,2005)$ of the 4 study years, maximum monthly ET occurred 1-2 months later at the Gothenburg site than at the Odessa site. During 2004, the wettest of the study years, maximum ET occurred during July at the Odessa site and during June at the Gothenburg site, a reversal of the pattern from other study years with dry to near normal precipitation.

Annual ET ranged from 514 to $586 \mathrm{~mm} / \mathrm{yr}$ at the Odessa site and 535 to $616 \mathrm{~mm} / \mathrm{yr}$ at the Gothenburg site (fig. 13C, F). The average annual ET during the study period was $551 \mathrm{~mm}$ at the Odessa site and $575 \mathrm{~mm}$ at the Gothenburg site. At both sites, the maximum and minimum annual ET values differed from the 4-year average by about 7 percent.

The $E T$ response to annual precipitation was different between the two study sites. Annual ET at Gothenburg was greater than at Odessa (fig. $13 C, F$ ) during the first 2 years of the study, corresponding to substantially below normal to nearly normal precipitation (fig. $11 C, F$ ). Conversely, annual $E T$ at the Odessa site was greater than at the Gothenburg site during the last 2 years of the study, corresponding to substantially above normal to slightly above normal precipitation. Thus, at the Odessa site, annual ET was larger during relatively wet years and smaller during relatively dry years. The opposite occurred at the Gothenburg site, where annual ET was smaller during relatively wet years and larger during relatively dry years. These results indicate that the dependence of ET on precipitation was different between the two sites. This important distinction is discussed further in the "Environmental Factors Affecting Evapotranspiration Rates" section of the report.

Based on an analysis of the $E B R_{\text {mean }}$, the ET rates determined using eddy covariance are estimated to be within about 15 percent of the actual rates. The largest source of uncertainty arises from the method used to adjust measured-energy fluxes to close the energy balance. Based only on days of complete data during March 12, 2002, through June 27, 2005, before gap-filling, the long-term $E B R_{\text {mean }}$ (eq. 4) was about 0.89 for both sites, indicating that either turbulent fluxes $(\lambda E+H)$ were 
Table 4. Summary of annual precipitation and interception at study sites near Odessa and Gothenburg, Nebraska, 2002-06.

[P, total precipitation; mm, millimeters; $\mathrm{I}_{1}$, interception in throughfall gage 1 underlying a full tree canopy; $\mathrm{I}_{2}$, interception in throughfall gage 2 underlying shrubs and a light tree canopy; $\mathrm{I}_{0}$, interception associated with no tree or shrub canopy; I/P, interception as a fraction of precipitation; $\mathrm{WA}_{1}$, weighted areal fraction represented by a full tree canopy; $\mathrm{WA}_{2}$, weighted areal fraction represented by shrubs and light tree canopy; $\mathrm{WA}_{0}$, weighted areal fraction represented by areas other than tree or shrub canopy; $\mathrm{I}_{\text {wa }}$, area-weighted interception]

\begin{tabular}{|c|c|c|c|c|}
\hline & $\begin{array}{l}\text { April 1, 2002- } \\
\text { March 30, } 2003\end{array}$ & $\begin{array}{l}\text { April 1, 2003- } \\
\text { March 30, } 2004\end{array}$ & $\begin{array}{c}\text { April 1, 2004- } \\
\text { March 30, } 2005\end{array}$ & $\begin{array}{l}\text { April 1, 2005- } \\
\text { March 30, } 2006\end{array}$ \\
\hline \multicolumn{5}{|c|}{ Odessa } \\
\hline $\mathrm{P}, \mathrm{mm}$ & 429 & 633 & 844 & 679 \\
\hline Mean $I_{1} / P$, gage 1 , full tree canopy ${ }^{1}$ & .27 & .27 & .27 & .27 \\
\hline Mean $\mathrm{I}_{2} / \mathrm{P}$, gage 2 , shrub and light tree canopy ${ }^{1}$ & .11 & .11 & .11 & .11 \\
\hline Mean $I_{0} / P$, no tree or shrub cover ${ }^{2}$ & .05 & .05 & .05 & .05 \\
\hline $\mathrm{WA}_{1}$, gage 1 , full tree canopy ${ }^{3}$ & .28 & .28 & .28 & .28 \\
\hline $\mathrm{WA}_{2}$, gage 2 , shrub and light tree canopy ${ }^{3}$ & .28 & .28 & .28 & .28 \\
\hline $\mathrm{WA}_{\mathrm{o}}$, no tree or shrub canopy, open and other ${ }^{3}$ & .44 & .44 & .44 & .44 \\
\hline Area-weighted interception $\left(\mathrm{I}_{\mathrm{wa}}\right), \mathrm{mm}^{4}$ & 55 & 81 & 107 & 86 \\
\hline $\mathrm{I}_{\mathrm{wa}} / \mathrm{P}$ & .13 & .13 & .13 & .13 \\
\hline \multicolumn{5}{|c|}{ Gothenburg } \\
\hline $\mathrm{P}, \mathrm{mm}$ & 359 & 610 & 791 & 589 \\
\hline Mean $I_{1} / \mathrm{P}$, gage 1 , full tree canopy ${ }^{1}$ & .18 & .18 & .18 & .18 \\
\hline Mean $\mathrm{I}_{2} / \mathrm{P}$, gage 2 , shrub and light tree canopy ${ }^{1}$ & .33 & .33 & .33 & .33 \\
\hline Mean $I_{0} / P$, no tree or shrub cover ${ }^{2}$ & .05 & .05 & .05 & .05 \\
\hline $\mathrm{WA}_{1}$, gage 1 , full tree canopy ${ }^{3}$ & .20 & .20 & .20 & .20 \\
\hline $\mathrm{WA}_{2}$, gage 2 , shrub and light tree canopy ${ }^{3}$ & .20 & .20 & .20 & .20 \\
\hline $\mathrm{WA}_{\mathrm{o}}$, no tree or shrub canopy, open and other ${ }^{3}$ & .59 & .59 & .59 & .59 \\
\hline Area-weighted interception $\left(\mathrm{I}_{\mathrm{wa}}\right), \mathrm{mm}^{4}$ & 48 & 82 & 106 & 79 \\
\hline $\mathrm{I}_{\mathrm{wa}} / \mathrm{P}$ & .13 & .13 & .13 & .13 \\
\hline
\end{tabular}

${ }^{1}$ Estimated from linear regression of throughfall against precipitation (fig. 12) subtracted from 1.0 to estimate interception.

${ }^{2}$ Interception fraction for open and other areas without tree and shrub canopy cover assumed to be 0.05 , slightly less than one-half of the lowest interception determined from throughfall gages.

${ }^{3}$ Areal weights calculated using percentages of vegetation cover shown in figure 7. Areas of woody vegetation were assumed to be equally represented by gages 1 and 2 . The relevant representative area is assumed to be the circular area of radius of 800 meters shown on figure 7.

$\left.{ }^{4} \mathrm{I}_{\mathrm{wa}}=\mathrm{P} \times\left(\left(\mathrm{I}_{1} / \mathrm{P}\right) \times \mathrm{WA}_{1}\right)+\left(\left(\mathrm{I}_{2} / \mathrm{P}\right) \times \mathrm{WA}_{2}\right)+\left(\left(\mathrm{I}_{\mathrm{o}} / \mathrm{P}\right) \times \mathrm{WA}_{\mathrm{o}}\right)\right)$ 

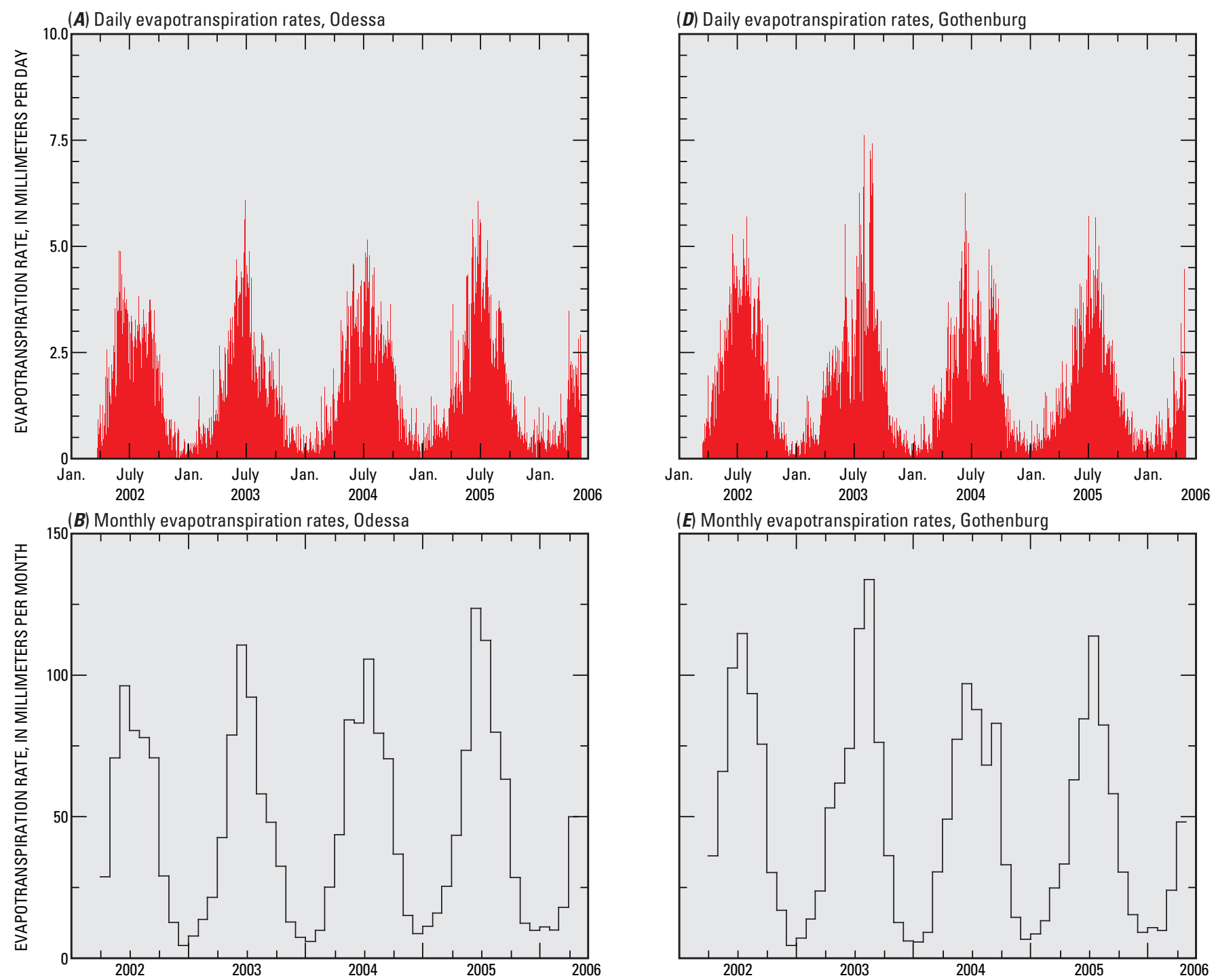

(E) Monthly evapotranspiration rates, Gothenburg
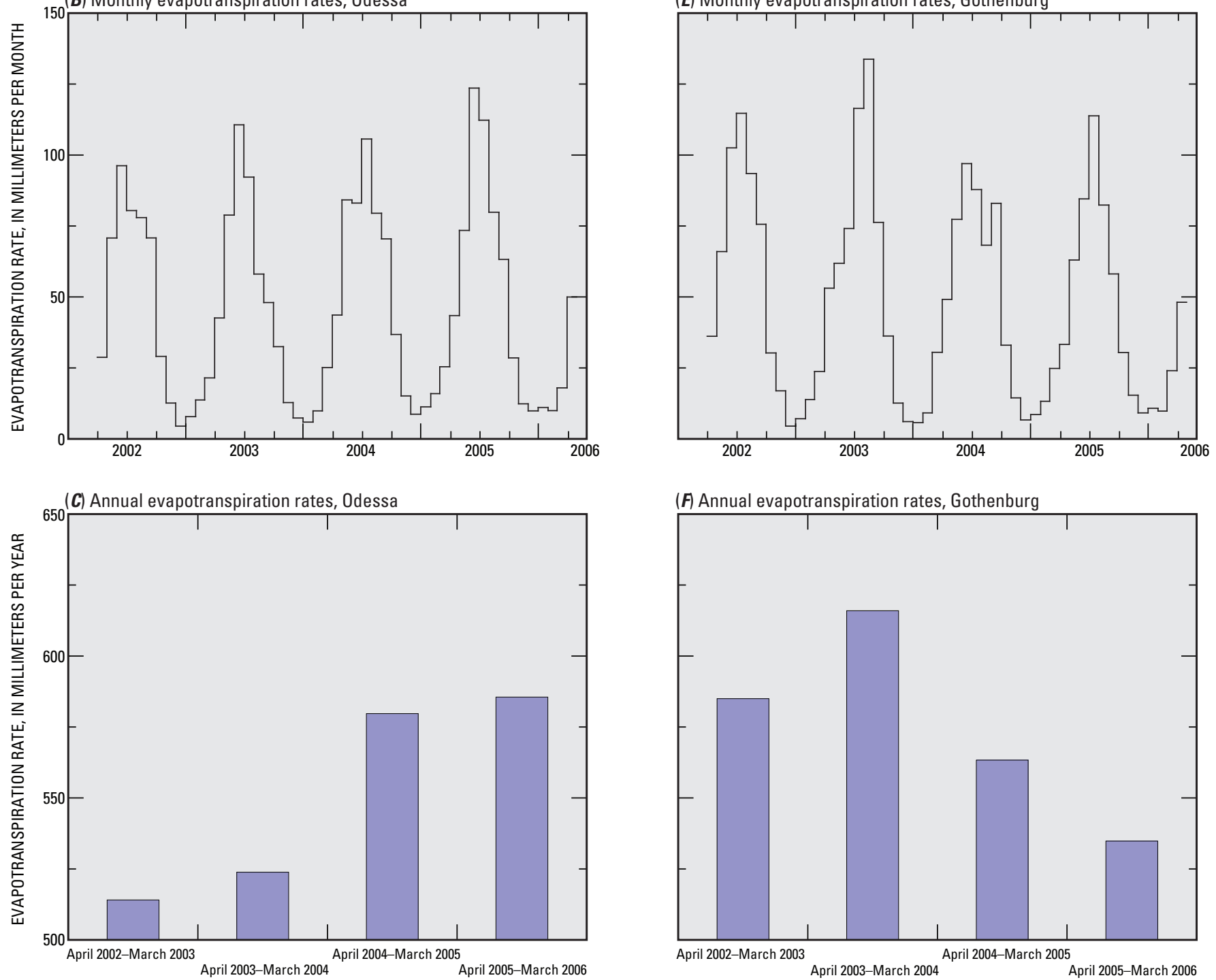

Figure 13. Daily, monthly, and annual evapotranspiration rates for study sites near Odessa and Gothenburg, Nebraska, 2002-06. 
being underestimated or available energy $(R n-\Delta P S-G)$ was being overestimated. This study assumed that available energy, which was dominated by the $R n$ term, was being overestimated. Therefore, to provide energy-balance closure, $R n$ data were adjusted downward by multiplying by $E B R_{\text {mean }}$. If instead the energy balance had been closed by dividing the turbulent fluxes by 0.89 and doing the same with $\lambda E_{p}$ during gaps when the atmosphere was saturated, then the resulting $E T$ would have been about 13 percent greater than the reported values. Actual ET values may lie between these estimates. For this reason, the reported ET values are estimated to represent minimum values with maximum values up to 13 percent greater.

Procedures used in filling data gaps probably had little effect on annual ET estimates. On average, gap-filled ET accounted for 2.9 percent of the total ET at the two sites, of which 2.4 percent was associated with data gaps filled by multiplying $\lambda E_{p}$ by 0.89 , and 0.5 percent was associated with data gaps filled with linear interpolation or regression procedures. It is expected that utilizing alternative gap-filling procedures would have had relatively little effect on annual ET estimates.

\section{Energy Balances}

Energy imbalances were used to evaluate the data quality. For the entire study period, energy imbalances as a percentage of available energy were 9 percent at Odessa (table 5) and 13 percent at Gothenburg (table 6). These imbalances are within the range of 0 to 30 percent typically present in energy-balance studies (Twine and others, 2000), indicating that the energy-flux data are reasonable. The energy balance was improved by adjusting net-radiation values to account for an observed underestimation of long-wave radiation presumed to be emanating from the land surface.

\section{Adjusted Net Radiation}

As stated, $R n$ values were adjusted to better account for long-wave radiation emanating from the land surface, which predominates at night. Separate adjustments were made for nighttime-operationally defined as periods with solar-radiation $(R)$ values less than $1 \mathrm{~W} / \mathrm{m}^{2}$ —and daytime periods. SLR techniques were used to relate $R n$ values measured from the conventional two-component net radiometer $(\mathrm{Rn}-2)$ with those from the four-component net radiometer $(\mathrm{Rn}-4)$ at Odessa to produce an adjusted $R n$ value $\left(R n_{a d j}\right)$.

Comparison of Rn-2 and Rn-4 data for Odessa indicated that the $\mathrm{Rn}-4$ included more long-wave radiation, resulting in smaller daily $R n$ values and subsequently better EBC than for the Rn-2 measurements. SLR relations between the Rn- 2 and Rn-4 were developed using 30-minute data from March 2004 through May 2005. Because nighttime values from the Rn-4 were less than the Rn-2 (fig. 14B), they were considered to better represent $R n$. Differences between the net radiometers were largest at more negative values from the Rn-2 (fig. 14B). The daytime slope coefficient for values from the $\mathrm{Rn}-2$ compared to those from the Rn-4 was smaller than the nighttime slope, indicating that the differences between the two radiometers were less important as values became increasingly positive (fig. 14). During the growing season, daily Rn-4 measurements were typically 0 to 20 percent less than those from the $\mathrm{Rn}-2$, with a median difference of about 10 percent. During the dormant season, there was more variability in the differences between the two sensors, but the Rn-4 measurements generally were less than those from the $\mathrm{Rn}-2$ by a greater amount than during the summer.

At Odessa, the SLR models of the relations between the $\mathrm{Rn}-4$ and the Rn-2 measurements for daytime and nighttime conditions (fig. 14) were the basis for estimating $R n_{a d j}$ for periods before the installation of the Rn-4. The SLR models were validated by comparing $R n_{a d j}$ to the Rn- 4 measurements for March 2004 through May 2005 with the expectation of a one-to-one relation (or a slope coefficient of one). The regression-estimated slope coefficient was 0.9941, which was not significantly different from one. The calculation for $R n_{a d j}$ subsequently was applied to the entire Odessa data set.

At Gothenburg, the Rn-4 was not deployed at any time during the study; however, SLR comparisons were made between Gothenburg and Odessa for Rn-2 measurements as well as for $R_{s}$. Though Odessa data typically were greater (albeit only slightly), relations for both data types were well constrained $\left(\mathrm{R}^{2}>0.90\right)$. Based on the comparability of $\mathrm{Rn}-2$ measurements and $R_{s}$ between the two sites, the SLR models of relations between the Rn- 4 and the Rn-2 for daytime and nighttime conditions at Odessa also were applied to the Rn-2 data at the Gothenburg site to adjust for the underestimation of long-wave radiation. Consequently, $R n$ values referred to hereinafter in this report are synonymous with $R n_{a d j}$.

\section{Seasonal and Diurnal Energy-Flux Cycles}

Within the study period, seasonal changes in the EBC and energy flux were evident. Energy fluxes generally were largest during the summer months (June through August) and smallest during the winter months (November through February), reflecting seasonal variations in $R n$ (fig. 15; tables 5 and 6). Monthly mean $R n$ values during summer months were roughly an order of magnitude greater than winter values, and generally were similar between years and between sites. Monthly means of $\lambda E, H, G$, and $\triangle P S$ generally were largest in summer and smallest in winter, roughly tracking summertime increases in $R n$.

During the growing season (May through September), $\lambda E$ accounted for the most energy leaving the system at both sites, whereas $\mathrm{H}$ was the dominant energy outflow during the dormant season (October through April). Monthly mean values of $\lambda E$ usually were greater than $H$ (meaning $H / \lambda E$, the Bowen ratio, was less than unity) during the growing season with a mean Bowen ratio of 0.65 at Odessa (table 5) and 0.60 at Gothenburg (table 6). During the dormant season, $H$ typically was the largest energy outflow term at both sites, with mean Bowen ratios of 1.72 at Odessa and 1.90 at Gothenburg. 


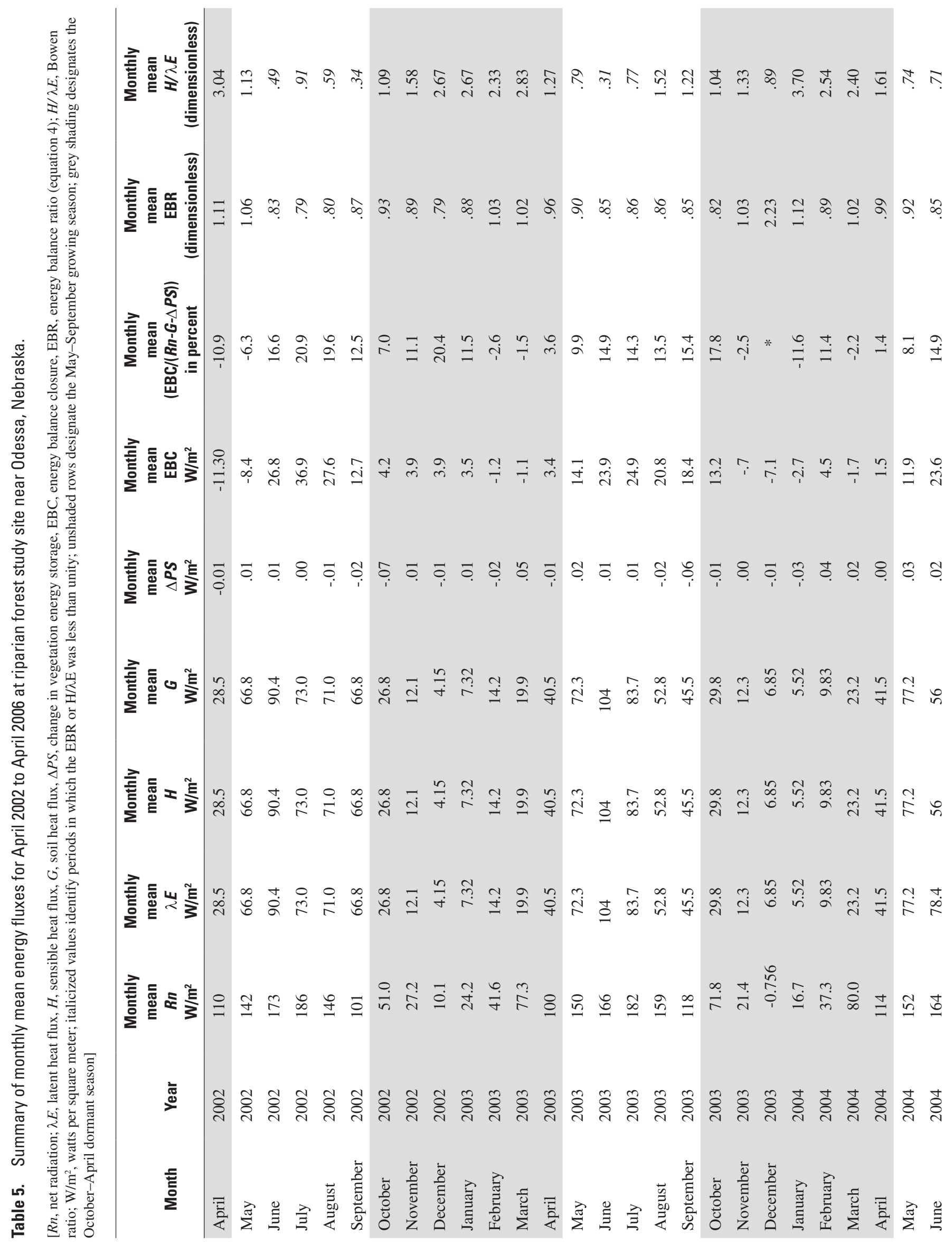




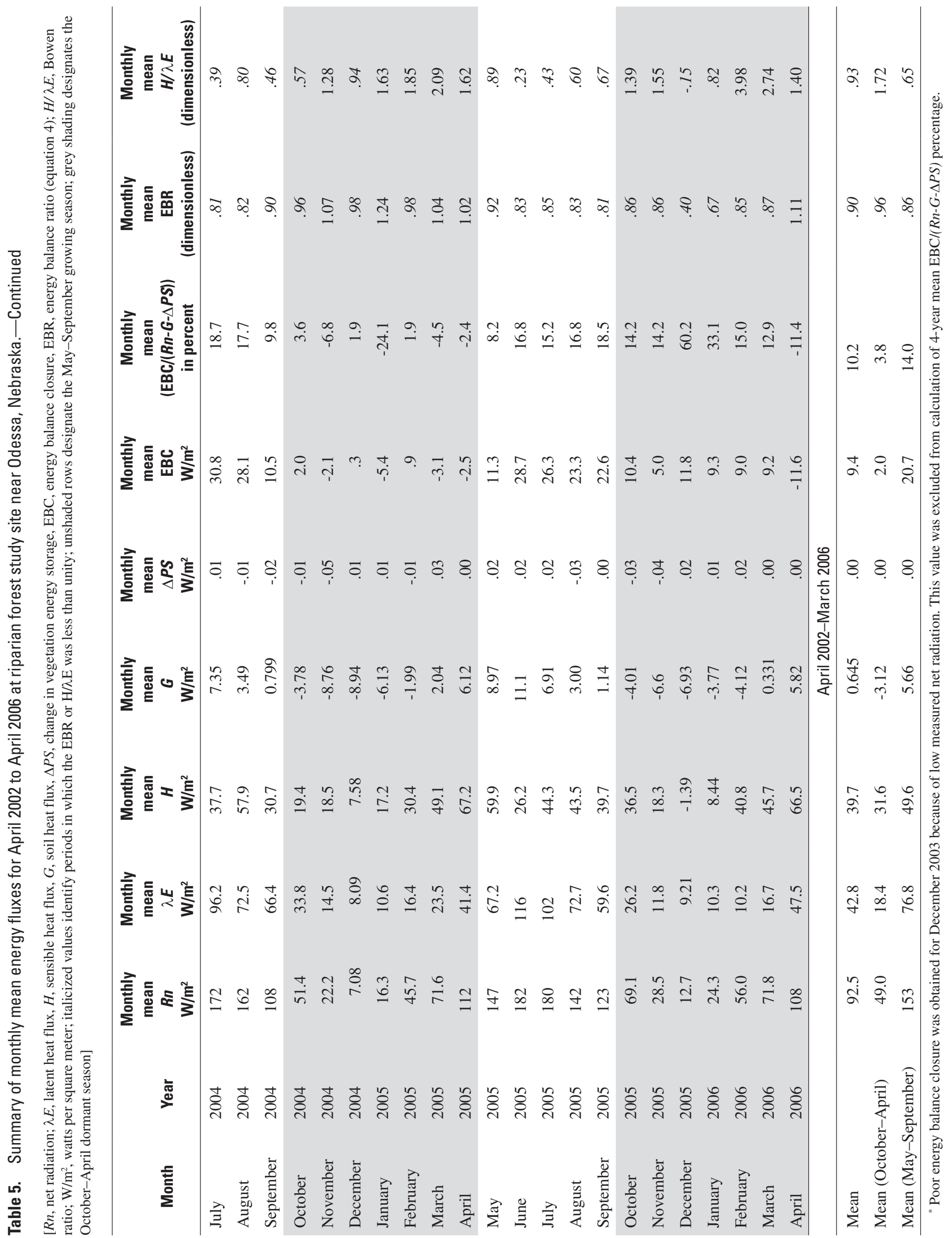




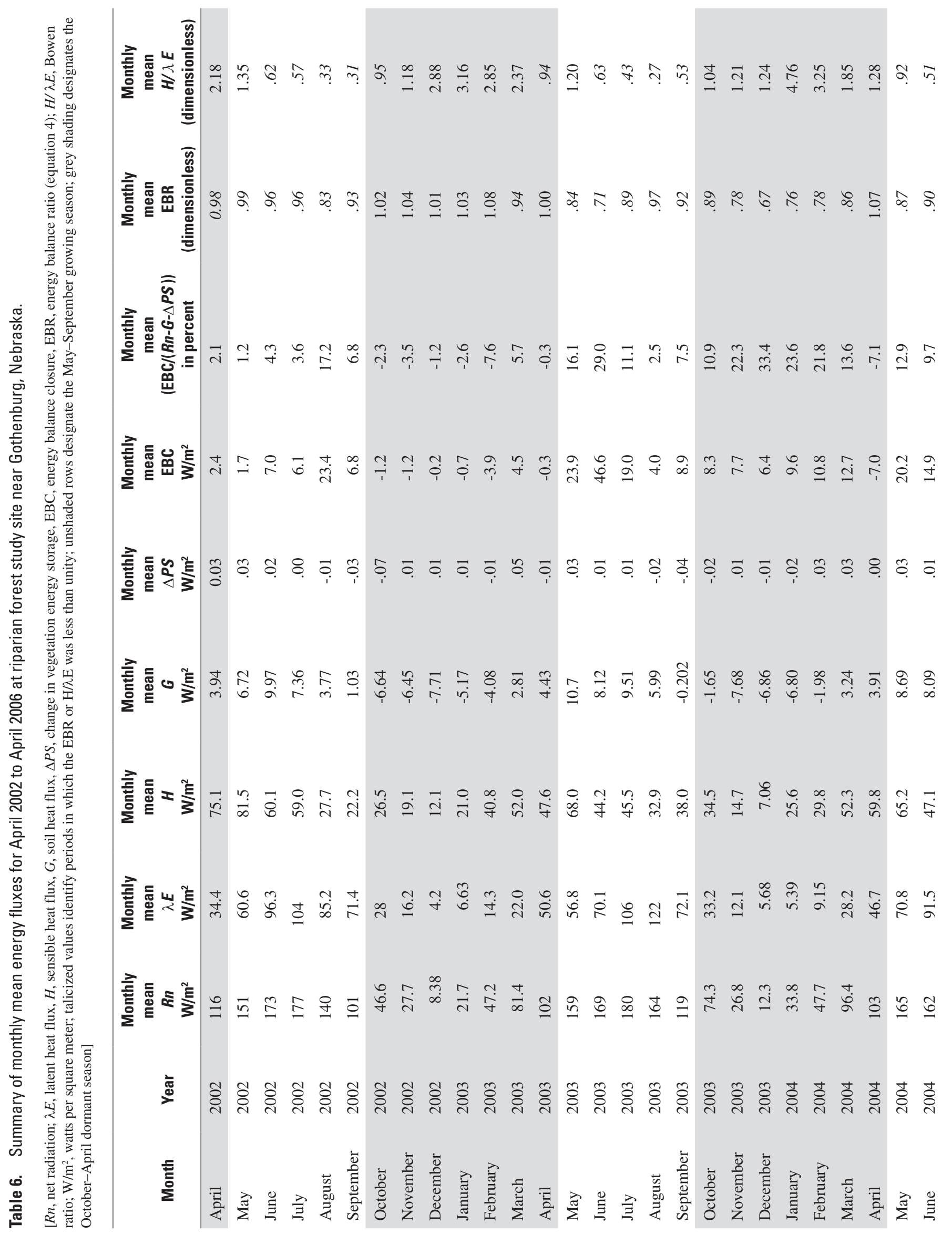




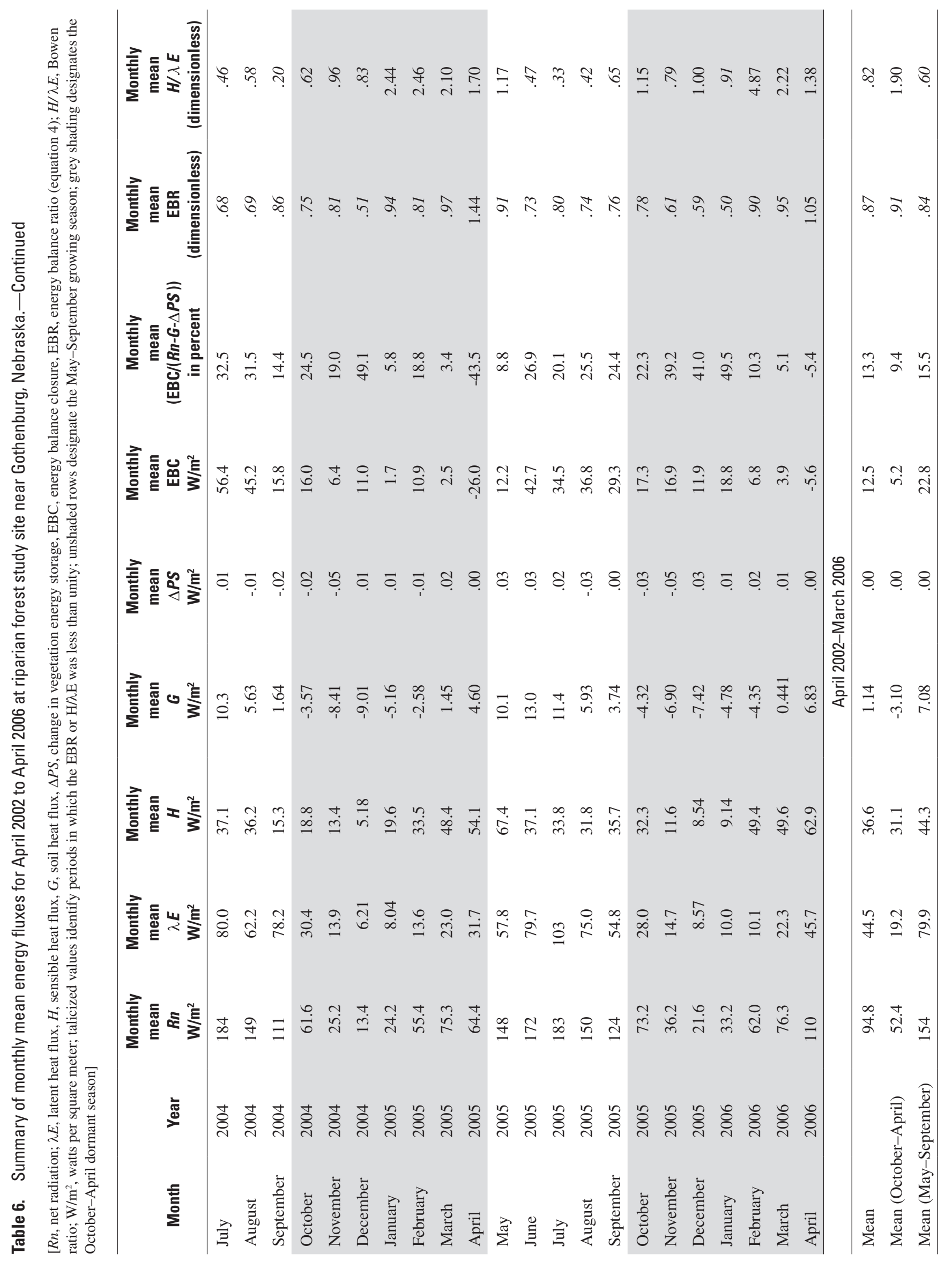



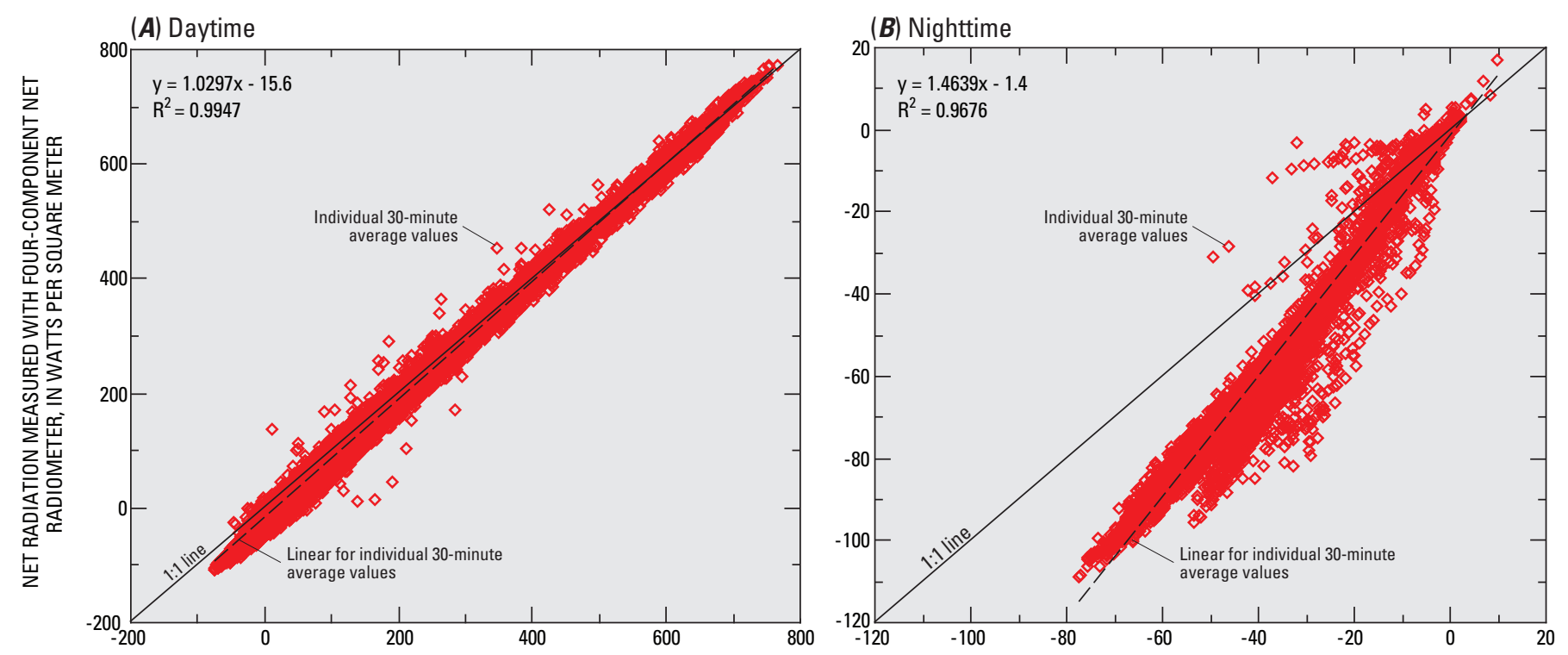

NET RADIATION MEASURED WITH TWO-COMPONENT NET RADIOMETER, IN WATTS PER SQUARE METER

Figure 14. Relations between net radiation measured with different net radiometers at study site near Odessa, Nebraska, March 2004-May 2005.

Within annual cycles, there were variations in values of $\lambda E, H$, and soil-heat flux $(G)$ within seasons and between sites. The maximum monthly mean $\lambda E$ typically occurred 1 to 2 months later at the Gothenburg site as compared to the Odessa site, with the exception of 2004 (fig. 15). The greatest monthly mean values of $H$ typically occurred earlier in the growing season than values of $\lambda E$. At Odessa, the greatest monthly mean values of $H$ occurred during April in 2002, 2004, and 2005 (fig. 15A; table 5). The exception occurred during 2003, when the greatest monthly mean $H$ for the year occurred during August. At the Gothenburg site, the greatest values of monthly mean $H$ occurred during May of each of the 4 study years, 1 to 3 months earlier than peak values of $\lambda E$ (fig. $15 B$; table 6).

Annually and monthly, $G$ typically was a small energy term relative to $\lambda E$ and $H$ (fig. 15; tables 5 and 6). The largest positive values of $G$ (indicating downward flow of heat into the soil from the land surface, or soil heating) typically occurred during June or July and the largest negative values (indicating upward flow of heat from soil to the land surface, or soil cooling) occurred during December. Calculated values of monthly average $\triangle P S$ were negligible at all times of the year at both sites.

Monthly EBCs were largest during the growing season because all energy terms were larger during these periods than during the dormant seasons (fig. 15). Values of EBC were nearly always positive reflecting that $R n-G-\triangle P S$ was greater than $H+\lambda E$ during most months. At the Odessa site, monthly $\mathrm{EBC} /(R n-G-\triangle P S)$ percentages for the growing season were less than 21 percent with a mean value of about 14 percent. At the Gothenburg site, monthly $\mathrm{EBC} /(R n-G-\triangle P S)$ percentages for the growing season were more variable than at Odessa, ranging from 1 to 32 percent with a mean of about 15 percent. The dormant-season $\mathrm{EBC} /(R n-G-\triangle P S)$ percentages were much more variable than during the growing season (fig. 15), although mean values were 3.8 percent at Odessa and 9.4 percent at Gothenburg. The largest $\mathrm{EBC} /(R n-G-\Delta P S)$ imbalances at both sites occurred during December and January when the lowest energy fluxes occurred.

Diurnal cycles in energy fluxes were examined using a subset of data to represent typical conditions. Median energy flux for every 30-minute period in a diurnal cycle is shown in figure 16 for summer (276 days of data for each 30-minute period) and for winter (212 days of data for each 30-minute period). The median energy fluxes for each 30 -minute period were calculated from data for 2002 through 2004.

Median diurnal cycles of $\lambda E$ and $H$ during summer approximately followed those of $R n$. Peak summer values of $R n, H$, and $\lambda E$ occurred in early afternoon and were nearly synchronous (fig. 16A, C). Diurnal cycles of $H$ closely followed those of $R n$ during summer and winter (fig. 16). Diurnal cycles of $\lambda E$ during summer had slightly broader and flatter afternoon peaks and a more gradual transition from daytime to nighttime values than did cycles for $H$. The looser relation between $R n$ and $\lambda E$ values than between $R n$ and $H$ values may indicate that a broader range of conditions such as humidity, water availability, and plant health, may be affecting $\lambda E$. At the Odessa site, peak values of $\lambda E$ occurred slightly after those of $R n$ and $H$ in the afternoon and peak values were less than those of $H$ (fig. 16A). At the Gothenburg site, median $\lambda E$ values exceeded $H$ values throughout the summer daily cycle; however, median diurnal values of $\lambda E$ and $H$ were fairly similar during summer at both sites. At Odessa during summer, median $G$ values peaked at 10:30 am and declined thereafter. In contrast, at the Gothenburg site during summer, median $G$ 


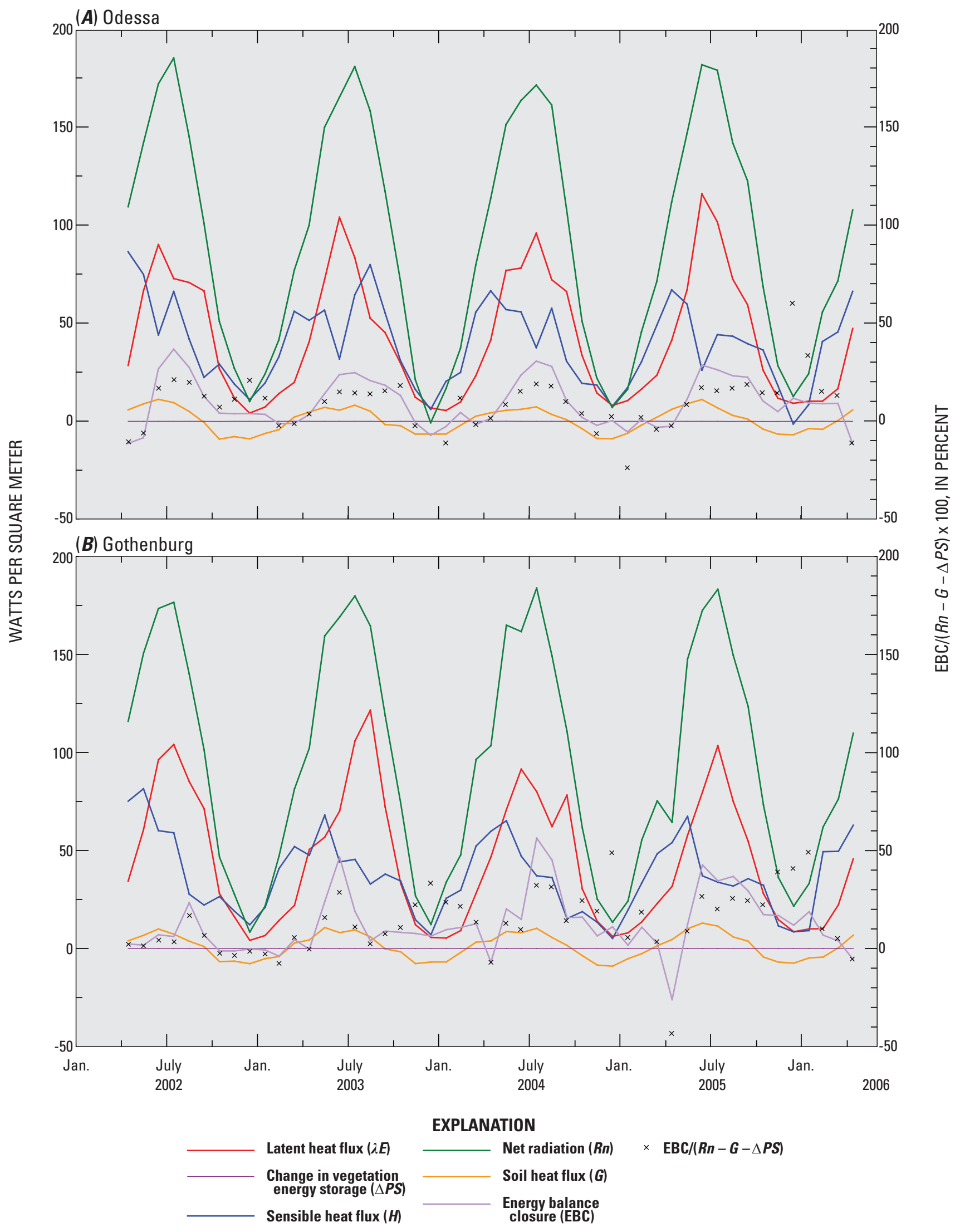

Figure 15. Monthly mean energy fluxes for study sites near Odessa and Gothenburg, Nebraska, 2002-06. 

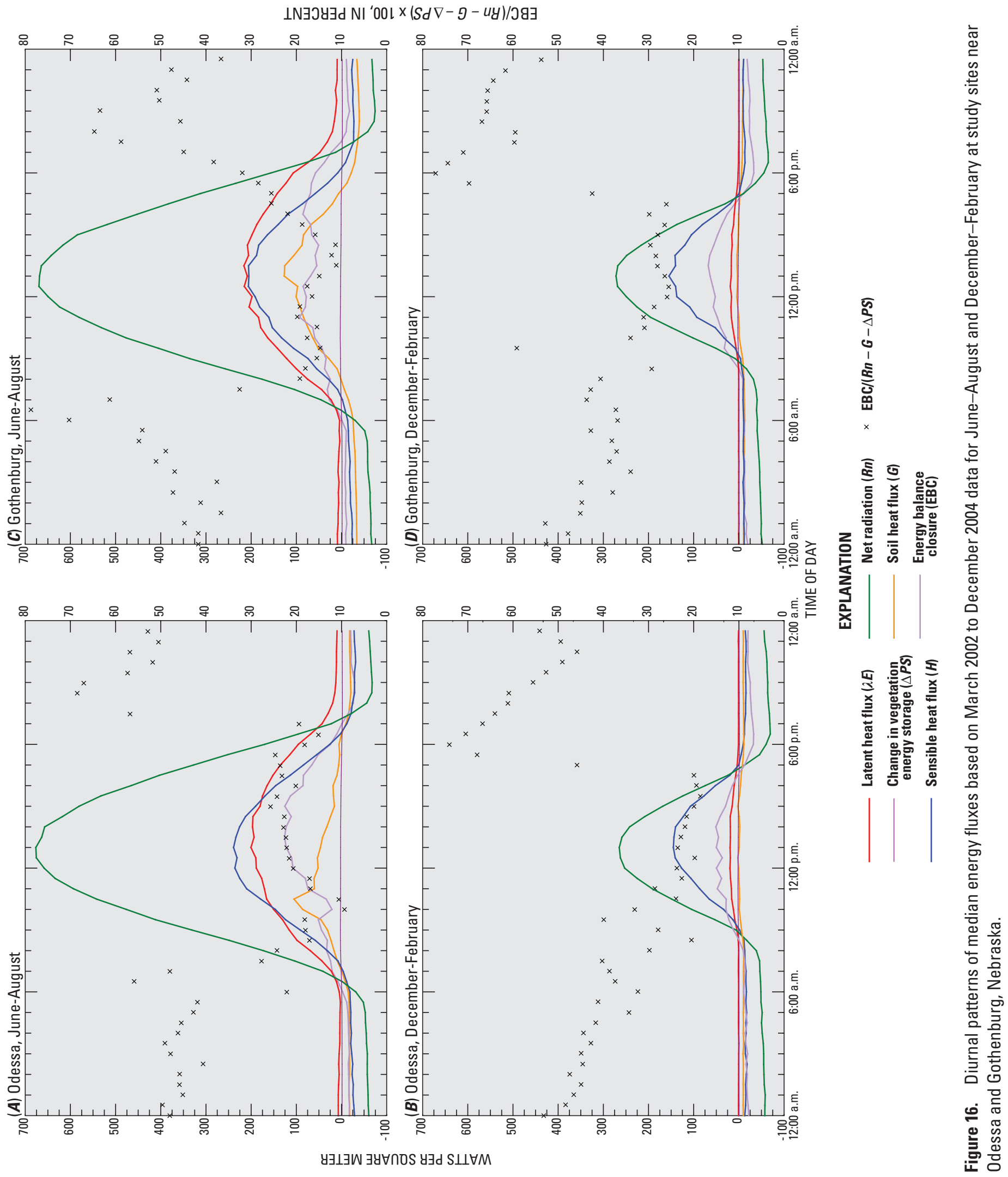
values peaked in the early afternoon and the shape of the diurnal cycle was approximately similar to that of $\lambda E$ and $H$.

During summer, all median nighttime-energy fluxes but $\lambda E$ were negative (fig. 16A). Median values of $\lambda E$ declined from about $20 \mathrm{~W} / \mathrm{m}^{2}$ at 8:00 p.m. to about $4 \mathrm{~W} / \mathrm{m}^{2}$ at $6: 00$ a.m., but were always greater than zero. Thus, a small latent heat flux occurred at night during the summer. During winter, nighttime mean $\lambda E$ values generally were less than $1 \mathrm{~W} / \mathrm{m}^{2}$.

For 30-minute periods during the diurnal cycle, the smallest median $\mathrm{EBC} /(R n-G-\Delta P S)$ imbalances, usually less than 20 percent, occurred between 8:00 a.m. and 6:00 p.m. during the summer when the greatest energy fluxes and ET occurred (fig. $16 A, C$ ). At both sites, approximately 70 percent of the total $\lambda E$ during the study period occurred under daytime conditions during the growing season. $\mathrm{EBC} /(R n-G-\triangle P S)$ imbalances typically were larger for nighttime and transitional periods from daytime to nighttime conditions when conditions were changing relatively quickly (fig. 16); however, $\lambda E$ was relatively small under these nighttime and transition conditions. Thus, the measurements of energy fluxes were of greatest accuracy for periods when most of the energy fluxes occurred.

\section{Water Balances}

The measured components of the water balance (precipitation, ET, soil-water and ground-water storage, eq. 12) were evaluated to determine that net ground-water recharge occurred during the study at both sites. Precipitation and ET were the dominant components of the annual water balance, with changes in soil-water and ground-water storage being comparatively minor terms (table 7). Annual precipitation fluctuated more than annual ET (fig. 17A). Annual precipitation varied by about 35 percent from the 4-year mean whereas annual $E T$ varied by about 7 percent from the 4-year mean. Because precipitation less ET $\left(P_{\text {excess }}\right)$ largely determined the calculated net ground-water inflow or outflow, the presence or absence of aquifer recharge was sensitive, though not strictly dependent, on these precipitation fluctuations at each study site (fig. 17B).

Positive values of $\left(G W_{\text {in }}-G W_{\text {out }}\right)$ from equation 12 indicated that net ground-water inflow to the riparian forests was necessary to satisfy the water balance (ground-water discharge occurs in the riparian forest). Negative values of $\left(G W_{\text {in }}-G W_{\text {out }}\right)$ indicated that net ground-water outflow from the riparian forests was necessary to satisfy the water balance (ground-water recharge occurs in the riparian forest).

Net ground-water discharge from the riparian forest to the atmosphere occurred at both sites in 2002 (fig. 17B), when annual ET exceeded annual precipitation. Because $P_{\text {excess }}$ was more negative at Gothenburg in 2002, ground-water discharge was larger at Gothenburg than at Odessa. Net ground-water recharge occurred at both sites in 2003, 2004, and 2005 (fig. $17 B)$. At the Odessa site, annual net ground-water flux was almost linearly related to $P_{\text {excess }}$, with increases in net ground- water recharge as $P_{\text {excess }}$ increased. At Gothenburg, the relation between annual net ground-water flux and $P_{\text {excess }}$ was less well defined, reflecting the greater variability in annual changes in Gothenburg soil-water storage.

The 4-year-average values of $\left(G W_{\text {in }}-G W_{\text {out }}\right)$ were negative, indicating that the study sites were a net source of ground-water recharge during the study period (table 7; fig. $17 B)$. The 4-year-average net ground-water recharge at Odessa (76 mm/yr) was larger than that at Gothenburg $(13 \mathrm{~mm} / \mathrm{yr})$, consistent with larger $P_{\text {excess }}$ values at Odessa than Gothenburg.

After adjusting the annual water-balance calculations to account for canopy interception (eq. 13), evaporation of intercepted water $\left(E_{I}\right)$ accounted for an average of about 14 percent of total ET at Odessa and 9 percent at Gothenburg (table 7). The fractions of ET attributable to $E_{I}$ at the study sites are within the lower range of values determined for other forests (Grelle and others, 1997; Savenije, 2004), most likely because of the relatively low tree density and windy, semi-arid climate.

There are several sources of uncertainty in the annual water-balance results. As discussed earlier, annual precipitation probably was measured with a precision of about 5 percent and $E T$ probably was estimated with an uncertainty of 10 percent. Uncertainties in $\Delta G W$ primarily reflect uncertainties in the estimate of specific yield. The porosity is an upper limit of the specific yield, but generally has been determined to be a reasonable estimate for sandy sediments (Loheide and others, 2005). When the specific yield was reduced to 50 percent of the porosity (Meyboom, 1964), values of $\left(G W_{i n}-\right.$ $\left.G W_{\text {out }}\right)$ increased by an average of 9 percent at Odessa and 19 percent at Gothenburg. Thus, if specific yield actually is less than porosity, the net ground-water discharge could be larger and net ground-water recharge smaller than the values reported in table 7. Uncertainties in determining $\Delta S W$ primarily reflect uncertainties in the accuracy of soil-water content measurements, areal weights assigned to UZ1 and UZ2 profiles, and the degree to which spatial heterogeneity in soil-water content can be represented by two profiles of 7 probes each. These uncertainties are difficult to quantify but are not expected to fundamentally change the results of the water-balance calculations, as changes in soil-water storage were a small term in the calculations.

The water-balance results can be used to estimate upper and lower boundaries on the values of GWET (ET derived from ground water rather than precipitation sources). The upper boundary of possible values of GWET is $E T_{G W S W}$ (eq. 14). $E T_{G W S W}$ ranged from 448 to $504 \mathrm{~mm} / \mathrm{yr}$ with an average value of $473 \mathrm{~mm} / \mathrm{yr}$ at the Odessa site, or roughly 86 percent of total $E T$ (table 7). $E T_{G W S W}$ ranged from 480 to $559 \mathrm{~mm} / \mathrm{yr}$ with an average value of $520 \mathrm{~mm} / \mathrm{yr}$ at the Gothenburg site, or roughly 90 percent of total ET. The lower boundary of possible values of GWET, annually, is $\left(G W_{\text {in }}-G W_{\text {out }}\right)$ or the net ground-water inflow into the riparian area to satisfy the annual water balance. The negative values of $\left(G W_{\text {in }}-G W_{\text {out }}\right)$ indicate that the lower bound of GWET was effectively zero during 2003-2005. During the driest study year, 2002, $\left(G W_{\text {in }}-G W_{\text {out }}\right)$ was $53 \mathrm{~mm}$ (10 percent of total ET of $514 \mathrm{~mm}$ ) at Odessa and 
Table 7. Annual water-balance results for riparian forest study sites near Odessa and Gothenburg, Nebraska, April 1, 2002, to March 31, 2006.

$[E T$, total evapotranspiration; $P$, precipitation; $P$-ET, precipitation less total evapotranspiration; $\Delta S W$, change in soil-water storage; $\Delta G W$, change in groundwater storage; $G W_{\text {in }}-\mathrm{GW}_{\text {out }}$, difference between ground-water inflow and ground-water outflow to representative control volume; $T F$, canopy throughfall; $I$, canopy interception, computed from $P-T F$ (equation 13); $E_{l}$, evaporation of canopy interception, assumed to be of equal magnitude as $I ; E T_{G W S W}$, evapotranspiration from ground- and soil-water sources, computed from $E T-E_{I}$ (equation 14 ); $E_{I} / E T$, evaporation of canopy interception as a percentage of total evapotranspiration; $\mathrm{mm}$, millimeters]

\begin{tabular}{|c|c|c|c|c|c|c|c|c|c|c|c|}
\hline \multirow[b]{2}{*}{ Year } & \multicolumn{6}{|c|}{$\begin{array}{l}\text { Water balance neglecting canopy interception (equation 12) } \\
\qquad G W_{\text {in }}-\mathbf{G} W_{\text {out }}=E T-P+\Delta S W+\Delta G W\end{array}$} & \multicolumn{5}{|c|}{$\begin{array}{l}\text { Water balance including canopy interception } \\
\text { (equation 15) } \\
\qquad G W_{\text {in }}-G W_{\text {out }}=E T_{G W S W}-T F+\Delta S W+\Delta G W\end{array}$} \\
\hline & $\begin{array}{c}\text { ET } \\
(\mathrm{mm})\end{array}$ & $\begin{array}{c}P \\
(\mathrm{~mm})\end{array}$ & $\begin{array}{l}P-E T \\
(\mathrm{~mm})\end{array}$ & $\begin{array}{l}\Delta S W \\
(\mathrm{~mm})\end{array}$ & $\begin{array}{l}\Delta G W \\
(\mathrm{~mm})\end{array}$ & $\begin{array}{l}G W_{\text {in }}-G W_{\text {out }} \\
\quad(\mathrm{mm})\end{array}$ & $\begin{array}{c}T F \\
(\mathrm{~mm})\end{array}$ & $\begin{array}{c}I \\
(\mathrm{~mm})\end{array}$ & $\begin{array}{c}E_{l} \\
(\mathrm{~mm})\end{array}$ & $\begin{array}{l}E T_{g w s w} \\
(\mathrm{~mm})\end{array}$ & $\begin{array}{c}E / E T \\
\text { (percent) }\end{array}$ \\
\hline \multicolumn{12}{|c|}{ Odessa } \\
\hline 2002 & 514 & 429 & -85 & -18 & -14 & 53 & 377 & 51 & 51 & 463 & 10 \\
\hline 2003 & 524 & 633 & 109 & 5 & -28 & -132 & 557 & 76 & 76 & 448 & 14 \\
\hline 2004 & 580 & 844 & 264 & 40 & 60 & -164 & 743 & 101 & 101 & 478 & 17 \\
\hline 2005 & 586 & 679 & 94 & -8 & 39 & -63 & 598 & 82 & 82 & 504 & 14 \\
\hline $\begin{array}{l}\text { 4-year } \\
\text { average }\end{array}$ & 551 & 646 & 95 & 5 & 14 & -76 & 569 & 78 & 78 & 473 & 14 \\
\hline \multicolumn{12}{|c|}{ Gothenburg } \\
\hline 2002 & 585 & 359 & -226 & -61 & -4 & 161 & 326 & 33 & 33 & 552 & 6 \\
\hline 2003 & 616 & 610 & -6 & -54 & -2 & -50 & 554 & 57 & 57 & 559 & 9 \\
\hline 2004 & 563 & 791 & 227 & 147 & 60 & -21 & 717 & 73 & 73 & 490 & 13 \\
\hline 2005 & 535 & 589 & 55 & -52 & -34 & -141 & 535 & 55 & 55 & 480 & 10 \\
\hline $\begin{array}{l}\text { 4-year } \\
\text { average }\end{array}$ & 575 & 587 & 13 & -5 & 5 & -13 & 533 & 54 & 54 & 520 & 9 \\
\hline
\end{tabular}

$161 \mathrm{~mm}$ (28 percent of total ET of $585 \mathrm{~mm}$ ) at Gothenburg. Thus, on an annual basis, ground water becomes an important, albeit minor, water source for satisfying riparian-forest ET demands during dry years, with the remainder of the ET demand satisfied by available precipitation. During wet years, all of the ET demand could be satisfied by available precipitation. These bounding limits do not imply that ground water is not an important source of water to riparian vegetationespecially to phreatophytes_-during increased ET periods in the summer. On summer days of increased ET and no precipitation, GWET demand could be considerable; however, the calculations imply that annually, ground-water use by riparian forests is likely to be balanced by periods of recharge from excess precipitation at other times of the year. In more arid settings, studies have determined that ground water may supply a large fraction of the water used for ET by riparian vegetation (Williams and others, 2006); however, along the Platte River in Nebraska, precipitation was great enough that annually, most or all of the ET demand can be satisfied by available precipitation.

\section{Simulation of Evapotranspiration Rates}

Crop coefficients were developed from the measured data that could be used to simulate $E T$ rates in other riparian forests along the Platte River. Daily mean $k_{c}$ values developed from the study-period data-calculated by dividing measured ET by reference ET from nearby weather stations-indicated considerable variation, reflecting short-term variations in sitespecific conditions. As these conditions would not necessarily occur at other sites or in subsequent years, mean $k_{c}$ values for 15-day and monthly periods were computed to produce a less erratic $k_{c}$ distribution (table 8; fig. 18). By rearranging equation 16 , the 15 -day and monthly $k_{c}$ values were multiplied by $E_{o}$ to simulate daily $E T\left(E T_{s i m}\right) . E T_{\text {sim }}$ was compared with measured $E T$ to evaluate the model performance.

The 15-day and monthly mean $k_{c}$ values (table 8 ; fig. 18) ranged from 0.07 to 0.51 , followed the same seasonal patterns, and generally were similar at Odessa and Gothenburg. The primary differences between the two sites were that $k_{c}$ values were greater at Odessa during parts of May, and greater at Gothenburg during August and parts of July and September. The summer-peak $k_{c}$ values occurred in June at Odessa as compared to August at Gothenburg. Although unexplained, $k_{c}$ values were greater in early February than in January or March 

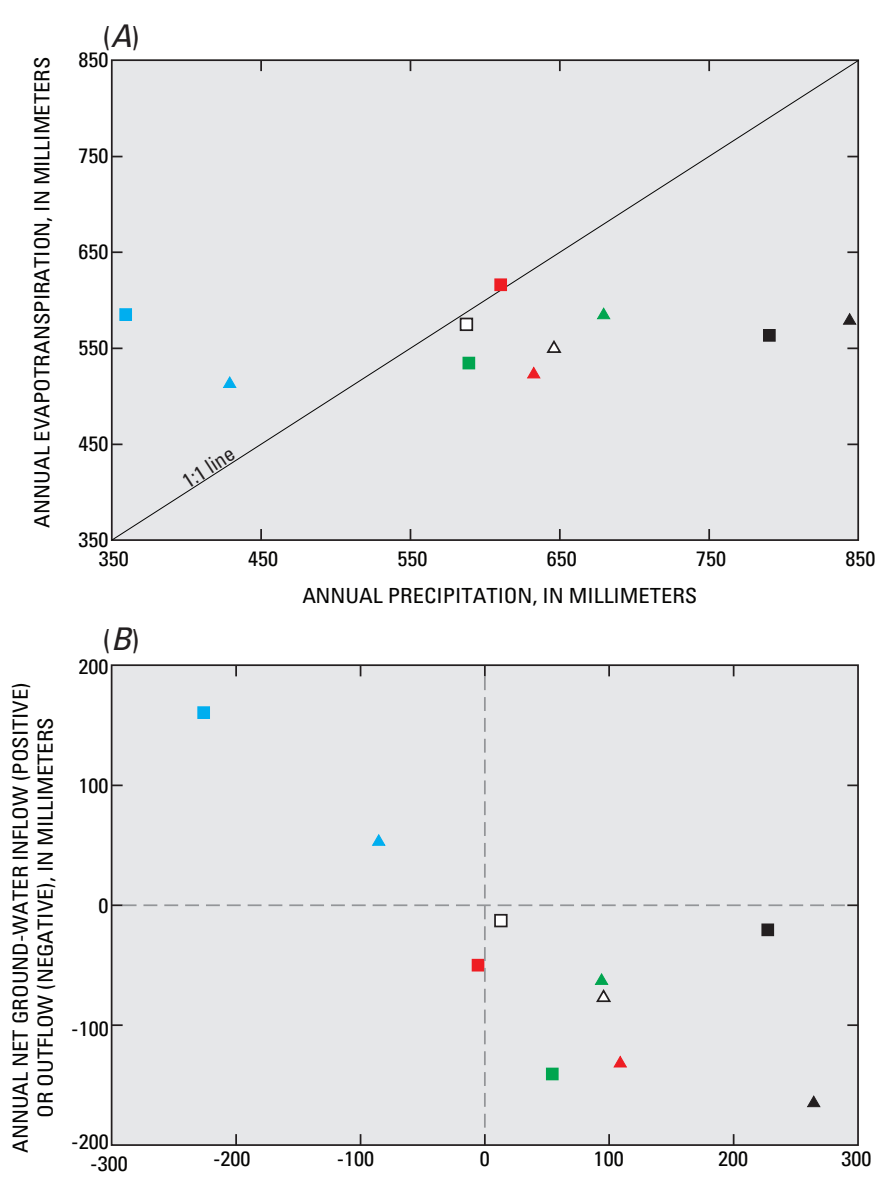

ANNUAL PRECIPITATION MINUS EVAPOTRANSPIRATION, $P_{\text {excess }}$ IN MILLIMETERS

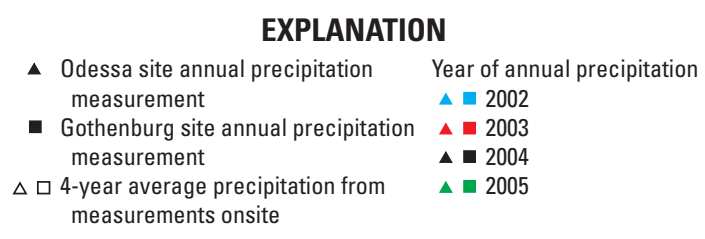

Figure 17. Relations among annual water-balance terms for study sites near Odessa and Gothenburg, Nebraska, 2002-06.

at both sites. Otherwise, the $k_{c}$ values generally followed a seasonal curve from a winter minimum to a summer maximum.

For annual simulation periods or longer, the simple cropcoefficient model using either monthly or 15-day average $k_{c}$ reasonably simulated measured $E T$. For the Odessa site, deviations of $E T_{\text {sim }}$ from annual $E T$ ranged from -11.7 percent to +7.5 percent with a 4-year average of -3.5 percent for monthly coefficients and -3.4 percent for 15-day coefficients (table 9). For the Gothenburg site, annual deviations of $E T_{\text {sim }}$ from $E T$ ranged from -6.7 percent to +9.0 percent, with a 4 -year average of +1.8 percent for monthly coefficients and +1.6 percent for 15-day coefficients. Annually, deviations of $E T_{\text {sim }}$ from $E T$ were similar whether modeled using the 15-day average or monthly mean $k_{c}$ values.

Generally, the simple-crop-coefficient models underpredicted $E T$ for days of increased $E T$ and overpredicted $E T$ for days of low $E T$. As a result, $E T_{\text {sim }}$ was less variable than measured ET. For annual or longer periods, these short-term discrepancies balanced out, and $E T_{\text {sim }}$ using simple crop-coefficient models was within 12 percent of measured ET (table 9).

The $k_{c}$ models were further tested by comparing the SLR relations between measured daily $E T$ and $E T_{\text {sim }}$ determined for the 2002 to 2004 calibration period with those determined for the 2005 validation period. The pattern of reduced variability in daily $E T_{\text {sim }}$ as compared to measured $E T$ occurred for both 2002 to 2004, and 2005. Coefficients of determination between daily $E T_{\text {sim }}$ and measured $E T$ were greater for 2005 than for 2002 to 2004 . These results indicate that the $k_{c}$ models approximated measured $E T$ for a nearly normal period other than the calibration period, but that the $k_{c}$ models are likely to be more accurate in predicting $E T$ for monthly or annual periods, rather than as daily values.

\section{Environmental Factors Affecting Evapotranspiration Rates}

The simple crop-coefficient models approximated measured $E T$ at the riparian-forest sites, particularly for longer periods, but these simple models do not contribute to an understanding of the environmental factors that affect ET rates. SLR and MLR models of the relations between explanatory variables and $E T$ were developed to better understand the factors affecting ET rates in riparian forests.

Numerous studies investigating the factors that affect ET rates commonly have determined $E T$ rates to be strongly dependent on vapor-pressure deficit $(D)$ (Monteith, 1965; Mackay and others, 2007), solar radiation $\left(R_{s}\right)$ (Schulz and Jarvis, 2004), air temperature $\left(T_{a}\right)$ (Rosenberry and others, 2004), moisture availability (Williams and others, 2006), and measures of vegetation state such as LAI (Kristensen, 1974; Ewers and others, 2002). For this study, daily values of $E T$ were compared to daily averages of environmental factors $D$, $R_{s}, T_{a}$, moisture availability, and LAI.

$D, R_{s}$, and $T_{a}$ followed seasonal patterns with the greatest values during the summer and the lowest values during the winter. $E T$ rates are expected to increase as $D$ increases because $D$ is considered a proxy for the vapor-pressure difference between the inside of leaves and the atmosphere. Water availability does not necessarily follow seasonal patterns because of the variability of precipitation and ground-water levels, and thus will not always be strongly correlated with $E T$. Moisture availability was evaluated using several variables, including the average soil-water content in the upper $8 \mathrm{~cm}$ (from the area-weighted average of soil-water contents at UZ1 and UZ2); the daily change in soil-water content; the deficit in the soil-water content below the 4-year median (assigned a value of zero for soil-water contents above or equal to the median); the depth to the ground-water table (DTW) in the well closest to the tower site; the daily change in ground-water level; the depth to ground water below the 4-year median DTW (assigned a value of zero for DTWs less than the median DTW); and the daily precipitation. Daily interpolated LAI was 
Table 8. Average crop coefficients for riparian forest study sites near Odessa and Gothenburg, Nebraska, $2002-05$.

$\left[E T\right.$, measured evapotranspiration at riparian study site; $E_{\mathrm{o}}$, evapotranspiration for well-watered alfalfa reference crop; $k_{c}$, crop coefficient determined as $E T / E T_{\mathrm{o}} ; \mathrm{mm} / \mathrm{d}$, millimeters per day]

\begin{tabular}{|c|c|c|c|c|c|c|}
\hline \multirow[b]{2}{*}{$\begin{array}{c}\text { Evaluation } \\
\text { Period }\end{array}$} & \multicolumn{3}{|c|}{ Odessa } & \multicolumn{3}{|c|}{ Gothenburg } \\
\hline & $\begin{array}{c}\text { Mean } \\
E T \\
(\mathrm{~mm} / \mathrm{d})\end{array}$ & $\begin{array}{c}\text { Mean } \\
E_{o}^{1} \\
(\mathrm{~mm} / \mathrm{d})\end{array}$ & $\begin{array}{c}\text { Mean } \\
k_{c} \\
\text { (dimensionless) }\end{array}$ & $\begin{array}{c}\text { Mean } \\
\text { ET } \\
(\mathrm{mm} / \mathrm{d})\end{array}$ & $\begin{array}{c}\text { Mean } \\
E_{o}^{1} \\
(\mathrm{~mm} / \mathrm{d})\end{array}$ & $\begin{array}{c}\text { Mean } \\
\boldsymbol{k}_{c} \\
\text { (dimensionless) }\end{array}$ \\
\hline & \multicolumn{6}{|c|}{ Values averaged for monthly evaluation periods } \\
\hline January & 0.27 & 1.41 & 0.19 & 0.23 & 1.61 & 0.14 \\
\hline February & .47 & 1.87 & .25 & .43 & 2.19 & .20 \\
\hline March & .77 & 4.27 & .18 & .85 & 4.50 & .19 \\
\hline April & 1.28 & 5.91 & .22 & 1.54 & 5.97 & .26 \\
\hline May & 2.51 & 6.60 & .38 & 2.21 & 6.91 & .32 \\
\hline June & 3.22 & 7.66 & .42 & 3.04 & 7.42 & .41 \\
\hline July & 2.99 & 7.79 & .38 & 3.43 & 7.83 & .44 \\
\hline August & 2.32 & 6.95 & .33 & 3.18 & 6.92 & .46 \\
\hline September & 2.10 & 6.34 & .33 & 2.61 & 6.45 & .40 \\
\hline October & 1.06 & 3.59 & .29 & 1.07 & 3.82 & .28 \\
\hline November & .45 & 2.45 & .18 & .49 & 2.49 & .20 \\
\hline December & .22 & 2.01 & .11 & .19 & 2.08 & .09 \\
\hline \multicolumn{7}{|c|}{ Values averaged for 15-day evaluation periods (Beginning date of period reported) } \\
\hline January 1 & .23 & 1.52 & .15 & .22 & 1.60 & .14 \\
\hline January 16 & .30 & 1.32 & .23 & .23 & 1.61 & .14 \\
\hline January 31 & .46 & 1.58 & .29 & .44 & 1.83 & .24 \\
\hline February 15 & .47 & 2.08 & .23 & .41 & 2.47 & .17 \\
\hline March 1 & .63 & 4.29 & .15 & .70 & 4.60 & .15 \\
\hline March 16 & .91 & 4.38 & .21 & 1.00 & 4.55 & .22 \\
\hline March 31 & 1.00 & 6.16 & .16 & 1.33 & 6.26 & .21 \\
\hline April 15 & 1.56 & 5.66 & .27 & 1.74 & 5.68 & .31 \\
\hline April 30 & 2.05 & 6.34 & .32 & 2.06 & 6.81 & .30 \\
\hline May 15 & 2.90 & 6.72 & .43 & 2.26 & 6.86 & .33 \\
\hline May 30 & 3.21 & 8.16 & .39 & 3.28 & 8.04 & .41 \\
\hline June 14 & 3.26 & 7.16 & .45 & 2.86 & 6.88 & .42 \\
\hline June 29 & 3.24 & 7.80 & .42 & 3.06 & 7.65 & .40 \\
\hline July 14 & 2.73 & 7.72 & .35 & 3.55 & 7.94 & .45 \\
\hline July 29 & 2.40 & 7.27 & .33 & 3.12 & 7.29 & .43 \\
\hline August 13 & 2.41 & 6.92 & .35 & 3.47 & 6.87 & .51 \\
\hline August 28 & 2.32 & 7.10 & .33 & 3.24 & 7.17 & .45 \\
\hline September 12 & 1.98 & 6.04 & .33 & 2.31 & 6.18 & .37 \\
\hline September 27 & 1.49 & 4.02 & .37 & 1.54 & 4.25 & .36 \\
\hline October 12 & .82 & 3.39 & .24 & .77 & 3.58 & .21 \\
\hline October 27 & .59 & 2.58 & .23 & .61 & 2.75 & .22 \\
\hline November 11 & .39 & 2.50 & .16 & .46 & 2.48 & .18 \\
\hline November 26 & .30 & 1.82 & .16 & .28 & 1.91 & .15 \\
\hline December 11 & .21 & 2.12 & .10 & .16 & 2.15 & .07 \\
\hline
\end{tabular}

${ }^{1} E_{\mathrm{o}}$ values, calculated using a modified Penman-evapotranspiration method, were obtained from High Plains Regional Climate Center (2006). Data from the Kearney station were used for the Odessa site and data from the Gothenburg station were used for the Gothenburg site. 


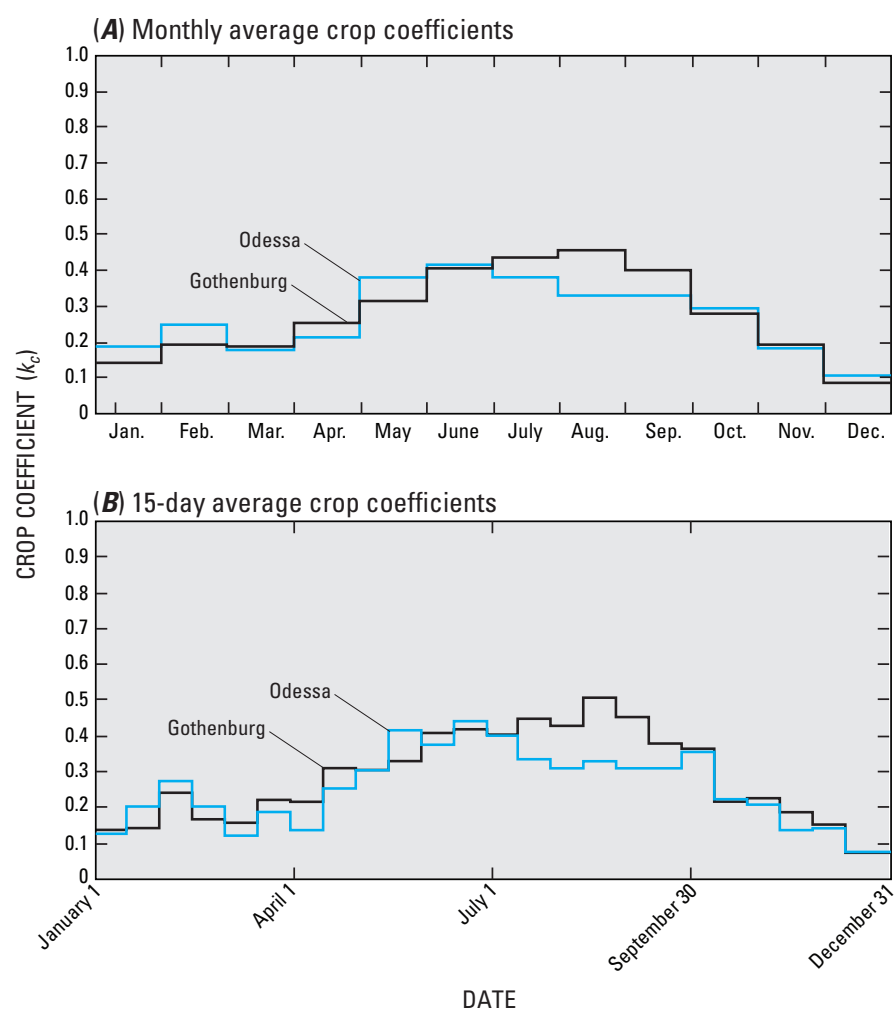

Figure 18. Average crop coefficients for riparian forests at study sites near Odessa and Gothenburg, Nebraska, 2002-05. only weakly $\left(0.10<\mathrm{R}^{2}<0.30\right)$ to all of the predefined indicators of moisture availability.

By separating the daily data into two groups according to the presence or lack of precipitation, the resulting SLR models indicated that $E T$ was larger on days with precipitation than days without precipitation (fig. 19). SLR relations of $E T$ with $D, R_{s}^{2}$, and $T_{a}^{2}$ all had similar slopes for both groups, but the intercepts of the SLR equations always were greater for days with precipitation than days without precipitation. $D, R_{s}^{2}$, $T_{a}^{2}$, and LAI using the SLR models had better fits (as evaluated by $\mathrm{R}^{2}$ values and residual standard errors) of $E T$ for days without precipitation than days with precipitation (table 10). SLR goodness-of-fit statistics ( $\mathrm{R}^{2}$, RSE) also were better for days without precipitation than for models fit using the entire data set. These results indicate that $E T$ was more strongly controlled by atmospheric and vegetation conditions on days without precipitation than days with precipitation, when the evaporation of wet surfaces affects ET rates. Thus, although the selected moisture-availability indicators were not directly related to ET rates, the relation of $E T$ to environmental factors was different on days with precipitation-when additional moisture availability resulted in ET that was probably limited only by energy-balance conditions - than on dry days when ET may have been water-limited. These comparisons indicated that to understand the factors controlling ET rates, it was necessary to consider different relations for days with and without precipitation. used as an indicator of vegetation state. Because LAI data were available only for 2002-04, average LAI values from those years were used to estimate LAI in 2005.

\section{Simple Linear Regressions}

Initial plots of daily average $R_{s}$ and $T_{a}$ against daily $E T$ indicated that these variables were nonlinearly related to $E T$. Quadratic transformations of $R_{s}$ and $T_{a}$ data improved the linearity with $E T$; therefore, SLRs of $E T$ as a function of the transformed variables $R_{s}^{2}$ and $T_{a}^{2}$ were performed (table 10; fig. 19), and these transformed variables also were used in the MLR models.

At both sites, ET increased with increasing $D, R_{s}^{2}, T_{a}^{2}$, and LAI, as identified by nonzero slope coefficients $(\mathrm{p}<$ 0.001 ). With $\mathrm{R}^{2}$ ranging from 0.50 to 0.64 for regressions that used data from every day in the study period (table 10; fig. 19), the relation of ET to these variables seemed reasonably well fit by SLR. Daily ET was either unrelated $\left(R^{2}<0.10\right)$ or was related
Table 9. Comparison of evapotranspiration simulated with 15-day average and monthly crop coefficient models to actual evapotranspiration at riparian forest study sites near Odessa and Gothenburg, Nebraska.

[ET, evapotranspiration; mm, millimeters; $\mathrm{k}_{\mathrm{c}}$, crop coefficient; \%, percent]

\begin{tabular}{|c|c|c|c|c|c|}
\hline & \multicolumn{4}{|c|}{ Study year ${ }^{1}$} & \multirow{2}{*}{$\begin{array}{l}\text { 4-year } \\
\text { mean }\end{array}$} \\
\hline & 2002 & 2003 & 2004 & 2005 & \\
\hline & \multicolumn{5}{|c|}{ Odessa } \\
\hline Measured annual ET (mm) & 514 & 524 & 580 & 586 & 551 \\
\hline \multicolumn{6}{|c|}{ Simulated annual ET compute from: } \\
\hline Monthly $\mathrm{k}_{\mathrm{c}}(\mathrm{mm})$ & 551 & 513 & 513 & 548 & 531 \\
\hline 15-day $\mathrm{k}_{\mathrm{c}}(\mathrm{mm})$ & 553 & 512 & 512 & 551 & 532 \\
\hline \multicolumn{6}{|c|}{ Deviation of simulated from measured ET: } \\
\hline Monthly $\mathrm{k}_{\mathrm{c}}(\%)$ & 7.2 & -2.0 & -11.5 & -6.4 & -3.5 \\
\hline \multirow[t]{2}{*}{15 -day k ${ }_{\mathrm{c}}(\%)$} & 7.5 & -2.3 & -11.7 & -5.9 & -3.4 \\
\hline & \multicolumn{5}{|c|}{ Gothenburg } \\
\hline Measured annual ET (mm) & 585 & 616 & 563 & 535 & 575 \\
\hline \multicolumn{6}{|c|}{ Simulated annual ET computed from: } \\
\hline Monthly $\mathrm{k}_{\mathrm{c}}(\mathrm{mm})$ & 638 & 601 & 526 & 575 & 585 \\
\hline 15-day $\mathrm{k}_{\mathrm{c}}(\mathrm{mm})$ & 637 & 598 & 528 & 573 & 584 \\
\hline \multicolumn{6}{|c|}{ Deviation of simulated from measured ET: } \\
\hline Monthly $\mathrm{k}_{\mathrm{c}}(\%)$ & 9.0 & -2.4 & -6.7 & 7.6 & 1.8 \\
\hline 15 -day k $(\%)$ & 9.0 & -2.9 & -6.3 & 7.2 & 1.6 \\
\hline
\end{tabular}

${ }^{1}$ For this report, study year is from April 1 of the reported year to March 31 of the following year. 


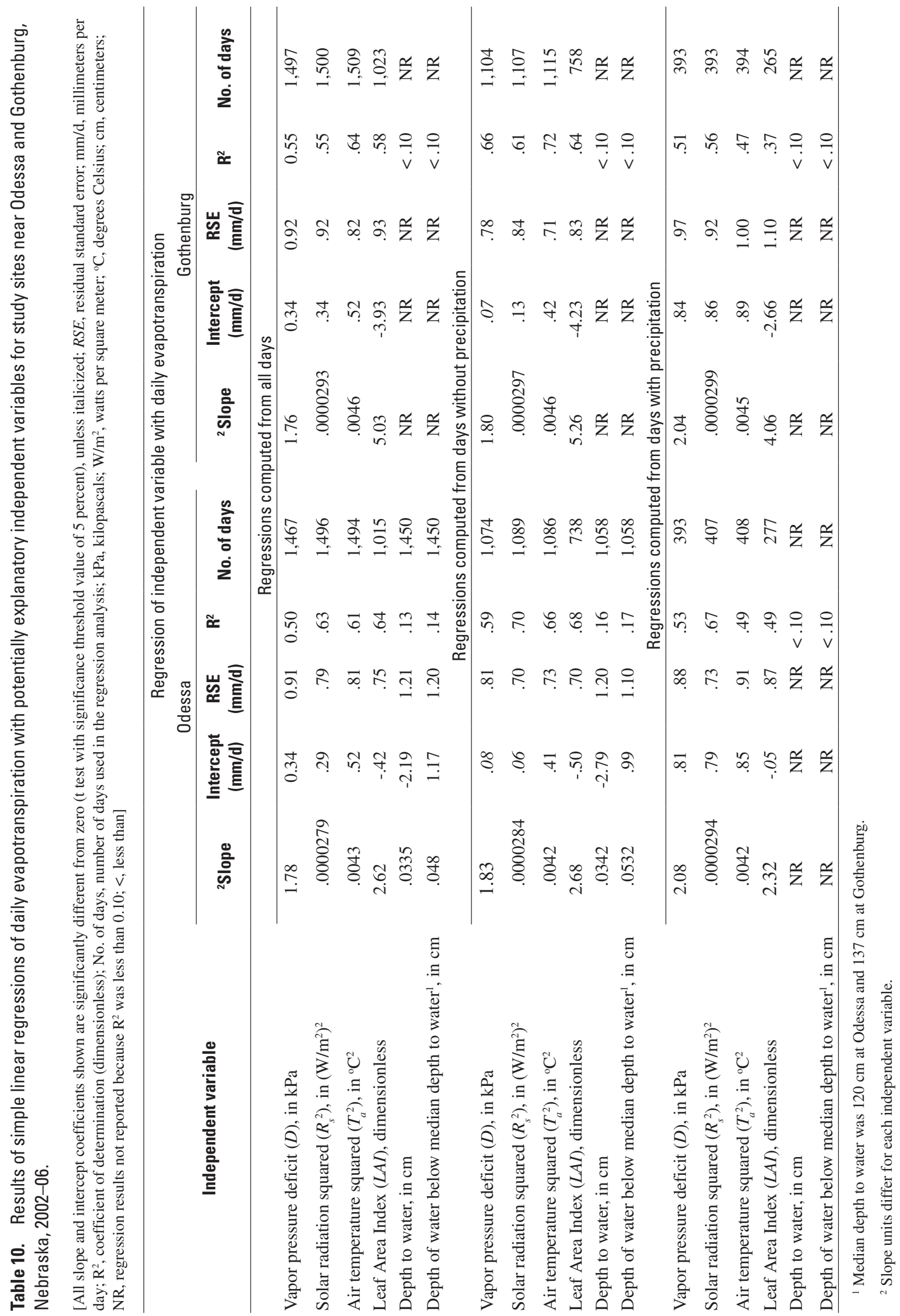




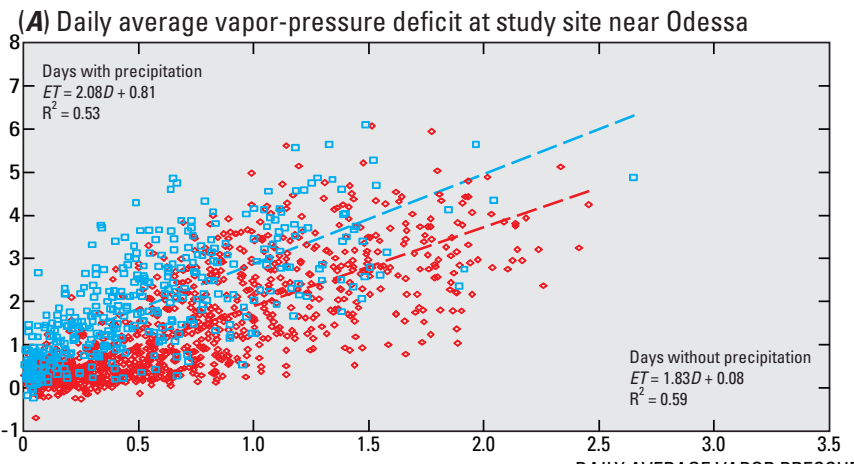

(E) Daily average vapor-pressure deficit at study site near Gothenburg

$(B)$ Daily average solar radiation at study site near Odessa
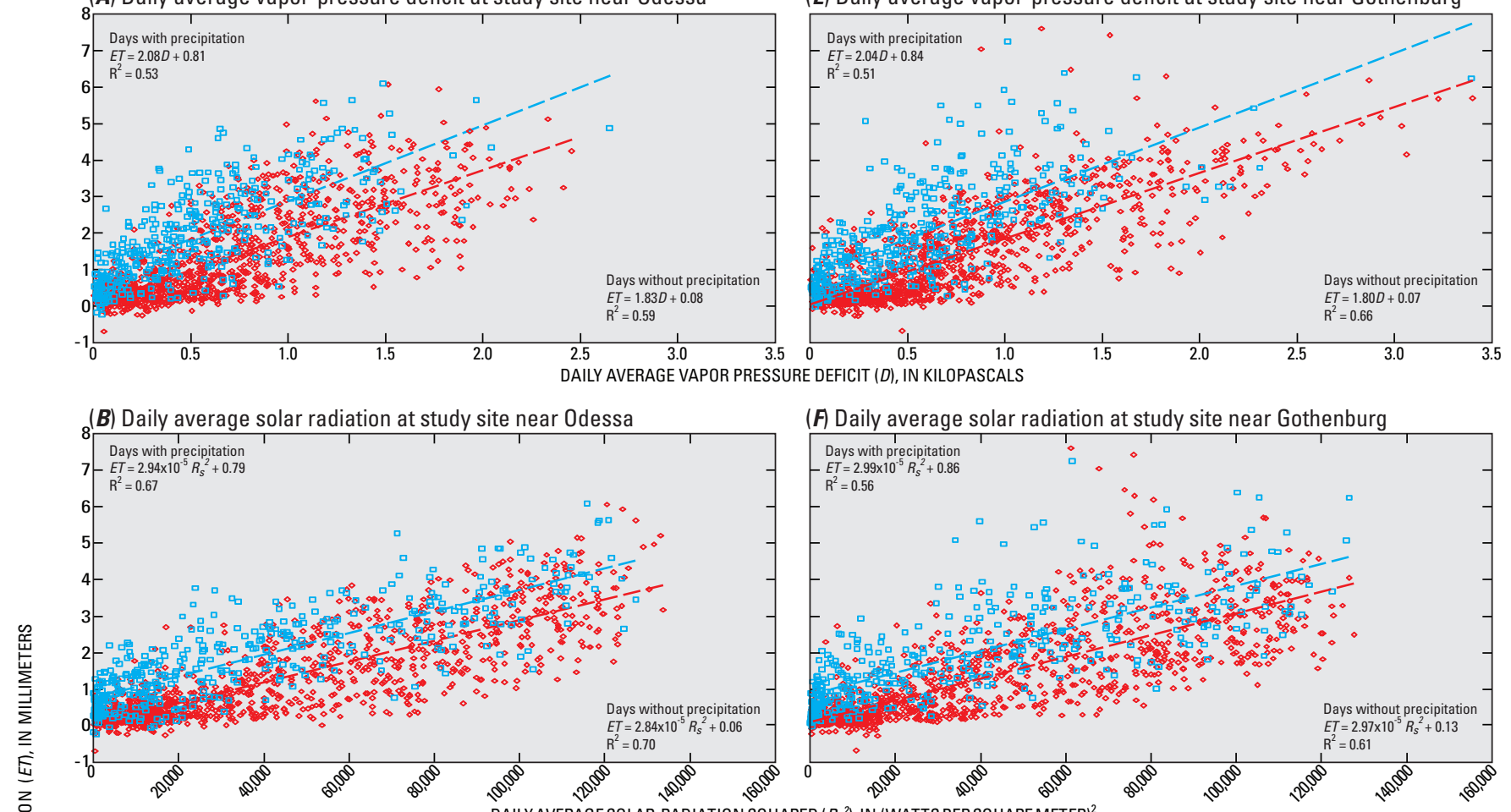

DAILYAVERAGE SOLAR RADIATION SQUARED $\left(R_{s}^{2}\right)$, IN (WATTS PER SQUAREMETER) $)^{2}$

(C) Daily average air temparature at study site near Odessa
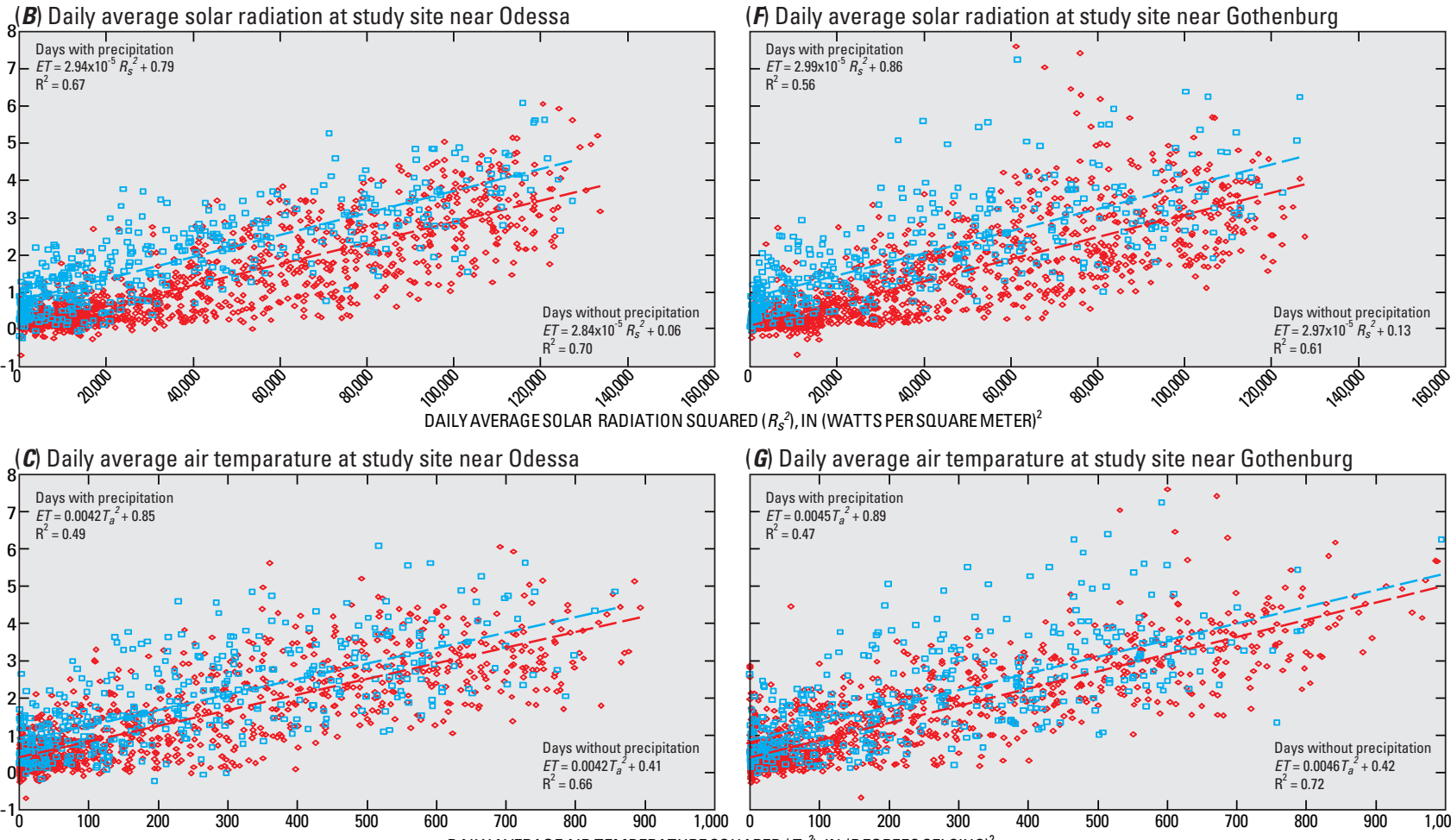

(G) Daily average air temparature at study site near Gothenburg
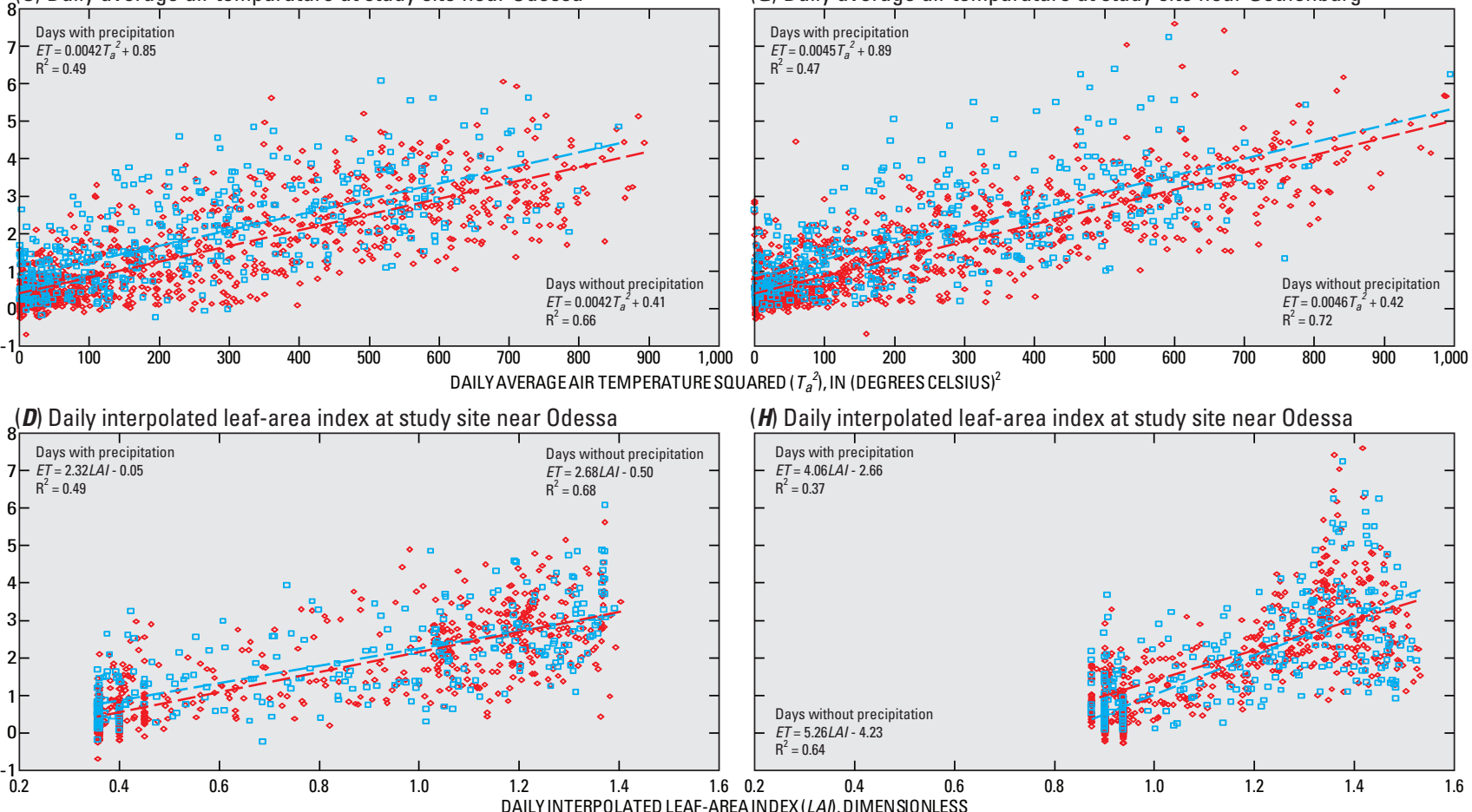

(H) Daily interpolated leaf-area index at study site near Odessa

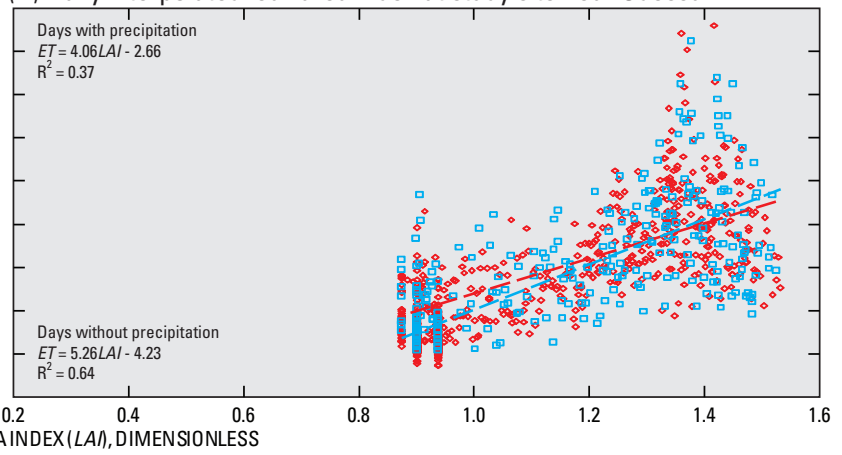

EXPLANATION

Figure 19. Simple linear regressions of daily evapotranspiration rates with vapor-pressure deficit, solar radiation, air temperature, and leaf-area index at study sites near Odessa and Gothenburg, Nebraska, 2002-06. 
Coefficients of determination for SLRs relating ET to $D, R_{s}^{2}$, or $T_{a}^{2}$ varied no more than 16 percent between Odessa and Gothenburg. On days without precipitation, $D, R_{s}^{2}, T_{a}^{2}$, and LAI were all strongly related to $E T$ at both sites $\left(\mathrm{R}^{2}\right.$ ranging from 0.59 to 0.72 ), with Gothenburg having stronger relations to $D$ and $T_{a}^{2}$ and Odessa having stronger relations to $R_{s}^{2}$ and LAI (table 10). For days with precipitation, $D$ and $R_{s}^{2}$ were most strongly related to $E T$ ( $\mathrm{R}^{2}$ ranging from 0.51 to 0.67 ), whereas $T_{a}^{2}$ ( $\mathrm{R}^{2}$ of 0.47 to 0.49 ) and LAI ( $\mathrm{R}^{2}$ of 0.37 to 0.49 ) were less strongly related to ET. Relations of ET to LAI varied between days with and without precipitation and were dissimilar between sites (table 10).

Surprisingly, on days without precipitation, Odessa $E T$ increased weakly as DTW $\left(\mathrm{R}^{2}=0.16\right)$ and depth of water below median DTW $\left(\mathrm{R}^{2}=0.17\right)$ increased. These relations were somewhat counterintuitive because they indicated that ET increased as the water table declined, whereas the opposite was expected. Because the relations are weak, they may be the result of variation in extraneous environmental factors; however, it is possible that this pattern reflects seasonal increases in ET that result in increases in the DTW during the summer.

\section{Multiple Linear Regressions}

Based upon the SLR relations between $E T$ and $D, R_{s}^{2}, T_{a}^{2}$, LAI, and DTW (at Odessa only) for days with and without precipitation, multiple linearregression models of $E T$ as a function of these variables were constructed (table 11). The goals of the MLR analysis were to compare the relative effect that each variable had on $E T$ between sites and to identify the assemblage of variables that most strongly affects $E T$ rates at each site. To allow for direct comparison between sites, initial models were constructed that included $D, R_{s}^{2}, T_{a}^{2}$, and LAI, even if some of those variables were not determined to be significant at the 5-percent significance level. In some cases, a second MLR model was developed that improved on the regression for a given site and precipitation condition by omitting some of those variables or by including DTW.

At Odessa for days without precipitation, two MLR models are listed in table 11. Stepwise MLR procedures identified $D, R_{s}^{2}, T_{a}^{2}$, LAI, and DTW as significant variables for inclusion in the model (model 2). All of the coefficients were significantly different (at the 0.05 significance level) from zero based on partial t-tests (Helsel and Hirsch, 2002), indicating that all of the variables were relevant to explaining $E T$. Positive coefficients for $D, R_{s}^{2}, T_{a}^{2}$, and LAI indicate that $E T$ increases with increases

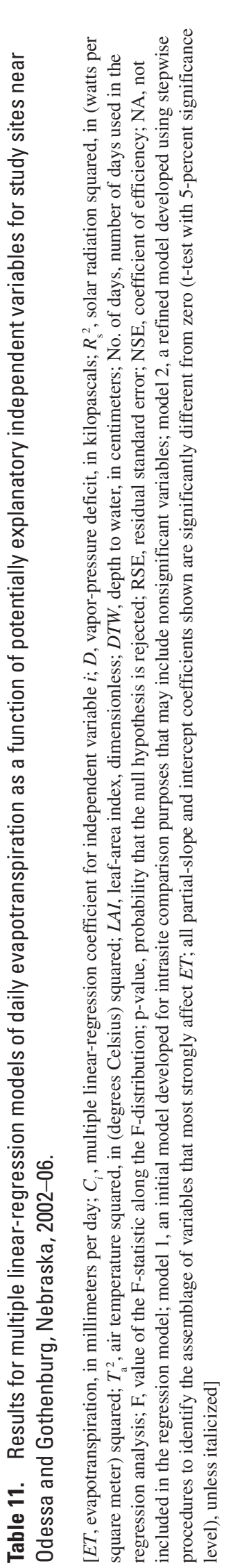


in these variables. Although the SLR relation of ET to DTW was not significant, DTW was significant in the MLR model, and resulted in a lower RSE and greater model efficiency as indicated by NSE values. Unlike the unexpectedly positive SLR relation between ET and DTW (table 10), the coefficient for DTW was negative in the MLR model (table 11), indicating that ET should decline as DTW increases, as would be expected.

At Odessa on days with precipitation, MLR model 1 indicated that the coefficients for $D$ and $T_{a}^{2}$ were not significantly different from zero, indicating that these variables contributed little to the explanatory power of the MLR model. However, stepwise techniques that included a larger potential array of variables for MLR model 2 found ET to be positively correlated to $D, R_{s}^{2}$, and $L A I$, and negatively correlated to $D T W$.

The results from the stepwise MLR models indicated that, regardless of precipitation conditions, Odessa ET increased with increases in $D, R_{s}^{2}$, and $L A I$ and decreases in $D T W$. On days without precipitation, $T_{a}^{2}$, also had a positive relation to $E T$. The uncertainty associated with MLR models, as indicated by RSE, was greater on days with precipitation than on days without precipitation.

At Gothenburg, stepwise MLR models indicated that, regardless of precipitation conditions, ET increased as $D, R_{s}^{2}$, and LAI increased. Similar to the Odessa ET response, $T_{a}^{2}$, had a positive relation to Gothenburg ET on days without precipitation, but not on days with it. The absence of DTW as a controlling variable at Gothenburg probably reflects the previously noted fundamental difference of reduced ground-water fluctuations as compared to Odessa.

The SLR and MLR analyses quantified relations that were either expected or were identified from previous studies. $D$, $R_{s}^{2}$, and LAI were important variables at both sites for days with and without precipitation. The slope coefficient of $D$ was considerably greater at Gothenburg than Odessa, which may be explained by average daily values of $D$ being 7 percent greater at Gothenburg. At both sites, $T_{a}^{2}$ was significantly related to ET on days without precipitation, but did not significantly contribute to explaining ET on days with precipitation. This may indicate that ET was limited by the amount of available energy on days without precipitation and by the amount of available water on days with precipitation.

\section{Evapotranspiration Responses to Seasonal Energy and Hydrologic Fluctuations}

Although ground-water depths were less than $2 \mathrm{~m}$ in the presence of phreatophytic vegetation, measured ET was substantially less than potential ET (calculated using the modifiedPenman method). The limited ET rates are consistent with plant limitations on ET through stomatal regulation in response to seasonal environmental and meteorological factors, as has been described in previous studies (Jarvis, 1976; Roberts, 1999; Ewers and others, 2002). Moreover, $\lambda E$ showed less of a seasonal dependence on $R n$ than $\operatorname{did} H$, indicating that $\lambda E$ is affected by a broader range of environmental factors including $D, L A I$, and water availability - which also affect stomatal regulation of plant water exchange with the atmosphere-than is $H$, which is largely a function of available energy.

With annual values differing by a maximum of 17 percent, and on average by only 4 percent, ET rates generally were similar between the two sites; however, the sites exhibited different patterns with respect to moisture availability and its effect on measured ET and vegetation health. The differences were reflected in seasonal and annual ET responses to water availability at each site. During the dry periods of April through July 2002 and August through September 2003, differences in vegetation characteristics and $D T W$ between the sites appeared to affect relative ET rates between the sites. At the Odessa site, decreases in area-weighted soil-water storage of up to 50 percent and declines in ground-water levels of 0.3 to $0.7 \mathrm{~m}$ (appendix 1) were coincident with wilting of the shrub understory and decreases in $E T$ values as compared to maximum values in June of each year (fig. 13A, B). The summer drought conditions resulted in many understory shrubs at the Odessa site going into dormancy during the growing season in July 2002 and August 2003. This was consistent with decreases, as compared to preceding months, in Odessa $L A I$ in July 2002 and August 2003. Partial dormancy or mortality continued in understory shrubs through the 2004 growing season. During the same period, there were no visually obvious declines in the vigor of overstory cottonwoods. Presumably, the shrubs are relatively shallow rooted and more dependent upon soil-water storage than the deeper-rooted trees.

At the Gothenburg site, with a similar cottonwood-dominated overstory, but an eastern redcedar-dominated understory without shrubs, no wilting of vegetation was evident during the summer drought conditions of 2002 and 2003. Seasonal declines in soil-water storage were similar between the Odessa and Gothenburg sites; however, in contrast to Odessa, ground-water levels declined only about 15 to $25 \mathrm{~cm}$ during May through June in 2002 and 2003 at the Gothenburg site (appendix 2) before water levels rose again following routing of irrigation water through the north channel of the Platte River beginning in July. During increased flows in the north channel, water-level altitudes were higher in the channel (fig. 2; GNC) than in wells GW1 and GW2, a reversal of hydraulichead gradients as compared to the rest of the year. Thus, ground-water level declines were less at Gothenburg than at Odessa. The smaller seasonal declines in ground-water levels and lack of understory shrubs at the Gothenburg site compared to the Odessa site may explain why high ET rates persisted later into the summer at Gothenburg, and why DTW had a significant effect on ET (as identified in the MLR model results) at Odessa but not at Gothenburg. It is likely that the larger summer declines in DTW at Odessa produced greater water stress in relatively shallow-rooted understory shrubs, resulting in moderate declines in ET.

These differences in the ET responses to seasonal drought conditions between the sites also may help to explain why, during years of increased precipitation, ET rates 
increased at Odessa, but decreased at Gothenburg. In addition to the vegetation response, average $D$ was 9 percent greater at Gothenburg than Odessa during 2002 and 2003 but only 5 percent greater in 2004 and 2005. The differences in responses of ET to environmental factors between the sites, although relatively subtle, highlight a greater sensitivity of ET rates to soil-moisture availability at the Odessa site than at Gothenburg.

\section{Transpiration in Individual Plants}

Transpiration was determined for five individual plants from May through August 2004, including two cottonwoods, a dogwood shrub, a green ash, and an eastern redcedar (table 12), using sap-flux techniques. Measured transpiration from a second dogwood was extremely variable and was not reported. Using SLR analysis, individual transpiration rates were compared to the aggregate ET rates measured for the entire footprint. Preliminary comparisons of these individual transpiration rates indicate that larger cottonwoods transpire at a greater rate than the aggregate $E T$ of the riparian-forest community.

Because transpiration rates were measured in only four trees and one shrub for one growing season, these sap-flow analyses represent preliminary reconnaissance results. Much more extensive monitoring is necessary to develop quantitative understanding of transpiration rates for individual tree species in the riparian forests of Nebraska.

The two cottonwoods represented a wide range in tree sizes in the riparian forest. Based on forest surveys of 47 cottonwood trees at the Odessa site, the diameter of cottonwood trees varied from 17.8 to $110 \mathrm{~cm}$, with a median of $39.6 \mathrm{~cm}$, and an average of $45.6 \mathrm{~cm}$. For this distribution, approximately 95 percent of the cottonwoods in the forest were expected to have diameters larger than the 22.9-cm diameter cottonwood, but only 15 percent were expected to be larger than the 61.0-cm diameter cottonwood.

The 61.0-cm diameter cottonwood had the greatest average transpiration rate at $3.8 \mathrm{~mm} / \mathrm{d}$ during May through August 2004 (figs. 20 and 21; table 12). These transpiration rates were greater than the aggregate ET rate measured for the entire riparian-forest footprint, which was an average of $2.8 \mathrm{~mm} / \mathrm{d}$ for the same period. If the measurements are considered to be comparable, the results imply that other vegetation is contributing less to the aggregate ET than large cottonwoods. Conversely, the smaller diameter $(22.9 \mathrm{~cm})$ cottonwood had lower transpiration rates than the green ash, the dogwood shrub, or the aggregate ET rate (table 12). The average transpiration rate of the smaller cottonwood $(1.4 \mathrm{~mm} / \mathrm{d})$ was approximately 50 percent of the aggregate ET rate, and only about 37 percent of the larger cottonwood's rate (table 12). The transpiration rate of the smaller cottonwood was correlated to the aggregate ET rate (fig. 21) but typically was much smaller in magnitude than the aggregate $E T$ rate.

Before leaf out in April 2004, the eastern redcedar had the greatest average transpiration rate $(0.98 \mathrm{~mm} / \mathrm{d}$; table 12$)$ of any of the monitored trees. The transpiration rate for eastern redcedar was similar to the aggregate $E T$ rate of $1.3 \mathrm{~mm} / \mathrm{d}$ measured from the tower during the same period (table 12; fig. 20). In contrast to deciduous trees and shrubs, for which transpiration rates from May through August 2004 were substantially greater than those during April 2004, transpiration rates for the eastern redcedar were slightly greater in April than in May through August (fig. 20; table 12). As a result, eastern redcedar transpiration was less correlated to aggregate ET rates from May through August 2004 (fig. 21E) as compared to that for the cottonwoods.

Table 12. Transpiration rates in individual plants determined from thermal dissipation probes and aggregate evapotranspiration rates determined from eddy-covariance methods for days with complete transpiration data, April to August 2004, riparian forest study site near Odessa, Nebraska.

[ET, evapotranspiration rate; $T$, transpiration rate; $\mathrm{mm} / \mathrm{d}$, millimeters per day; $\%$, percent $]$

\begin{tabular}{|c|c|c|c|c|c|c|c|c|c|c|}
\hline \multirow{3}{*}{$\begin{array}{c}\text { Aggregate } \\
\qquad E T \\
(\mathrm{~mm} / \mathrm{d})\end{array}$} & \multicolumn{10}{|c|}{ Plant species and diameter, in centimeters } \\
\hline & \multicolumn{2}{|c|}{$\begin{array}{c}\text { Eastern } \\
\text { cottonwood, } \\
61.0\end{array}$} & \multicolumn{2}{|c|}{$\begin{array}{c}\text { Eastern } \\
\text { cottonwood, } \\
22.9\end{array}$} & \multicolumn{2}{|c|}{$\begin{array}{c}\text { Roughleaf } \\
\text { dogwood, } \\
2.5\end{array}$} & \multicolumn{2}{|c|}{$\begin{array}{c}\text { Green ash, } \\
11.0\end{array}$} & \multicolumn{2}{|c|}{$\begin{array}{c}\text { Eastern } \\
\text { redcedar, } \\
15.2\end{array}$} \\
\hline & $\begin{array}{c}T \\
(\mathrm{~mm} / \mathrm{d})\end{array}$ & $\begin{array}{l}\text { T/ET } \\
(\%)\end{array}$ & $\begin{array}{c}T \\
(\mathrm{~mm} / \mathrm{d})\end{array}$ & $\begin{array}{l}\text { T/ET } \\
(\%)\end{array}$ & $\begin{array}{c}T \\
(\mathrm{~mm} / \mathrm{d})\end{array}$ & $\begin{array}{l}\text { T/ET } \\
(\%)\end{array}$ & $\begin{array}{c}T \\
(\mathrm{~mm} / \mathrm{d})\end{array}$ & $\begin{array}{l}T / E T \\
(\%)\end{array}$ & $\begin{array}{c}T \\
(\mathrm{~mm} / \mathrm{d})\end{array}$ & $\begin{array}{l}\text { T/ET } \\
(\%) \\
\end{array}$ \\
\hline & & & & Apr & gust & & & & & \\
\hline \multirow[t]{2}{*}{2.52} & 3.06 & 121 & 1.15 & 46 & 1.54 & 61 & 1.70 & 68 & 0.81 & 32 \\
\hline & & & \multicolumn{4}{|c|}{ April (dormant season month) } & & & & \\
\hline \multirow[t]{2}{*}{1.34} & .26 & 19 & .05 & 3 & .04 & 3 & .40 & 30 & .98 & 73 \\
\hline & & & \multicolumn{5}{|c|}{ May-August (growing season months) } & & & \\
\hline 2.82 & 3.78 & 134 & 1.44 & 51 & 1.93 & 68 & 2.04 & 72 & .76 & 27 \\
\hline
\end{tabular}



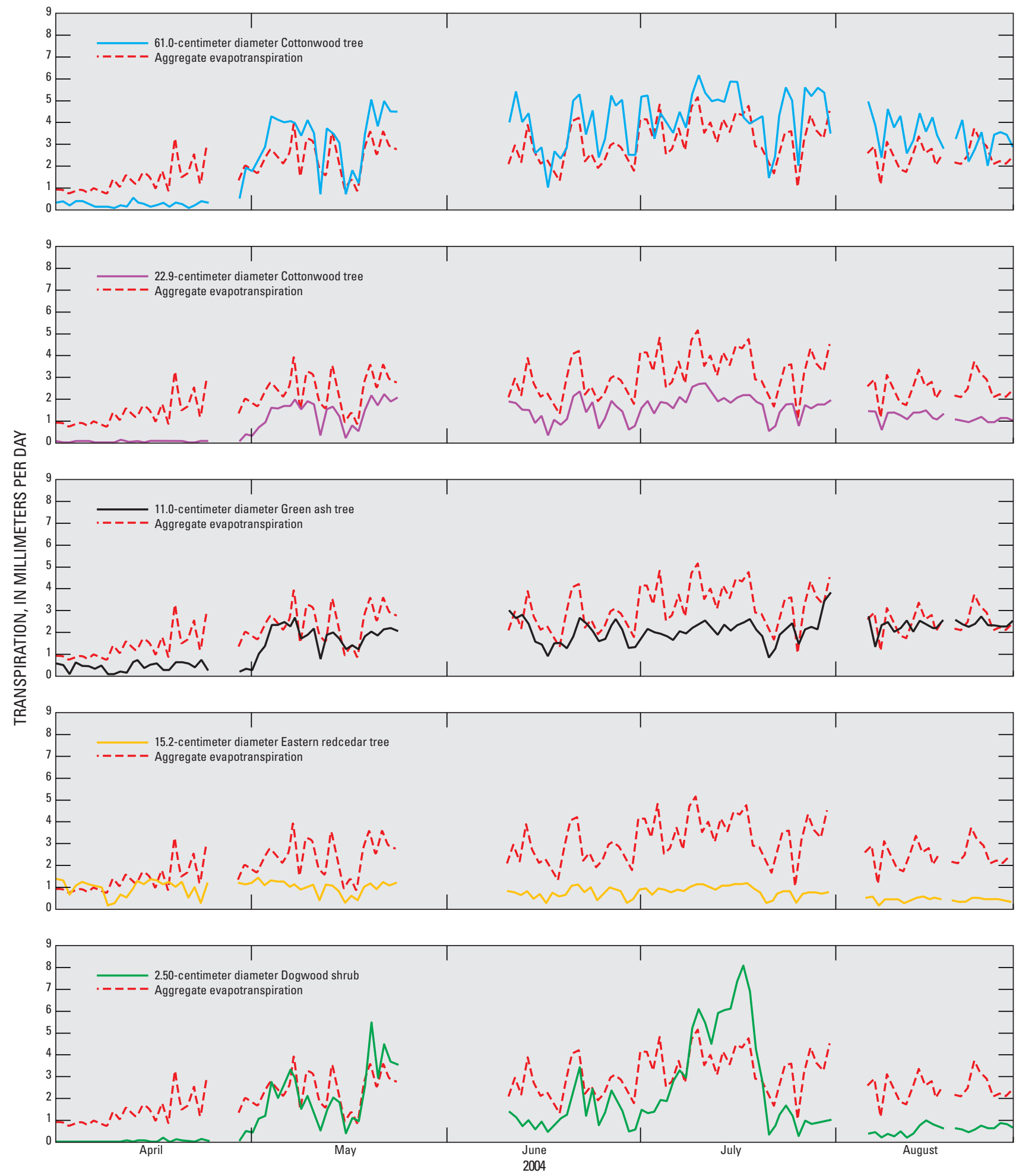

Figure 20. Daily average transpiration rates for monitored trees and shrubs and aggregate evapotranspiration measured by eddy-covariance method, April through August 2004, at study site near Odessa, Nebraska. 

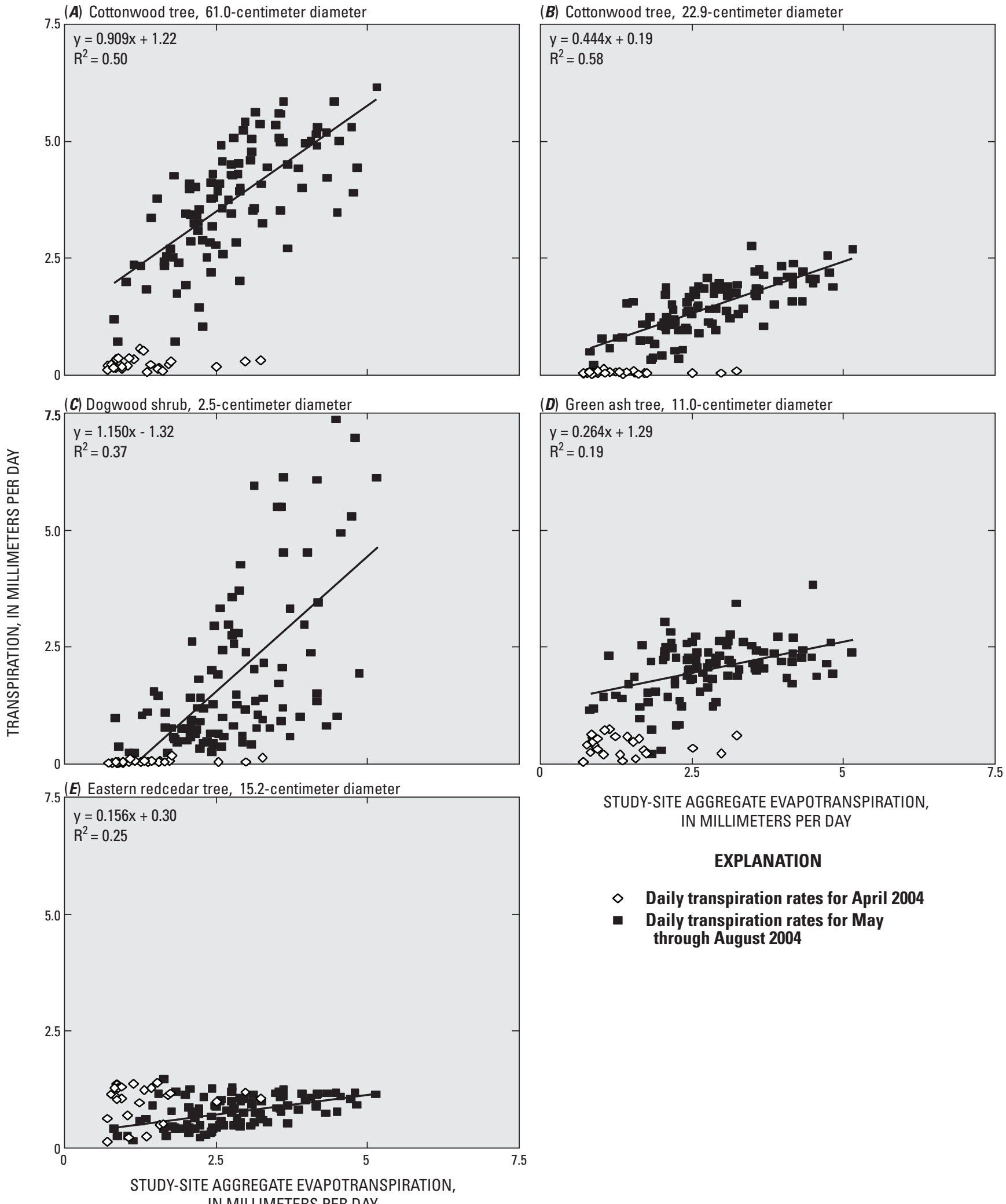

STUDY-SITE AGGREGATE EVAPOTRANSPIRATION IN MILLIMETERS PER DAY

\section{EXPLANATION}

$\diamond \quad$ Daily transpiration rates for April 2004

- Daily transpiration rates for May through August 2004 IN MILLIMETERS PER DAY

Figure 21. Relation of daily transpiration rates for monitored trees and shrubs with evapotranspiration determined from eddy covariance, April through August 2004, at study site near Odessa, Nebraska. 
If the measured transpiration rate of the eastern redcedar before leaf out is representative of those of most other conifers, the results imply that transpiration from conifers was a primary contributor to aggregate ET before leaf out of deciduous vegetation. Based on micrometeorologic data from both sites, dormant-season (October through April) ET accounted for approximately 25 percent of the annual total, whereas growing season (May through September) ET accounted for 75 percent of the total. Although there is more uncertainty in estimating dormant-season ET than in growing-season estimates, these results indicate that dormant-season ET needs to be included in assessments of the water balance to produce reliable results.

Dogwood transpiration rates were more variable than those of the other monitored plants (fig. 20). For example, dogwood transpiration rates spiked in mid-May and late July to a much greater degree than either the monitored trees or the aggregate ET. It is not known whether or not this is a real effect or an artifact of increased sensitivity to thermal gradients in the small diameter of the dogwood trunk (2.5-cm). Average transpiration rates for the dogwood shrub from May through August 2004 were similar to those for the green ash (table 12). The monitored dogwood (plant 1; table 2) was located among shrubs that were partially shaded by tree canopy. A second dogwood (plant 2; table 2) located in a comparatively wet area with shallower depth to water was characterized by extremely variable transpiration and was not considered reliable enough to report.

Daily transpiration rates for green ash were intermediate in comparison with the other monitored plants, and were about 72 percent of aggregate ET rates during May through August (table 12). Similar to the eastern redcedar, transpiration rates for the green ash were less well correlated with aggregate ET rates (fig. 21D) than were the cottonwood rates. Additionally, transpiration rates for green ash increased slightly during August 2004 at a time when transpiration rates for cottonwoods generally were decreasing.

Fluctuations in daily transpiration rates generally were similar to those of aggregate daily ET, but the magnitude of the fluctuations often differed (fig. 20). Sap-flow-derived transpiration rates and aggregate $E T$ rates both indicated considerable daily variations, reflecting daily variations in the environmental factors controlling ET.

\section{Extrapolating Evapotranspiration Rates Beyond the Study Sites}

The importance of this study lies not in the site-specific water- and energy-balance measurements, but in the ability to estimate the ET from similar forests throughout the riparian zone of the Platte River by extrapolating those measurements to different spatial and temporal scales. It should be noted, however, that extrapolated-ET estimates may deviate from the actual ET rates in other forests as the vegetation communities and environmental conditions deviate further from those of this study. These study results could be generally similar to those for zones of riparian forests in the northern and central Great Plains that are narrower than $800 \mathrm{~m}$; however, as riparian zones become narrower, energy balances may change because advective energy transfers from adjacent land covers may become more important in these settings than along the Platte River.

Specifically, riparian-forest ET rates along the Platte River can be extrapolated by using the $k_{c}$ values determined for this study in conjunction with atmospheric data from other climate stations in central Nebraska. Generally, $k_{c}$ values from the Odessa site probably are best suited for locations east of the midway point between Odessa and Gothenburg, whereas $k_{c}$ values from the Gothenburg site probably are best suited for locations west of this point.

In light of recent (1999 to 2003) drought conditions in Nebraska (Hayes and others, 2005), the ET from riparian forests, and more specifically riparian phreatophytes such as cottonwoods and saltcedar (Tamarix spp), has received increased scrutiny in terms of its effect on ground-water resources and stream depletion. This partly is because of the concept of ET salvage, which is loosely defined as ground water that is made available for other uses by reducing the ET of riparian phreatophytes either through vegetation management (Cleverly and others, 2006) or by lowering the water table by pumping ground-water wells (Cooper and others, 2006). Nebraska Legislative Bill (LB) 701 became law in 2007 and established riparian-vegetation-management programs in areas where available water resources were fully appropriated or over appropriated (State of Nebraska, 2007).

Although few, if any, studies have focused on cottonwoods, considerable uncertainty is associated with the effects of ET-salvage programs in the American Southwest involving saltcedar (Shafroth and others, 2005), and there has been little evidence of streamflow increases following saltcedar removal there (Hart and others, 2005). Although the effects of vegetation management on riparian-forest ET are not the subject of this study, the results indicate that ET rates are constrained by vegetation, moisture-availability, and climatic conditions. As a result, ET rates in riparian forests were considerably lower than potential ET rates and were similar to ET rates of irrigated corn (Younts, 2002). Additionally, removing cottonwoods from riparian areas may not reduce ET in the long term, because vegetation communities adapt dynamically to changes in environmental variables. It is possible that the ET of replacement vegetation in the altered riparian system may be similar to cottonwoods or other existing (as of 2005) riparian vegetation. Changes in vegetation cover alter the partitioning of energy between latent and sensible heat (Ewers and others, 2002). Annual ET by forests may be relatively stable because of factors such as understory vegetation and climate coupling (Roberts, 1999; Ewers and others, 2002). Additional studies are needed to quantify the effects of natural or managed changes in riparian vegetation on water availability and to consider the economic and environmental effects of sustainable vegetation removal or alternative management plans. 


\section{Summary}

Evapotranspiration (ET) in riparian areas is a poorly understood component of the regional water balance in the Platte River Basin, where competing demands have resulted in water shortages in the coupled ground-water/surface-water system. In 2002, the U.S. Geological Survey in cooperation with the Nebraska Platte River Cooperative Hydrology Study Group and Central Platte Natural Resources District began a micrometeorological study of water and energy balances at two sites in central Nebraska to improve understanding of ET rates and factors affecting them in Platte River riparian forests. This report includes descriptions of the micrometeorological methods and data analysis, interpretations of amounts of canopy interception and evaporation of intercepted water, calibration of a crop-coefficient model used for simulating riparianforest ET rates, analysis of environmental variables affecting ET rates, transpiration rates in individual plants (measured using sap flux techniques), and a discussion of extrapolating the results to other locations.

Source-area, or footprint, calculations and analysis of land-cover data indicated that at least 85 percent of the fluxes measured by the eddy-covariance sensors originated from areas of riparian forest. Both study sites have a forest canopy or overstory dominated by cottonwoods and characteristics generally representative of riparian forests in the region. Because the land cover at both study sites consists of woody vegetation interspersed with open areas and some river channels, the water- and energy-balance measurements for this study characterize the riparian-vegetation community rather than just riparian trees. Riparian trees are a dominant component of the riparian-vegetation community, but forests in this study have low tree density in comparison with many forests, and are characterized by relatively widely spaced trees with intervening open areas.

At both sites, the stratigraphy of the unsaturated zone and upper-saturated zone coarsened with depth, consisting of 10 to 20 centimeters of sandy loam overlying 40 to 50 centimeters of fine sand with interbedded silt layers of variable thickness overlying poorly sorted sand and fine gravel. As a result, capillary rise into the unsaturated zone was minimal. Typical depth to water in early spring at the Odessa site was 90 centimeters compared to 110 centimeters at the Gothenburg site. However, the greater fluctuation of depth to water at Odessa than Gothenburg throughout the study proved to be a fundamental difference between the sites.

The study period of April 2002 through March 2006 encompassed conditions ranging from wet to dry. Variations in annual precipitation primarily reflected wet and dry periods during May through September, when most precipitation occurred. Precipitation ranged from 429 to 844 millimeters per year at Odessa and 359 to 791 millimeters per year at Gothenburg. During the study period, annual precipitation at both sites varied by about 35 percent from its 4 -year mean, and was much more variable than annual ET, which stayed within about 7 percent of its 4-year mean.

Average throughfall in two gages beneath the canopy at each site ranged from about 67 to 89 percent of total precipitation, indicating a relatively strong relation between precipitation and throughfall for the measured range of rainfall intensities and amounts. Interception of precipitation by the plant canopy was calculated as the difference between precipitation and throughfall. Area-weighted interception, based on interception determined from the two throughfall gages and the distribution of vegetation cover, was 13 percent of precipitation at each site.

Daily ET rates determined using eddy-covariance methods ranged from about -0.7 to 7.5 millimeters per day and commonly were greater than 2.5 millimeters per day during June through August, but only rarely were greater than 5.0 millimeters per day. Daily ET rates during December, January, and February often were less than 0.5 millimeter per day. Annual ET ranged from about 514 to 586 millimeters per year (average 551 millimeters per year) at the Odessa site and 535 to 616 millimeters per year (average 575 millimeters per year) at the Gothenburg site. These values were within the range of annual precipitation. Based on an analysis of the energybalance closure, the ET rates determined using eddy covariance are estimated to be within about 13 percent of the actual rates; the reported ET rates are thought to represent minimum values.

For the study period, energy imbalances as a percentage of available energy were 9 percent at Odessa and 13 percent at Gothenburg. These imbalances are within the range of 0 to 30 percent typically present in energy balance studies. Energy fluxes generally were largest during June through August, and smallest during November through February, reflecting seasonal variations in net radiation. During the growing season (May through September), latent-heat flux was the largest energy outflow at both sites, whereas sensible-heat flux was the dominant energy outflow during the dormant season (October through April). At both sites, approximately 70 percent of the total latent-heat flux during the study period occurred during daytime conditions during the growing season. For 30 -minute periods during the diurnal cycle, the smallest mean energy imbalances, usually less than 20 percent of available energy, occurred between 8:00 am and 6:00 pm during the summer when the greatest energy fluxes and ET occurred. Thus, the measurements of energy fluxes were of greatest accuracy for periods when most of the energy fluxes occurred.

Precipitation and ET were the dominant components of the annual water balance, with changes in soil-water and ground-water storage being comparatively minor terms. Net ground-water discharge to both sites (ground-water inflow to the riparian forests necessary to satisfy the water balance) occurred in 2002, when annual ET exceeded annual precipitation. Net ground-water recharge occurred from both sites in 2003, 2004, and 2005 (ground-water outflow from the riparian forests necessary to satisfy the water balance). The 4-year- 
average water balance indicated that the study sites were a net source of ground-water recharge for the study period (table 7; fig. 17B). The 4-year-average net ground-water recharge at Odessa (76 millimeters per year) was larger than that at Gothenburg (13 millimeters per year), consistent with larger precipitation surpluses at Odessa than Gothenburg. After adjusting the annual water-balance calculations to account for canopy interception, evaporation of intercepted water accounted for an average of about 14 percent of total ET at Odessa and 9 percent at Gothenburg.

The upper boundary of possible values of ground-water ET ranged from 448 to 504 millimeters per year with an average value of 473 millimeters per year at the Odessa site, or roughly 86 percent of total ET, and ranged from 480 to 559 millimeters per year with an average value of 520 millimeters per year at the Gothenburg site, or roughly 90 percent of total ET. This upper boundary is met if none of the throughfall precipitation infiltrates into the soil, which probably is unrealistic given the relatively flat and sandy terrain of the study sites. The lower boundary of possible values of annual ground-water ET is the net ground-water inflow into the riparian area to satisfy the annual water balance. Net ground-water outflow from the riparian zone occurred during 2003 to 2005, indicating that the lower boundary of annual ground-water ET effectively was zero during 2003 to 2005. During the driest study year, 2002, net ground-water inflow was 53 millimeters (10 percent of total ET of 514 millimeters) at Odessa and 161 millimeters (28 percent of total ET of 585 millimeters) at Gothenburg. Thus, annually, ground water becomes an important water source, albeit minor compared to precipitation, during dry years for satisfying riparian-forest ET demands. During wet years, all of the ET demand could be satisfied by available precipitation. These results do not imply that ground water is not an important source of water to riparian vegetation-especially to phreatophytes - during increased ET periods in the summer, particularly during periods of lower than normal precipitation. However, annual ground-water use by these riparian forests likely is balanced by periods of recharge of excess precipitation at other times of the year. In contrast to more arid settings, where literature indicates that ground water may supply a large fraction of the water used for ET by riparian vegetation, along the Platte River of Nebraska, precipitation was large enough — and generally larger than ET — that for annual or longer periods most or all of the ET demand can be satisfied by available precipitation.

The 15-day and monthly average crop coefficientscalculated by dividing measured ET by reference ET from nearby weather stations - had values that ranged from 0.07 to 0.51 , and generally were similar between sites. The simple crop-coefficient models using either monthly or 15-day average crop coefficients reasonably simulated annual ET. For the Odessa site, annual ET simulations deviated from measured ET by -11.7 percent to +7.5 percent with a 4 -year average of -3.5 percent for monthly coefficients and -3.4 percent for 15-day coefficients. For the Gothenburg site, annual ET simulations deviated from measured ET by -6.7 percent to
+9.0 percent with a 4-year average of +1.8 percent for monthly coefficients and +1.6 percent for 15 -day coefficients. Generally, the simple crop-coefficient models underpredicted large daily ET and overpredicted small daily ET. For annual or longer periods, these short-term discrepancies averaged out, and simulated ET was close to measured ET.

Simple linear-regression and multiple linear-regression models of ET were developed to better understand the factors affecting ET rates in riparian forests. At both sites, simple linear regression indicated that ET increased with increasing vapor-pressure deficit, solar radiation, air temperature, and leaf-area index, all of which followed seasonal patterns with summer peaks and winter lows. When analyzing all of the days in the data set, ET was statistically unrelated to soil-water content and precipitation and depth to water was only significant at Odessa; however, by separating the daily data into two groups according to the presence or lack of precipitation, ET was larger on days with precipitation than days without. These results indicate that ET was more strongly controlled by atmospheric and vegetation conditions on days without precipitation than days with precipitation, when the evaporation from wet surfaces affects ET rates. Thus, although moisture availability was not directly related to ET rates, the relation of ET to environmental factors was different on days with precipitation — when additional moisture availability resulted in increased ET — than on dry days. These comparisons indicated that to understand the factors affecting ET rates, it was necessary to consider different relations for days with and days without precipitation.

Based upon the simple linear-regression relations between ET and vapor-pressure deficit, solar radiation, air temperature, leaf-area index, and depth to water (at Odessa only) for days with and without precipitation, multiple linearregression models of ET as a function of these variables were constructed using stepwise techniques to identify the assemblage of variables that most strongly affect ET rates.

At Odessa, on days without precipitation, ET rates were best explained by a multiple linear-regression model including vapor-pressure deficit, solar radiation, air temperature, leaf-area index, and depth to water. The model indicated that ET rates increase with increasing vapor-pressure deficit, solar radiation, air temperature, and leaf-area index, and decreasing depth to water. At Odessa on days with precipitation, air temperature became insignificant in the model, but the assemblage and trend of variables were otherwise similar to days without precipitation, suggesting that ET was limited by the amount of available energy on days without precipitation but, on days with precipitation, ET was limited by the amount of available water.

At Gothenburg on days without precipitation, ET was a function of vapor-pressure deficit, solar radiation, air temperature, and leaf-area index but not depth to water. As with Odessa, the best Gothenburg ET model on days with precipitation was similar to the model on days without precipitation except that air temperature became insignificant, thereby lending further evidence that the system was energy-limited on 
days without precipitation. The absence of depth to water as a controlling variable at Gothenburg probably reflects reduced ground-water fluctuations as compared to Odessa.

The simple and multiple linear-regression analyses quantified relations that were either expected or were identified from previous studies. Solar radiation, vapor-pressure deficit, and leaf-area index were important variables at both sites for days with and without precipitation.

Despite the presence of phreatophytic vegetation in areas of shallow ground water, measured ET was substantially less than potential ET. The limited-ET rates are consistent with plant limitations on ET through stomatal regulation in response to environmental and meteorological factors, as has been described in previous studies.

With annual values differing by a maximum of 17 percent and an average of 4 percent, ET rates generally were similar between the two sites; however, the sites exhibited different patterns with respect to moisture availability and its effect on ET and vegetation health. The smaller seasonal declines in ground-water levels and lack of understory shrubs at the Gothenburg site, as compared to the Odessa site, may explain why high ET rates persisted later in the summer at Gothenburg and why depth to water had a significant effect on ET (as identified by the multiple linear-regression model) at Odessa but not at Gothenburg. It is likely that the larger summer declines in depth to water at Odessa provided more opportunity for water stress to develop in relatively shallow-rooted understory shrubs, resulting in moderate declines in ET. These differences between the sites in ET responses to seasonal drought conditions also may help to explain why, during years of increased precipitation, ET rates increased at Odessa but decreased at Gothenburg.

Transpiration rates calculated from sap-flow measurements in five individual trees and shrubs during the summer of 2004 at Odessa gave preliminary indication that a large cottonwood transpired more than the aggregate ET of the riparian-forest community. Because transpiration rates were measured in four trees and one shrub only for one growing season, these sap-flow analyses represent preliminary reconnaissance results. Much more extensive monitoring is necessary to develop quantitative understanding of transpiration rates in individual tree species in the riparian forests. The 61.0-centimeter diameter cottonwood had the greatest average transpiration rate at 3.8 millimeters per day during May through August 2004, greater than the aggregate ET rate measured for the entire riparian-forest footprint, which was an average of 2.8 millimeters per day for the same period. Conversely, the smaller diameter (22.9 centimeter) cottonwood had lower transpiration rates than the green ash, the dogwood shrub, or the aggregate ET rate.

Before leaf out in April 2004, the eastern redcedar had the greatest average transpiration rate $(0.98$ millimeters per day) of any of the monitored trees, similar to the aggregate ET rate of 1.3 millimeters per day measured for the same period. If the measured transpiration rate of the eastern redcedar before leaf out is representative of those of most other coni- fers, the results imply that transpiration from conifers was a primary contributor to aggregate ET before leaf out of deciduous vegetation. Based on micrometeorologic data from both sites, dormant-season (October through April) ET accounted for approximately 25 percent of the annual total, whereas growing season (May through September) ET accounted for 75 percent of the total. Although there is more uncertainty in estimating dormant-season ET than in growing-season estimates, these results indicate that dormant-season ET needs to be included in reliable assessments of the water balance.

The importance of this study lies not in the site-specific results, but in the ability to estimate the ET from similar forests throughout the riparian zone of the Platte River by extrapolating those measurements, and in the understanding of processes and factors affecting ET. Specifically, riparianforest ET rates along the Platte River can be extrapolated by using the crop-coefficient values determined for this study in conjunction with atmospheric data from other climate stations in central Nebraska, keeping in mind that extrapolated ET estimates may deviate from the actual ET rates in other forests as the vegetation communities and environmental conditions deviate further from those of this study.

\section{References Cited}

\section{Allen, R.G., Pereira, L.S., Raes, Dirk, and Smith, Martin, 1998, Crop evapotranspiration-Guidelines for computing crop water requirements: Rome, Italy, Food and Agriculture Organization of the United Nations Irrigation and Drainage Paper 56, accessed October 16, 2008, at http://www.fao.org/ docrep/X0490E/x0490e00.HTM}

Aubinet, Marc, Grelle, Achim., Ibrom Andreas, Rannik, Üllar., Moncrieff, John, and others, 2000, Estimates of the annual net carbon and water exchange of European forests - the EUROFLUX methodology, in Fitter, A.H., and Raffaelli, D.G., eds., Advances in Ecological Research Volume 30: Academic Press, San Diego, California, p. 113-175.

Baldocchi, D.D., Hicks, B.B., and Meyers, T.P., 1988, Measuring biosphere-atmosphere exchanges of biologically related gases with micrometeorological methods: Ecology, v. 69, no. 5 , p. $1,331-1,340$.

Barr, A.G., Morgenstern, Kai, Black, T.A., McCaughey, J.H., and Nesic, Zoran, 2006, Surface energy balance closure by the eddy-covariance method above three boreal forest stands and implications for the measurement of the $\mathrm{CO}_{2}$ flux: Agricultural and Forest Meteorology, v. 140, p. 322-337.

Bastiaanssen, W.G.M., Menenti, Massimo, Feddes, R.A., and Holtslag, A.A.M., 1998, A remote sensing surface energy balance algorithm for land (SEBAL). 1. Formulation: Journal of Hydrology, v. 212-213, p. 198-212. 
Batcheler, C.L., 1973, Estimating density and dispersion from truncated or unrestricted joint point-distance nearest-neighbour distances: Proceedings of the New Zealand Ecological Society, v. 20, p. 131-147.

Bentall, Ray, and Shaffer, F.B., 1979, Availability and use of water in Nebraska, 1975: Conservation and Survey Division, University of Nebraska-Lincoln, Nebraska Water Survey Paper 48, $121 \mathrm{p}$.

Bergen, J.D., 1987, A vertical profile of lateral and longitudinal turbulence over a forest stand, in Conference on Agricultural and Forest Meteorology, 18th, 1987, Boston, Mass., American Meteorological Society, p. 193-195.

Bidlake, W.R., 2002, Evapotranspiration from selected fallowed agricultural fields on the Tule Lake National Wildlife Refuge, California, During May to October 2000: U.S. Geological Survey Water-Resources Investigations Report 02-4055, 59 p.

Bossung, C.R., Cain, J.S., Stannard, D.I., Flynn, J.L., Stevens, M.R., and Heiny-Dash, J.S., 2003, Hydrologic conditions and assessment of water resources in the Turkey Creek watershed, Jefferson County, Colorado, 1998-2001: U.S. Geological Survey Water-Resources Investigations Report 03-4034, 148 p.

Brutsaert, Wilfried, 1982, Evaporation into the atmosphere Theory, history, and applications: Boston, Massachusetts, Kluwer Publications, 299 p.

Bureau of Reclamation, 1985, Republican River Basin water management study, Colorado, Nebraska, Kansas-Special Report: Denver, Colorado., Bureau of Reclamation, 120 p.

Bureau of Reclamation, 1998, Executive summary-Central Platte River 1998 land cover/use mapping project: Bureau of Reclamation, accessed August 29, 2008, at http://www. platteriver.org/library/GISrpt.htm

Bureau of Reclamation, 1999, Platte River color-infrared (CIR) digital orthophotos: Denver, Colorado, Bureau of Reclamation, accessed June 1, 2005, at http://ne.water.usgs. gov/platte/cir.htm

Busch, D.E., Ingraham, N.L., and Smith, S.D., 1992, Water uptake in woody riparian phreatophytes of the southwestern United States - a stable isotope study: Ecological Applications, v. 2, p. 450-459.

Businger, J.A., Miyake, M., Dyer, A.J., and Bradley, E.F., 1967, On the direct determination of the turbulent heat flux near the ground: Journal of Applied Meteorology, v. 6, p. 1025-1032.

Calder, L.R., 1990, Evaporation in the uplands: New York, John Wiley and Sons, 148 p.
Campbell Scientific, Inc., 1996a, Q-7.1 net radiometer, revision 5/96: Logan, Utah, Campbell Scientific, Inc., 8 p.

Campbell Scientific, Inc., 1996b, CS615 water content reflectometer, revision 10/96: Logan, Utah, Campbell Scientific, Inc., $11 \mathrm{p}$.

Campbell Scientific, Inc., 1999, HFT3 soil heat flux plate, revision 2/99: Logan, Utah, Campbell Scientific, Inc., 4 p.

Campbell Scientific, Inc., 2007, CNR1 net radiometer, revision 08/07: Logan, Utah, Campbell Scientific, Inc., 32 p.

Campbell Scientific, Inc., 2008, TE525 tipping bucket rain gage, revision 02/08: Logan, Utah, Campbell Scientific, Inc., $16 \mathrm{p}$.

Campbell, G.S., and Norman, J.M., 1998, An introduction to environmental biophysics, $2^{\text {nd }}$ ed: New York, SpringerVerlag, 286 p.

Center for Advanced Land Management Information Technologies (CALMIT), 2000, Delineation of 1997 land use patterns for the Cooperative Hydrology Study in the central Platte River Basin: Lincoln, Nebraska, CALMIT, 73 p., accessed August 29, 2008, at http://www.calmit.unl.edu cohyst/data/1997_finalreport.pdf

Chen, J.M., Rich, P.M., Gower, S.T., Norman, J.M., and Plummer, Stevent, 1997, Leaf area index of boreal forests - theory, techniques, and measurements: Journal of Geophysical Research, v. 102, no. D24, p. 29,429-29,443.

Clearwater, M.J., Meinzer, F.C., Andrade, J.L., Goldstein, Guillermo, and Holbrook, N.M., 1999, Potential errors in measurement of nonuniform sap flow using heat dissipation probes: Tree Physiology, v. 19, p. 681-687.

Cleverly, J.R., Dahm, C.N., Thibault, J.R., McDonnell, D.E., and Allred Coonrod, J.E., 2006, Groundwater, vegetation, and atmosphere-Comparative riparian evapotranspiration, restoration, and water salvage, in Aguirre-Bravo, Celedonio, and others, eds., Monitoring Science and Technology Symposium-Unifying knowledge for sustainability in the Western Hemisphere: Fort Collins, Colorado, U.S. Department of Agriculture, Forest Service, Rocky Mountain Research Station, Proceedings RMRS-P-42CD, p. 75-80.

Cooper, D.J., Sanderson, J.S., Stannard, D.I., and Groeneveld, D.P., 2006, Effects of long-term water table drawdown on evapotranspiration and vegetation in an arid region phreatophyte community: Journal of Hydrology, v. 325, p. 21-34.

Currier, P.J., 1982, The floodplain vegetation of the Platte River-phytosociology, forest development, and seedling development: Ames, Iowa State University, Ph.D. dissertation, $332 \mathrm{p}$. 
Currier, P.J., Lingle, G.R., and VanDerwalker, J.G., 1985 , Migratory bird habitat on the Platte and North Platte Rivers in Nebraska: Grand Island, Nebr., Platte River Whooping Crane Maintenance Trust, $177 \mathrm{p}$.

Davie, Tim, 2003, Fundamentals of hydrology: New York, Routledge, 169 p.

De Bruin, H.A.R., and Moore, C.J., 1985, Zero-plane displacement and roughness length for tall vegetation, derived from a simple mass conservation hypothesis: Boundary-Layer Meteorology, v. 31, p. 39-49.

Delta-T Devices, Ltd., 1999, Hemiview users manual: Cambridge, United Kingdom, Delta-T Devices, Ltd., 85 p., accessed November 19, 2007, at http://www.delta-t.co.uk/ cgi-bin/attach.cgi?item=faq2005100703399.2

Eddy, T.A., 1995, Phreatophyte survey and water-use estimates for nine river systems in Kansas, in North American Prairie Conference, 14th, Manhattan, Kansas, 1994, Proceedings: Manhattan, Kansas, Kansas State University, p. 171-173.

Ewers, B.E., and Oren, Ram, 2000, Analyses of assumptions and errors in the calculation of stomatal conductance from sap flux measurements: Tree Physiology, v. 20, p. 579-589.

Ewers, B.E., Mackay, D.S., Gower, S.T., Ahl, D.E., Burrows, S.N., and Samanta, S.S., 2002, Tree species effects on stand transpiration in northern Wisconsin: Water Resources Research, v. 38 no. 7, 10.1029/2001WR000830, 11 p.

Falge, Eva, Baldocchi, Dennis, Olson, Richard, Anthoni, Peter, Aubinet, Marc, and others, 2001, Gap filling strategies for long term energy flux data sets: Agricultural and Forest Meteorology, v. 107, p. 71-77.

Field, R.T., Fritschen, L.J., Kanemasu, E.T., Smith, E.A., Stewart, J.B., Verma, S.B., and Kustas, W.P., 1992, Calibration, comparison, and correction of net radiation instruments used during FIFE: Journal of Geophysical Research, v. 97 , no. D17, p. 18,681-18,695.

Fitzpatrick, F.A., Waite, I.R., D'Arconte, P.J., Meador, M.R., Maupin, M.A., and Gurtz, M.E., 1998, Revised methods for characterizing stream habitat in the National Water-Quality Assessment Program: U.S. Geological Survey WaterResources Investigations Report 98-4052, 67 p.

Freeman, L.A., Carpenter, M.C., Rosenberry, D.O., Rousseau, J.P., Unger, Randy, and McLean, J.S., 2004, Use of submersible pressure transducers in water-resources investigations: U.S. Geological Survey Techniques of WaterResources Investigations, book 8, chap. A3, 52 p.

Gash, J.H.C., 1986, A note on estimating the effect of limited fetch on micrometeorological evaporation measurements: Boundary-Layer Meteorology, v. 35, p. 409-413.
Good, B.K., 1999, Central Platte River forests—-breeding birds and woody vegetation: Lincoln, University of Nebraska, M.S. Thesis, $47 \mathrm{p}$.

Goodrich, D.C., Goff, Bruce, Unkrich, C.L., Moran, M.S., Williams, David, and others, 2000, Seasonal estimates of riparian evapotranspiration using remote and in situ measurements: Agricultural and Forest Meteorology, v. 105, no. 1-3, p. 281-309.

Granier, André, 1987, Evaluation of transpiration in a Douglas-fir stand by means of sap flow measurements: Tree Physiology, v. 3, p. 309-320.

Granier, André., Anfodillo, Tommaso, Sabatti, Maurizio, Cochard, Hervé, Dreyer, Erwin, and others, 1994, Axial and radial water-flow in the trunks of oak trees-a quantitative and qualitative analysis: Tree Physiology, v. 14, p. $1,383-1,396$.

Grelle, Achim., Lundberg, Angela, Lindroth, Anders, Moren, A.S., and Cienciala, Emil, 1997, Evaporation components of a boreal forest-variations during the growing season: Journal of Hydrology, v. 197 p. 70-87.

Gu, Lianhong, Meyers, T.P., Pallardy, S.G., Hanson, P.J., Yang, Bai, Heuer, Mark, Hosman, K.P., Liu, Qing, Riggs, J.S., Sluss, Dan, and Wullschleger, S.D., 2007, Influences of biomass heat and biochemical energy storages on the land surface fluxes and radiative temperature: Journal of Geophysical Research, v. 112, paper D02107, 11 p., doi:10.1029/2006JD007425.

Gutentag, E.D., Heimes, F.J., Krothe, N.C., Luckey, R.R., and Weeks, J.B., 1984, Geohydrology of the High Plains aquifer in parts of Colorado, Kansas, Nebraska, New Mexico, Oklahoma, South Dakota, Texas, and Wyoming: U.S. Geological Survey Professional Paper 1400-B, 63 p.

Hall, R.J., Davidson, D.P., and Peddle, D.R., 2003, Ground and remote estimation of leaf-area index in Rocky Mountain forest stands, Kananaskis, Alberta: Canadian Journal of Remote Sensing, v. 29, no. 3, p. 411-427.

Hart, C.R., White, L.D., McDonald, Alyson, and Sheng, Zhuping, 2005, Saltcedar control and water salvage on the Pecos River, Texas, 1999-2003: Journal of Environmental Management, v. 75, p. 399-409.

Hayes, Michael, Knutson, Cody, and Hu, Q.S., 2005, Multiple-year droughts in Nebraska: Lincoln, Nebraska, University of Nebraska-Lincoln Cooperative Extension, 4 p.

Healy, R.W., Winter, T.C., LaBaugh, J.W., and Franke, O.L., 2007, Water budgets-Foundations for effective waterresources and environmental management: U.S. Geological Survey Circular 1308, $90 \mathrm{p}$. 
Helsel, D.R., and Hirsch, R.M., 2002, Statistical methods in water resources: U.S. Geological Survey Techniques of Water-Resources Investigations, book 4, chap. A3, 510 p.

High Plains Regional Climate Center, 2006, National Weather Service surface observations and automated weather data network data: Lincoln, Nebraska, University of Nebraska, digital data, accessed November 1, 2006, at http://www. hprcc.unl.edus,

Hillel, Daniel, 1980, Applications of soil physics: Orlando, Florida, Academic Press, Inc., 413 p.

Hodgman, C.D., and Holmes, H.N., eds., 1941, Handbook of chemistry and physics, $25^{\text {th }}$ ed.: Cleveland, Ohio, Chemical Rubber Publishing Co., 2,503 p.

Insightful Corporation, 2002, S-PLUS® 6.1 for Windows, professional edition, release 1: Seattle, Wash., Insightful Corporation.

Jarvis, P.G., 1976, The interpretation of the variations in leaf water potential and stomatal conductance found in canopies in the field: Philosophical Transactions of the Royal Society of London, Series B, v. 273, p. 593-610.

Jensen, M.E., Burman, R.D., and Allen, R.G., eds., 1990, Evapotranspiration and irrigation water requirements: New York, American Society of Civil Engineers, ASCE Manuals and Reports on Engineering Practice No. 70, 332 p.

Johnson, W.C., 1994, Woodland expansion in the Platte River, Nebraska_patterns and causes: Ecological Monographs, v. 64 , p. 45-84.

Johnson, W.C., 1997, Equilibrium response of riparian vegetation to flow regulation in the Platte River, Nebraska: Regulated Rivers: Research and Management, v. 13, no. 5, p. 403-415.

Johnson, W.C., Burgess, R.L., and Keammerer, W.R., 1976, Forest overstory vegetation and environment on the Missouri River floodplain in North Dakota: Ecological Monographs v. 46, p. 59-84.

Kaimal, J.C., and Finnigan, J.J., 1994, Atmospheric boundary layer flows - their structure and measurement: New York, Oxford University Press, 289 p.

Kanemasu, E.T., Wesely, M.L., Hicks, B.B., and Heilman, J.L., 1979, Techniques for calculating energy and mass fluxes, in Barfield, B.J., and Gerber, J.F., eds., Modification of the aerial environment of crops: St. Joseph, Michigan, American Society of Agricultural Engineers, p. 156-182.

Kelley, C.E., and Krueger, W.C., 2005, Canopy cover and shade determinations in riparian zones: Journal of the American Water Resources Association, v. 41, no. 1, p. 37-46.
Kristensen, K.J., 1974, Actual evapotranspiration in relation to leaf area: Nordic Hydrology, v. 5, p. 173-182.

Laczniak, R.J., DeMeo, G.A., Reiner, S.R., Smith, J.L., and Nylund, W.E., 1999, Estimates of ground-water discharge as determined from measurements of evapotranspiration, Ash Meadows area, Nye County, Nevada: U.S. Geological Survey Water-Resources Investigations Report 99-4079, 70 p.

Lee, Xuhui, Finnigan J.J., and Paw U, K.T., 2004, Coordinate systems and flux bias error, in Lee, Xuhui, Massman, W.J., and Law, Beverly, eds., Handbook of Micrometeorology: New York, Kluwer Academic Publishers, p. 33-66.

Leonard, R.E., and Federer, C.A., 1973, Estimated and measured roughness parameters for a pine forest: Journal of Applied Meteorology, v. 12, p. 302-307.

Levia, D.F., and Frost, E.E., 2003, A review and evaluation of stemflow literature in the hydrologic and biochemical cycles of forested and agricultural ecosytems: Journal of Hydrology, v. 274, p. 1-29.

Liu, S.G., 1997, A new model for the prediction of rainfall interception in forest canopies: Ecological Modeling, v. 99, p. $151-159$.

Loheide, S.P., II, Butler, J.J., Jr., and Gorelick, S.M., 2005, Estimation of groundwater consumption by phreatophytes using diurnal water table fluctuations-A saturated-unsaturated flow assessment: Water Resources Research, v. 41, paper W07030, 14 p., doi:10.1029/2005WR003942.

Lowe, P.R., 1977, An approximating polynomial for the computation of saturation vapor pressure: Journal of Applied Meteorology, v. 16, p. 100-103.

Luckey, R.R., and Cannia, J.C., 2006, Groundwater flow model of the western model unit of the Nebraska Cooperative Hydrology Study (COHYST) area: Lincoln, Nebraska, Department of Natural Resources, 63 p., accessed November 15, 2007, at http://cohyst.dnr.ne.gov/cohyst_ preliminarydata.html

Luckey, R.R., Woodward, D.A., and Carney, C.P., 2006, Estimated stream depletion in the Nebraska Platte Basin due to new irrigated land developed after July 1, 1997: Lincoln, Nebraska, Department of Natural Resources, 39 p., accessed November 15, 2007, at http://cohyst.dnr.ne.gov/cohyst_ preliminarydata.html

Mackay, D.S., Ewers, B.E., Cook, B.D., and Davis, K.J., 2007, Environmental drivers of evapotranspiration in a shrub wetland and an upland forest in northern Wisconsin: Water Resources Research, v. 43, paper W03442, 14 p., doi:10.1029/2006WR005149. 
Massman, W.J., and Lee, Xuhui, 2002, Eddy covariance flux corrections and uncertainties in long-term studies of carbon and energy exchanges: Agricultural and Forest Meteorology, v. 113, p. 121-144.

McCaughey, J.H., and Saxton, W.L., 1988, Energy balance storage terms in a mixed forest: Agricultural and Forest Meteorology, v. 44, p. 1-18.

Meinzer, F.C., Goldstein, Guillermo, and Andrade, J.L., 2001, Regulation of water flux through tropical forest canopy trees-do universal rules apply?: Tree Physiology, v. 21, p. 19-26.

Meyboom, Peter, 1964, Three observations on streamflow depletion by phreatophytes: Journal of Hydrology, v. 2, p. 248-261.

Meyers, T.P., and Hollinger, S.E., 2004, An assessment of storage terms in the surface energy balance of maize and soybean: Agricultural and Forest Meteorology, v. 125, p. $105-115$.

Moore, C.J., 1986, Frequency response corrections for eddy correlation systems: Boundary-Layer Meteorology, v. 37, p. $17-35$.

Monteith, J.L., 1965, Evaporation and environment-the state and movement of water in living organisms: Symposia of the Society of Experimental Biology, v. 19, p. 205-234.

Mueller-Dombois, Dieter, and Ellenberg, Heinz, 1974, Aims and methods of vegetation ecology: New York, John Wiley \& Sons, Inc., 547 p.

Nagel, H.G., and Dart, M.S., 1980, Platte River evapotranspiration-a historical perspective in central Nebraska: Transactions of the Nebraska Academy of Sciences, v. 8, p. $55-76$.

Nagler, P.L., Scott, R.L., Westenburg, Craig, Cleverly, J.R., Glenn, E.P, and Huete, A.R., 2005, Evapotranspiration on western U.S. rivers estimated using the enhanced vegetation index from MODIS and data from eddy covariance and Bowen ratio flux towers: Remote Sensing of Environment v. 97, p. 337-351.

Nash, J.E., and Sutcliffe, J.V., 1970, River flow forecasting through conceptual models, part I-A discussion of principles: Journal of Hydrology, v. 10, no. 3, p. 282-290.

Natural Resources Conservation Service, 2004, Soil Survey Laboratory methods manual, version 4.0: U.S. Department of Agriculture Soil Survey Investigations Report No. 42, $700 \mathrm{p}$.

Nebraska Department of Natural Resources, 2000, Nebraska Digital Orthophoto Quadrangles-1999: Lincoln, Nebraska, Nebraska Department of Natural Resources, accessed July 20, 2004, at http://dnr.ne.gov/databank/coq.html
Nichols, W.D., 1993, Estimating discharge of shallow groundwater by transpiration from greasewood in the northern Great Basin: Water Resources Research, v. 29, no. 8, p. 2771-2778.

Paw U, K.T., Baldocchi, D.D., Meyers, T. P., and Wilson, K. B., 2000, Correction of eddy-covariance measurements incorporating both advective effects and density fluxes: Boundary-Layer Meteorology, v. 97, p. 487-511.

Platts, W.S., Armour, Carl, Booth, G.D., Bryant, Mason, Bufford, J.L., Cuplin, Paul, Jensen, Sherman, Lienkaemper, G.W., Minshall, G.W., Monsen, S.B., Nelson, R.L., Sedell, J.R., and Tuhy, J.S., 1987, Methods for evaluating riparian habitats with applications to management: Ogden, Utah, U.S. Forest Service, General Technical Report INT-221, $177 \mathrm{p}$.

Platte River Endangered Species Partnership, 1997, Cooperative agreement for Platte River research and other efforts relating to endangered species habitats along the central Platte River, Nebraska—Signed July 1, 1997, by the Governors of Wyoming, Colorado, and Nebraska, and the Secretary of the Interior: Platte River Endangered Species Partnership, accessed November 1, 2006, at http:// www.platteriver.org/library/CooperativeAgreement/ CooperativeAgreement.htm

Priestley, C.H.B., and Taylor, R.J., 1972, On the assessment of surface heat flux and evaporation using large-scale parameters: Monthly Weather Review, v. 100, p. 81-92.

Rand, P.J., 1973, The woody phreatophyte communities of the Republican River valley in Nebraska: Denver, Colorado, Bureau of Reclamation, $110 \mathrm{p}$.

Ringold, P.L., Sickle, J.V., Rasar, Kristie, and Schacher, Jason, 2003, Use of hemispheric imagery for estimating stream solar exposure: Journal of the American Water Resources Association, v. 39, no. 6, p. 1,373-1,384.

Roberts, John, 1999, The influence of physical and physiological characteristics of vegetation on their hydrological response: Hydrological Processes, v. 14, p. 2,885-2,902.

Rosenberg, N.J., Blad, B.L., and Verma, S.B., 1983, Microclimate-The biological environment: New York, John Wiley and Sons, $495 \mathrm{p}$.

Rosenberry, D.O., Stannard, D.I., Winter, T.C., and Martinez, M.L., 2004, Comparison of 13 equations for determining evapotranspiration from a prairie wetland, Cottonwood Lake area, North Dakota, U.S.A.: Wetlands, v. 24, p. 483-497.

Samson, Roeland, and Lemeur, Raoul, 2001, Energy balance storage terms and big-leaf evapotranspiration in a mixed deciduous forest: Annals of Forest Science, v. 58, p. 529-541. 
Savenije, H.H.G., 2004, The importance of interception and why we should delete the term evapotranspiration from our vocabulary: Hydrological Processes, v. 18, p. 1,507-1,511.

Schotanus, P., Nieuwstadt, F.T.M., and De Bruin, H.A.R., 1983, Temperature measurement with a sonic anemometer and its application to heat and moisture fluxes: BoundaryLayer Meteorology, v. 26, p. 81-93.

Schuepp, P.H., Leclerc, M.Y., Macpherson, J.I., and Desjardins, R.L., 1990, Footprint prediction of scalar fluxes from analytical solutions of the diffusion equation: BoundaryLayer Meteorology, v. 50, p. 335-373.

Schulz, K., and Jarvis, A.J., 2004, Environmental and biological controls on the seasonal variations in latent heat fluxes derived from flux data for three forest sites: Water Resources Research, v. 40, paper W12501, 10 p., doi:10.1029/2004WR003155.

Sedgewick, J.A., and Knopf, F.L., 1989, Demography, regeneration, and future projections for a bottomland cottonwood community, in R.R. Sharitz and J.W. Gibbons, eds., Freshwater wetlands and wildlife: Oak Ridge, Tenn., U.S. Department of Energy, Office of Scientific and Technical Information, p. 249-266.

Shafroth, P.B., Cleverly, J.R., Dudley, T.L., Taylor, J.P., Van Riper, Charles, III, Weeks, E.P., and Stuart, J.N., 2005, Control of Tamarix in the western United States-Implications for water salvage, wildlife use, and riparian restoration: Environmental Management, v. 35, no. 3, p. 231-246.

Sidle, J.G., and Faanes, C.A., 1997, Platte River ecosystem resources and management, with emphasis on the Big Bend reach in Nebraska: Grand Island, Nebraska, U.S. Fish and Wildlife Service, and Jamestown, North Dakota, U.S. Geological Survey, online report, accessed November 15, 2007, at http://www.npwrc.usgs.gov/resource/habitat/plrivmgth index.htm

Stanhill, Gerald, 1969, A simple instrument for the field measurement of turbulent diffusion flux: Journal of Applied Meteorology, v. 8, p. 509-513.

Stannard, D.I., 1993, Comparison of Penman-Monteith, Shuttleworth-Wallace, and modified Priestley-Taylor evapotranspiration models for wildland vegetation in semiarid rangeland: Water Resources Research, v. 29, no. 5, p. $1,379-1,392$.

Stannard, D.I., Blanford, J.H., Kustas, W.P., Nichols, W.D., Amer, S.A., Schmugge, T.J., and Weltz, M.A., 1994, Interpretation of surface flux measurements in heterogeneous terrain during the Monsoon '90 experiment: Water Resources Research, v. 30, no. 5, p. 1,227-1,239.
State of Nebraska, 2007, Legislative Bill 701, approved by the Governor May 1, 2007: Lincoln, Nebraska., Legislature of Nebraska, 21 p., accessed March 14, 2008, at http://uniweb. legislature.ne.gov/FloorDocs/Current/PDF/Slip/LB701.pdf

Stewart, J.B., 1988, Modeling surface conductance of pine forest: Agricultural and Forest Meteorology, v. 43, p. 19-35.

Sumner, D.M., 1996, Evapotranspiration from successional vegetation in a deforested area of the Lake Wales Ridge, Florida: U.S. Geological Survey Water-Resources Investigations Report 96-4244, 38 p.

Sumner, D.M., 2001, Evapotranspiration from a cypress and pine forest subjected to natural fires in Volusia County, Florida, 1998-99: U.S. Geological Survey Water-Resources Investigations Report 01-4245, 56 p.

Szilagyi, Jozsef, Harvey, F.E., and Ayers, J.F., 2003, Regional estimation of base recharge to ground water using water balance and a base-flow index: Ground Water, v. 41, no. 4, p. 504-513.

Szilagyi, Jozsef, Harvey, F.E., and Ayers, J.F., 2005, Regional estimation of total recharge to ground water in Nebraska: Ground Water, v. 43, no. 1, p. 63-69.

Tanner, B.D., and Greene, J.P., 1989, Measurements of sensible heat and water vapor fluxes using eddy-covariance methods-Final report: Dugway, Utah, U.S. Army Dugway Proving Grounds, 17 p.

Thompson, N., 1979, Turbulence measurements above a pine forest: Boundary-Layer Meteorology, v. 16, p. 293-310.

Tomanek, G.W., and Ziegler, R.L., 1960, Ecological studies of saltcedar: Hays, Kans., Fort Hays State University Division of Biological Sciences, $128 \mathrm{p}$.

Twine, T.E., Kustas, W.P., Norman, J.M., Cook, D.R., Houser, P.R., Meyers, T.P., Prueger, J.H., Starks, P.J., and Wesely, M.L., 2000, Correcting eddy-covariance flux underestimates over a grassland: Agricultural and Forest Meteorology, v. 103 , p. 279-300.

Unland, H.E., Arain, A.M., Harlow, Chawn, Houser, P.R., Garatuza-Payan, Jaime, Sen, O.L., and Shuttleworth, W.J., 1998, Evaporation from a riparian system in a semi-arid environment: Hydrological Processes, v. 12, p. 527-542.

U.S. Geological Survey, 1999-2000, National Land Cover Data Base: Sioux Falls, South Dakota, U.S. Geological Survey digital data, accessed June 26, 2006, at http://edcwww. cr.usgs.gov/products/landcover.htm

Webb, E.K., Pearman, G.I., and Leuning, Ray, 1980, Correction of flux measurements for density effects due to heat and water vapor transfer: Quarterly Journal of the Royal Meteorological Society, v. 106, p. 85-100. 
Weeks, E.P., and Sorey, M.L., 1973, Use of finite-difference arrays of observation wells to estimate evapotranspiration from ground water in the Arkansas River Valley, Colorado: U.S. Geological Survey Water-Supply Paper 2029-C, 27 p.

Williams, D.G., Scott, R.L., Huxman, T.E., Goodrich, D.C., and Lin, Guanghui, 2006, Sensitivity of riparian ecosystems in arid and semiarid environments to moisture pulses: Hydrological Processes v. 20, p. 3,191-3,205.

Wilczak, J.M., Oncley, S.P., and Stage, S.A., 2001, Sonic anemometer tilt correction algorithms: Boundary-Layer Meteorology, v. 99, p. 127-150.

Winter, T.C., Rosenberry, D.O., and Sturrock, A.M., 1995, Evaluation of 11 equations for determining evaporation for a small lake in the north central United States: Water Resources Research, v. 31, no. 4, p. 983-993.

Younts, C.D., 2002, Crop water use in western Nebraska: Lincoln, Nebraska, University of Nebraska-Lincoln Cooperative Extension, 4 p. 



\section{Appendixes}

Appendix 1. Appendix1. $x l s$ —Daily values of micrometeorological variables from riparian forest study site near Odessa, Nebraska, March 23, 2002, to May 10 , 2006.

Excel spreadsheet

Appendix 2. Appendix2.xls-Daily values of micrometeorological variables

from riparian forest study site near Gothenburg, Nebraska, March 23, 2002, to May 10, 2006.

Excel spreadsheet 
Publishing support provided by: Rolla Publishing Service Center

For more information concerning this publication, contact: Director, USGS Nebraska Water Science Center

5231 South 19 Street

Lincoln, Nebraska 68512

(402) $328-4100$

Or visit the Nebraska Water Science Center Web site at:

http://ne.water.usgs.gov 



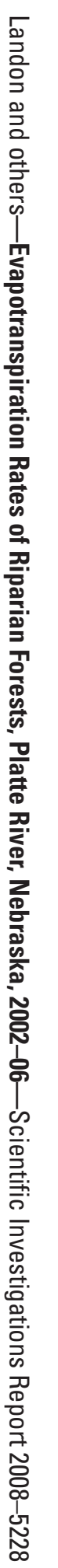

